RAPHAEL QUACHIO

Identificação de sistemas não-lineares de modelos com estrutura de Wiener e Hammerstein para NMPC

SÃO PAULO

2019 


\section{RAPHAEL QUACHIO}

Identificação de sistemas não-lineares de modelos com estrutura de Wiener e Hammerstein para NMPC

Tese apresentada à Escola Politécnica da Universidade de São Paulo para obtenção do título de Doutor em Ciências 
RAPHAEL QUACHIO

Identificação de sistemas não-lineares de modelos com estrutura de Wiener e Hammerstein para NMPC

Tese apresentada à Escola Politécnica da Universidade de São Paulo para obtenção do título de Doutor em Ciências

Área de Concentração: Engenharia de Sistemas

Orientador: Prof. Dr. Claudio Garcia 
Autorizo a reprodução e divulgação total ou parcial deste trabalho, por qualquer meio convencional ou eletrônico, para fins de estudo e pesquisa, desde que citada a fonte.

Este exemplar foi revisado e corrigido em relação à versão original, sob responsabilidade única do autor e com a anuência de seu orientador.

São Paulo de de

Assinatura do autor:

Assinatura do orientador:

Catalogação-na-publicação

Quachio, Raphael

Identificação de sistemas não-lineares de modelos com estrutura de Wiener e Hammerstein para NMPC / R. Quachio -- versão corr. -- São Paulo, 2019.

$101 \mathrm{p}$.

Tese (Doutorado) - Escola Politécnica da Universidade de São Paulo. Departamento de Engenharia de Telecomunicações e Controle.

1.IDENTIFICAÇÃO DE SISTEMAS 2.SISTEMAS NÃO LINEARES 3.CONTROLE PREDITIVO I.Universidade de São Paulo. Escola Politécnica. Departamento de Engenharia de Telecomunicações e Controle II.t. 
À minha filha Bianca 


\section{AGRADECIMENTOS}

Ao prof. Dr. Claudio Garcia, pela orientação, e todas as recomendações, que muito auxiliaram no desenvolvimento desta tese.

Ao Programa de Pós-Graduação em Engenharia Elétrica, pelo subsídio para apresentação de artigo em um congresso com alguns dos resultados apresentados nesta tese.

Aos colegas da Chemtech, por apoiaram e incentivaram o desenvolvimento deste trabalho.

Aos meus pais, Edson e Valdete, por me ensinarem, dentre tantas outras coisas, a importância de não desistirmos daquilo que acreditamos.

E a minha esposa, Luana, por estar todos os dias ao meu lado, escutando o meu praguejar para cada simulação que não funcionava, comemorando junto comigo cada pequeno resultado positivo e principalmente por entender os momentos que eu precisava me ausentar, para poder desenvolver esta tese. 


\section{RESUMO}

Esta tese tem por objetivo a obtenção de modelos que apresentem melhor desempenho quando utilizados em controladores preditivos baseados em modelo (Model-based Predictive Control, MPC). Ao longo dos últimos 25 anos diversos trabalhos propuseram métodos baseados na minimização de uma função de predição múltiplos passos à frente, que se caracteriza por ser uma função não linear. Estes métodos foram denominados MPC Relevent Identification (MRI). A maioria destes artigos propõe técnicas para a obtenção de modelos lineares. Ao longo dos últimos 5 anos, alguns métodos, também baseados na minimização da função de predição múltiplos passos à frente, foram propostos para a identificação de modelos não lineares. Estes trabalhos são baseados na minimização direta da função de custo não linear, para obter com estrutura NARMAX (Nonlinear Autoregressive Moving Average with exogenous inputs). Entretanto, estruturas simplificadas de controladores MPC não lineares podem ser obtidas utilizando modelos com estruturas de Wiener e de Hammerstein. Esta tese apresenta novos resultados teóricos que permitem a obtenção de algoritmos de identificação MRI para modelos com estrutura de Wiener e Hammerstein, sem a necessidade de minimizar a função de custo não linear. Além da demonstração dos resultados teóricos, novos algoritmos são propostos tendo a sua capacidade de predição, propriedades estatísticas e aplicação em controladores MPC não lineares avaliadas.

Palavras-chave: Identificação de Sistemas. Sistemas não lineares. Controle Preditivo. 


\section{ABSTRACT}

This thesis focuses on obtaining models that may produce a better performance of Model-based Predictive Controllers (MPC). Several papers published in the last 25 years have proposed methods based on the minimization of multi-step ahead prediction functions, which are inherently nonlinear. These methods have been called MPC Relevant Identification (MRI). Most of the papers focused on obtaining linear models. In the last 5 years, some methods have been proposed to obtain nonlinear models based on the minimization of the same cost function. These papers were based on the direct minimization of the nonlinear cost function to produce models with NARMAX (nonlinear Autoregressive Moving Average with exogenous inputs) structure. However, simplified MPC schemes may be obtained using models with Wiener and Hammerstein structures. This thesis presents new theoretical results which allow the development of MRI identification algorithms for models with Wiener and Hammerstein structures, without the need to perform the minimization of the nonlinear cost function. Besides the proof of theoretical results, new algorithms are developed and have their prediction capability statistical properties and performance in nonlinear MPC controllers evaluated.

Keywords: Systems Identification. Nonlinear Systems. Predictive Control. 
LISTA DE FIGURAS

FIGURA 2.1 - FENÔMENOS DE RESPOSTA ASSIMÉTRICA E MULTIPLICIDADE DE ENTRADAS.

FIGURA 2.2 - FENÔMENO DA GERAÇÃO DE HARMÔNICOS. .26

FIGURA 2.3 - ANÁLISE DO FENÔMENO DE ESTABILIDADE DEPENDENTE DA ENTRADA. EM (A) É APRESENTADA A RESPOSTA DO SISTEMA LINEAR (4) A UM DEGRAU COM AMPLITUDE 2,6. EM (B) É APRESENTADA A RESPOSTA DO SISTEMA NÃO LINEAR (3) A UM DEGRAU COM AMPLITUDE 2.6. EM (C) É APRESENTADA A RESPOSTA DO SISTEMA LINEAR (4) A UM DEGRAU COM AMPLITUDE 26. EM (D) É APRESENTADA A RESPOSTA DO SISTEMA NÃO LINEAR (3) A UM DEGRAU COM AMPLITUDE 26. 28

FIGURA 2.4 - FENÔMENO DE MULTIPLICIDADE DE SAÍDA. .30

FIGURA 2.5 - FENÔMENO DE GERAÇÃO DE SUBHARMÔNICOS 31

FIGURA 2.6 - RESPOSTA TEMPORAL E MAPA DE PRIMEIRO RETORNO DE UM SISTEMA DINÂMICO EM REGIME CAÓTICO (A E B) E NÃO CAÓTICO (C E D).

FIGURA 2.7 - ESTRUTURAS DE MODELOS DE BLOCOS INTERCONECTADOS.

(A) HAMMERSTEIN E (B) WIENER. 35

FIGURA 4.1 - EXEMPLOS DE MÉTODOS MRI

FIGURA 5.1 - ESTRUTURA DO MODELO DE HAMMERSTEIN SISO IDENTIFICADO PELO ALGORITMO PROPOSTO.

FIGURA 5.2 - ESTRUTURA DO MODELO DE WIENER SISO IDENTIFICADO COM O ALGORITMO PROPOSTO 61 
FIGURA 5.3 - ESTRUTURA DE MODELO DE HAMMERSTEIN MIMO 2X2 IDENTIFICADA PELO ALGORITMO PROPOSTO.

FIGURA 6.1 - DADOS DE ENTRADA E SAÍDA DE IDENTIFICAÇÃO E VALIDAÇÃO PARA O SISTEMA TÉRMICO COM DISSIPAÇÃO. 66

FIGURA 6.2 - AUTOVALORES DA MATRIZ JACOBIANA PARA 20 PONTOS DE OPERAÇÃO DISTINTOS DO SISTEMA TÉRMICO COM DISSIPAÇÃO. OS PRIMEIROS AUTOVALORES DE CADA PAR SÃO INDICADOS COMO "+" E OS SEGUNDOS AUTOVALORES DE CADA PAR SÃO INDICADOS COMO "X".

FIGURA 6.3 - COMPARAÇÃO DO VALOR FUNÇÃO CUSTO PONDERADA PARA A PREDIÇÃO MÚLTIPLOS PASSOS EM FUNÇÃO DA VARIAÇÃO DO HORIZONTE DE PREDIÇÃO PARA O MODELO MRI E O MODELO BJ 69

FIGURA 6.4 - COMPARAÇÃO ENTRE A SAÍDA REAL DA PLANTA (DADOS CENTRADOS E ESCALADOS) E A PREDIÇÃO 1 PASSO À FRENTE OBTIDA PELOS MODELOS MRI E BJ. .70

FIGURA 6.5 - COMPARAÇÃO ENTRE A SAÍDA REAL DA PLANTA (DADOS CENTRADOS E ESCALADOS) E A PREDIÇÃO 10 PASSOS À FRENTE OBTIDA PELOS MODELOS MRI E BJ.

FIGURA 6.6- DADOS DE ENTRADA E SAÍDA DE IDENTIFICAÇÃO E VALIDAÇÃO PARA O FORNO ELÉTRICO. .72

FIGURA 6.7- AUTOVALORES DA MATRIZ JACOBIANA PARA 20 PONTOS DE OPERAÇÃO DISTINTOS DO FORNO ELÉTRICO. OS PRIMEIROS AUTOVALORES DE CADA PAR SÃO INDICADOS COMO "+" E OS SEGUNDOS AUTOVALORES DE CADA PAR SÃO INDICADOS COMO "X". . 73

FIGURA 6.8- COMPARAÇÃO DO VALOR FUNÇÃO CUSTO PONDERADA PARA A PREDIÇÃO MÚLTIPLOS PASSOS À FRENTE EM FUNÇÃO DA VARIAÇÃO DO HORIZONTE DE PREDIÇÃO PARA O MODELO MRI E O MODELO BJ...75 
FIGURA 6.9 - COMPARAÇÃO ENTRE A SAÍDA REAL DA PLANTA (DADOS CENTRADOS E ESCALADOS) E A PREDIÇÃO 1 PASSO À FRENTE OBTIDA PELOS MODELOS MRI E BJ. .75

FIGURA 6.10 - COMPARAÇÃO ENTRE A SAÍDA REAL DA PLANTA (DADOS CENTRADOS E ESCALADOS) E A PREDIÇÃO 10 PASSOS À FRENTE OBTIDA PELOS MODELOS MRI E BJ 76

FIGURA 6.11 - GRÁFICO DE POLOS E ZEROS DO SISTEMA LINEAR DA PLANTA UTILIZADA PARA A ANÁLISE DE MONTE CARLO DE UM MODELO DE HAMMERSTEIN.

FIGURA 6.12 - MÉDIA E DESVIO PADRÃO DOS PARÂMETROS DA NÃO

LINEARIDADE ESTÁTICA IDENTIFICADOS EM EXPERIMENTOS DE MONTE CARLO PARA DIFERENTES VALORES DE AMOSTRAS. .80

FIGURA 6.13- MÉDIA E DESVIO PADRÃO DOS PARÂMETROS DO

DENOMINADOR DA FUNÇÃO DE TRANSFERÊNCIA IDENTIFICADOS EM EXPERIMENTOS DE MONTE CARLO PARA DIFERENTES VALORES DE AMOSTRAS.

FIGURA 6.14 - MÉDIA E DESVIO PADRÃO DOS PARÂMETROS DO NUMERADOR DA FUNÇÃO DE TRANSFERÊNCIA IDENTIFICADOS EM EXPERIMENTOS DE MONTE CARLO PARA DIFERENTES VALORES DE AMOSTRAS.

FIGURA 7.1 - VARIÁVEIS DE ENTRADA E SAÍDA UTILIZADAS PARA A IDENTIFICAÇÃO DO SISTEMA MIMO. 86

FIGURA 7.2 - VALORES DE WLRPI PARA DIFERENTES HORIZONTES DE PREDIÇÃO PARA OS MODELOS MRI E BJ.

FIGURA 7.3 - PREDIÇÃO 1 PASSO À FRENTE PARA O CONJUNTO DE DADOS DE VALIDAÇÃO PARA OS MODELOS MRI E BJ, ASSIM COMO OS RESPECTIVOS VALORES DOS PARÂMETROS FIT. 
FIGURA 7.4 - PREDIÇÃO 10 PASSOS À FRENTE PARA O CONJUNTO DE DADOS DE VALIDAÇÃO PARA OS MODELOS MRI E BJ, ASSIM, COMO OS RESPECTIVOS VALORES DO ÍNDICE FIT.

FIGURA 7.5 - RESPOSTA DA SAÍDA 1 DO SISTEMA SIMULADO, CONSIDERANDO A UTILIZAÇÃO DE CONTROLADORES NMPC UTILIZANDO OS MODELOS ORIUNDOS DA IDENTIFICAÇÃO MRI E OSAPI. 90

FIGURA 7.6 - RESPOSTA DA SAÍDA 2 DO SISTEMA SIMULADO, CONSIDERANDO A UTILIZAÇÃO DE CONTROLADORES NMPC UTILIZANDO OS MODELOS ORIUNDOS DA IDENTIFICAÇÃO MRI E OSAPI. .90 
LISTA DE TABELAS

TABELA 6.1 - PARÂMETROS UTILIZADOS PARA AVALIAÇÃO DOS AUTOVALORES DA MATRIZ JACOBIANA DO SISTEMA TÉRMICO COM DISSIPAÇÃO. 66

TABELA 6.2 - FAIXA DE VARIAÇÃO DE ALGUNS PARÂMETROS UTILIZADOS NA IDENTIFICAÇÃO DO MODELO DE HAMMERSTEIN.

TABELA 6.3 - PARÂMETROS UTILIZADOS PARA AVALIAÇÃO DOS AUTOVALORES DA MATRIZ JACOBIANA DO FORNO ELÉTRICO. .72

TABELA 6.4 - FAIXA DE VARIAÇÃO DE ALGUNS PARÂMETROS UTILIZADOS NA IDENTIFICAÇÃO DO MODELO DE WIENER.

TABELA 6.5 - MÉDIA, DESVIO PADRÃO E COEFICIENTE DE VARIAÇÃO (ENTRE PARÊNTESES) DOS PARÂMETROS IDENTIFICADOS PELO ALGORITMO MRI PARA O MODELO DE HAMMERSTEIN PARA DIFERENTES INTENSIDADES DE PERTURBAÇÃO. .79

TABELA 6.6 - MÉDIAS E DESVIOS PADRÃO DOS PARÂMETROS IDENTIFICADOS PELO ALGORITMO MRI PARA O MODELO DE WIENER PARA DIFERENTES RELAÇÕES SINAL-RUÍDO

TABELA 7.1 - PARÂMETROS UTILIZADOS PARA A IDENTIFICAÇÃO DO SISTEMA MIMO. .86

TABELA 7.2 - FAIXA DE VARIAÇÃO DE ALGUNS PARÂMETROS UTILIZADOS NA IDENTIFICAÇÃO DO MODELO DE HAMMERSTEIN. 
LISTA DE ABREVIATURAS E SIGLAS

\begin{tabular}{ll} 
APC & Advanced Process Control \\
ARMA & Auto Regresive Moving Average \\
ARMAX & Auto Regresive Moving Average with eXogenous Inputs \\
ARX & Auto Regresive with eXogenous Inputs \\
BIBO & Bounded Input Bounded Output \\
BJ & Box-Jenkins \\
BPCS & Basic Process Control System \\
CLP & Controlador Lógico Programável \\
CSTR & Continuously Stirred Tank Reactor \\
DMC & Dynamic Matrix Control \\
EMPEM & Enhanced Multi-step Prediction Error Method \\
ERR & Error Reduction Ratio \\
FIR & Finite Input Response \\
GBN & Generalized Binary Noise \\
GPC & Generalized Predictive Control \\
ISA & Inernational Society of Automaton \\
LARNMAX & Linear Auto Regresive Nonlinear Moving Average with eXogenous \\
inputs \\
LMI & Linear Matrix Inequalities \\
LRPI & Long Range Prediction Identification \\
MIMO & Multiple Output Multiple Input \\
MISO & Multiple Input Single Output \\
MMPC & Multi-Model Predictive Control \\
MPC & Model Predictive Control \\
\hline M & \\
\hline
\end{tabular}




\begin{tabular}{ll} 
MPEM & Multi-step Prediction Error Method \\
MRI & MPC Relevant Identification. \\
MSE & Mean Square Error \\
NARMAX & Nonlinear Auto Regresive Moving Average with eXogenous inputs \\
NARX & Nonlinear Auto Regresive with eXogenous inputs \\
NMPC & Nonlinear Model Predictive Control \\
OE & Output Error \\
OSAPI & One Step Ahead Prediction Identification \\
PAC & Programmable Automation Controller \\
PEM & Predicton Error Methods \\
PID & Proporcional - Integral - Derivativo \\
PLS-PH & Partial Least Squares - Prediction Horizon \\
PRMS & Pseudo-Random Mulple amplitude Sequence \\
QDMC & Quadratic Dynamic Matrix Control \\
QP & Quadratic Programming \\
SDCD & Sistema Digital de Controle Distribuído \\
SISO & Single Input Sigle Output \\
SNR & Signal to Noise Ratio \\
\hline
\end{tabular}




\section{SUMÁRIO}

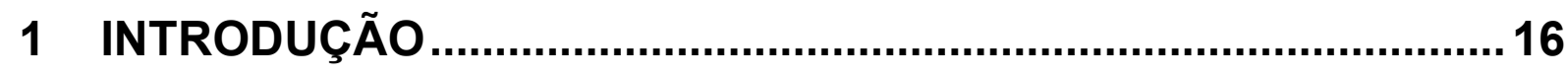

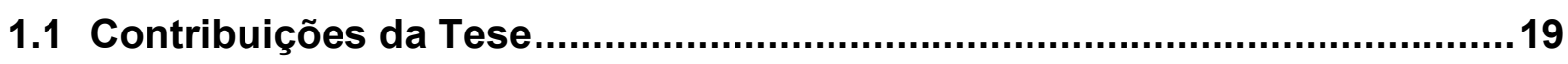

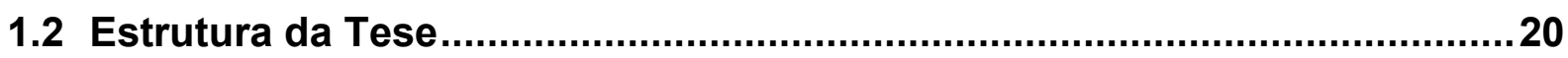

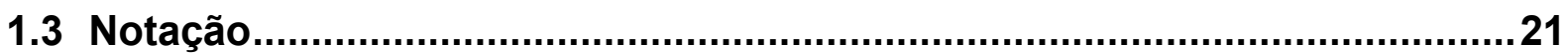

2 SISTEMAS NÃO LINEARES ................................................... 22

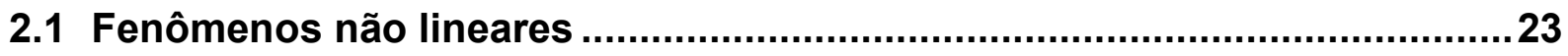

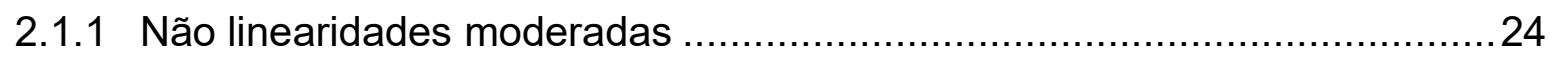

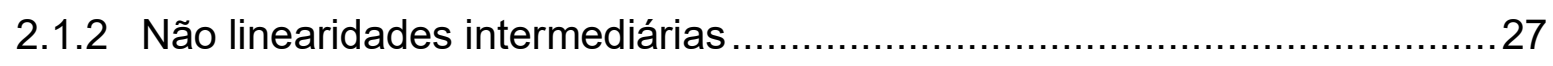

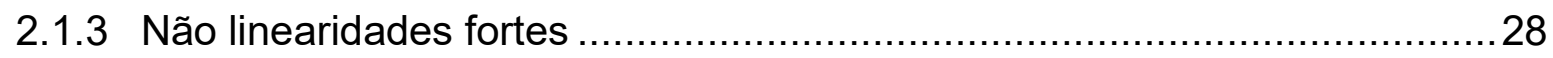

2.2 Estruturas de modelos de entrada-saída não lineares..................................33

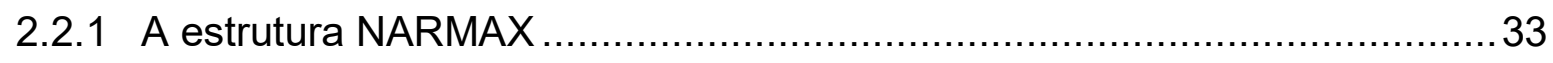

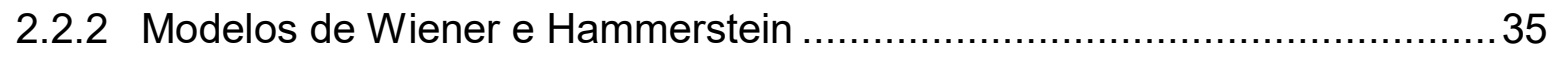

2.3 Aplicabilidade de modelos com estrutura de Wiener e Hammerstein para o controle de processos .........................................................................................

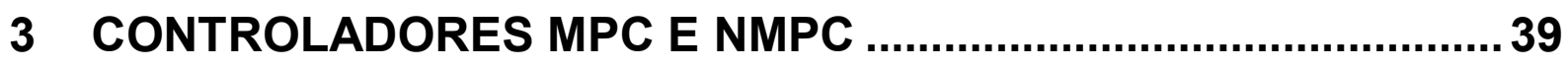

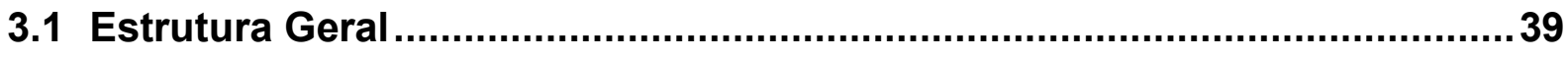

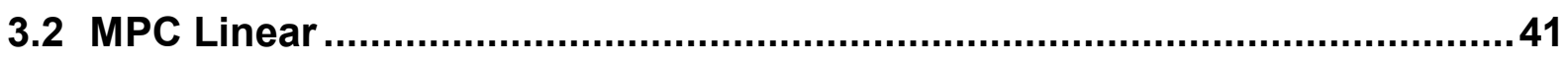

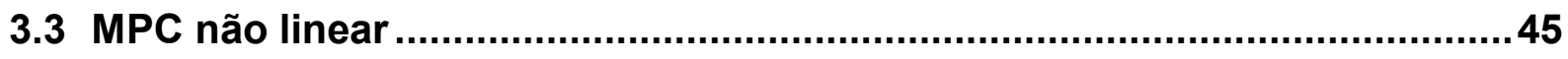




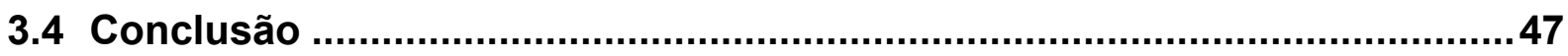

4 IDENTIFICAÇÃO DE SISTEMAS ............................................. 48

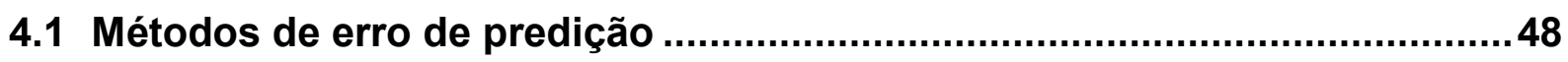

4.2 Métodos de Identificação Relevante para MPC (MRI).................................50

4.3 Identificação de sistemas não lineares com estruturas de Wiener e

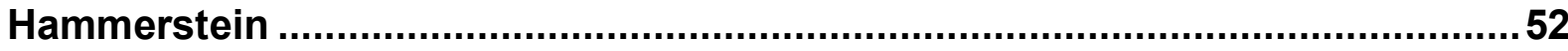

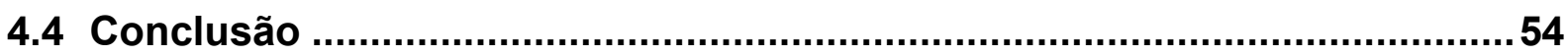

5 ALGORITMOS DE IDENTIFICAÇÃO MRI PARA MODELOS DE

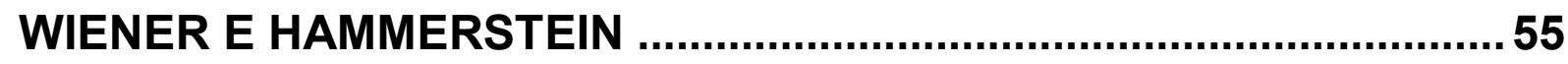

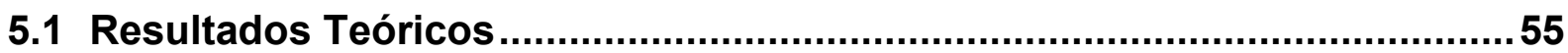

5.2 Algoritmo de identificação MRI para modelos de Wiener e de Hammerstein

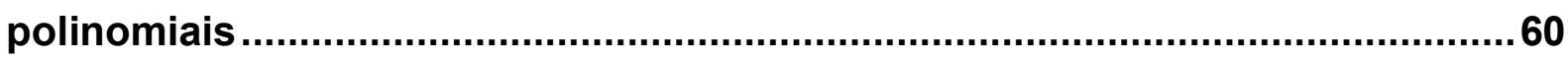

5.2.1 Caso SISO - modelos de Hammerstein e de Wiener..............................60

5.2.2 Caso MIMO - modelos de Hammerstein …........................................62

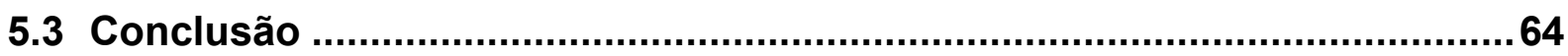

6 APLICAÇÕES DA IDENTIFICAÇÃO COM ESTRUTURA DE HAMMERSTEIN E DE WIENER SISO ...............................................65

6.1 Avaliação da capacidade de predição múltiplos passos à frente ...............65

6.1.1 Identificação de sistema térmico com dissipação ......................................65

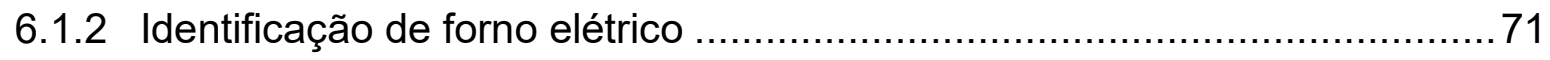


6.2 Avaliação da acurácia e precisão dos modelos obtidos

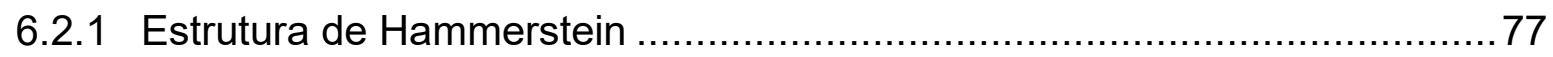

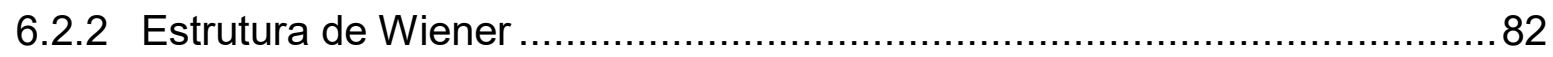

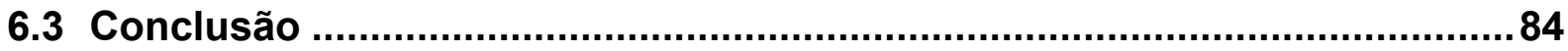

7 APLICAÇÃO DA IDENTIFICAÇÃO COM ESTRUTURA DE

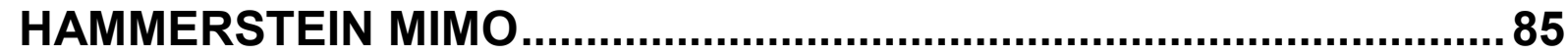

7.1 Sistema proposto e experimento de identificação .................................. 85

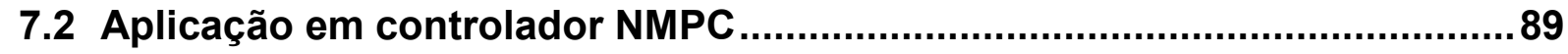

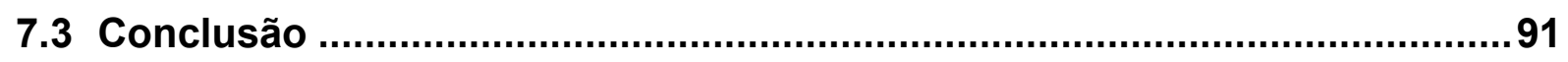

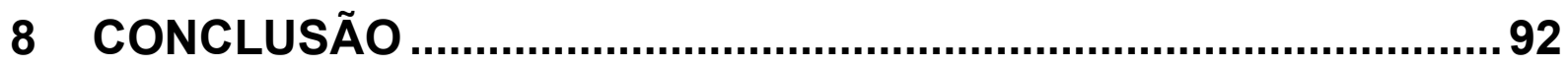

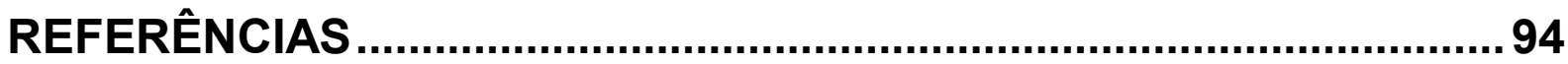




\section{Introdução}

A base instalada de controladores na indústria de processos é muito elevada, de modo que atualmente, em qualquer unidade é muito raro não encontrar a presença de algum controlador. Diversas denominações são utilizadas para se referir a estes controladores, sendo as mais usuais Controlador Lógico Programável (CLP) ou Sistema Digital de Controle Distribuído (SDCD). A fim de padronizar a nomenclatura, nesta tese é utilizada aquela proposta pela International Society of Automation (ISA) que denomina todos estes sistemas de controle como Basic Process Control Systems (BPCS). De posse de um BPCS, a indústria de processo tem à sua disposição um grande arcabouço de algoritmos de controle com as quais ela pode:

- Reduzir o desperdício de energia;

- Reduzir a quantidade de produtos fora da especificação; e

- Reduzir a variabilidade do processo, de maneira a aumentar a produção dentro dos limites de segurança do processo.

Avaliando os possíveis ganhos dos controladores, é possível notar que a principal finalidade das estratégias de controle consiste na redução dos custos unitários de produção e no aumento de produtividade da unidade. Assim, os algoritmos de controle acabam sendo um diferencial competitivo entre as empresas. $O$ mais clássico algoritmo de controle de processos, o controlador PID (proporcional integral e derivativo), atualmente encontra-se tão difundido, que sua não utilização, isto é, a operação de malhas em modo manual, deve ser considerada como uma deficiência da unidade.

Assim, para se diferenciar, são usados os controladores APC (Advanced Process Control). Este nome é utilizado para representar todas as estratégias de controle que não se limitam ao controlador PID. Nesta categoria são incluídos diversos algoritmos de controle, que podem ser encontrados em livros de controle de processos, como é o caso de Campos e Teixeira (2006) e Seborg, et al. (2010). Podem ser citadas estratégias como controle em cascata, gain scheduling, preditor de Smith e os controladores preditivos baseados em modelo, ou MPC. 
Entretanto, apesar de ser uma forma de diferenciação técnica entre as empresas desde a década de 1980, os controladores MPC não tiveram uma difusão tão ampla quanto os controladores PID. Diversas dificuldades associadas ao desenvolvimento e manutenção de um controlador MPC foram apontadas em Forbes et al (2015), dentre as quais pode-se destacar:

- dificuldade em justificar as perturbações no processo necessárias para a obtenção dos modelos. Assim, quando os testes são autorizados, muitas vezes a faixa de variação permitida é muito pequena, de maneira que os dados coletados sejam não informativos;

- dificuldade em transmitir à equipe de operação o comportamento do controlador, fazendo com que essa desligue o controlador quando a ação de controle the parece incorreta;

- dificuldade em realizar o ajuste correto dos parâmetros de sintonia, fazendo com que o desempenho seja inferior ao esperado; e

- dificuldade em manter os modelos atualizados, fazendo com que, gradativamente, seja reduzido o desempenho do controlador até um eventual descomissionamento do mesmo.

Conforme citado em Forbes et al. (2015), diversas iniciativas vêm sendo desenvolvidas pelos fornecedores de sistemas de controle, visando permitir a popularização do controlador MPC, como ferramentas para auxiliar na identificação, estratégias de controle pré-definidas para algumas operações unitárias específicas, sugestões de sintonia, etc. Adicionalmente, alguns fabricantes de BPCS vêm disponibilizando controladores MPC lineares de maneira nativa, juntamente com o sistema. Todos esses elementos incentivam a implantação de controladores MPC em unidades industriais.

No entanto, muitos (se não todos) processos industriais apresentam algum grau de não linearidade, como é o caso de colunas de destilação de alta pureza (SKOGESTAD; MORARI, 1988) e (SRINIWAS et al., 1995), reatores de polimerização (SHAFIEE et al., 2008) e neutralização (MAHMOODI et al., 2009). A aplicação de controladores MPC lineares a estes processos pode apresentar desempenho considerado insatisfatório. 
Duas possíveis soluções para a utilização de controladores MPC em sistemas não lineares são: a utilização de controladores lineares multimodelos (MMPC) e a utilização de controladores MPC não lineares (NMPC).

Controladores MMPC foram aplicados a uma coluna de destilação industrial por Porfírio; Almeida Neto e Odloak, (2003). Esses algoritmos possuem a vantagem de permitir uma interpretação simples, por se basearem em múltiplos modelos lineares. Infelizmente, os controladores de mercado usualmente apresentam restrições associadas ao modo como o problema de otimização é construído e quais são as variáveis selecionadas no problema de otimização. Desta maneira, em muitos controladores de mercado pode não ser possível implementar a estrutura de LMI (Linear Matrix Inequalities) necessária para a utilização de controladores MMPC.

Em relação à aplicação de controladores NMPC, Xi; Li e Lin (2013) indicam que esta família de controladores apresenta elevado interesse por parte da academia e da indústria. Entretanto, enquanto um grande desenvolvimento foi realizado nos controladores MPC, os controladores NMPC ainda se encontram em estágio pouco avançado. Algumas possíveis razões para tal discrepância são:

1. conforme apontado por $\mathrm{Xi}$; Li e Lin (2013) a obtenção de modelos para controladores NMPC pode ser difícil, demorada e cara;

2. a interpretação do comportamento de modelos não lineares pode não ser intuitiva, o que pode ser um problema, conforme apresentado em Forbes et al. (2015); e

3. a resolução de problemas NMPC, pode implicar a resolução de problemas de otimização não linear, enquanto muitos controladores MPC comerciais possuem implementados algoritmos para a resolução de problemas quadráticos de otimização.

Para contornar os problemas apresentados no parágrafo anterior, uma solução pode ser a utilização de modelos não lineares com estrutura de Wiener ou Hammerstein, isto é, modelos compostos por um bloco dinâmico linear e uma função não linear estática. Caso a não linearidade seja aplicada na entrada da parte linear, o modelo possuirá estrutura de Hammerstein. Caso a não linearidade seja aplicada na saída 
da parte linear, o modelo possuirá estrutura de Wiener. Pelo fato de a dinâmica ser decorrente de um modelo com estrutura linear, a interpretação é mais intuitiva, contornando assim o problema 2 listado anteriormente.

Conforme apresentado por Fruzetti; Palazoglu e McDonald (1997) e Norquay; Palazoglu e Romagnoli (1998), utilizando a não linearidade estática inversa (ou uma aproximação dessa), o controlador NMPC baseado em modelos não lineares com estrutura de Wiener ou Hammerstein, é reduzido a um controlador MPC linear tradicional, que pode ser resolvido por controladores de mercado. Desta maneira, o problema 3 pode ser resolvido.

Como os problemas 2 e 3 podem ser solucionados pela utilização de modelos com estrutura de Wiener e de Hammerstein, se tais estruturas de modelos forem utilizadas, apenas o problema 1 continua em aberto. Assim, esta tese busca desenvolver um algoritmo para a identificação de modelos não lineares com estruturas de Wiener ou Hammerstein, que possa ser utilizado em controladores NMPC.

A solução para este problema não é única e os próprios artigos de Fruzetti; Palazoglu e McDonald (1997) e Norquay; Palazoglu e Romagnoli (1998) indicam maneiras de obter os modelos. Nesta tese foi escolhida a utilização de algoritmos MRI (MPC Relevant Identification) para a identificação de modelos com estrutura de Wiener e de Hammerstein. A grande maioria dos algoritmos MRI foi desenvolvida para a obtenção de modelos lineares para aplicação em controladores MPC. Dentre as iniciativas relativas a obtenção de modelos não lineares com métodos MRI, destacam-se o trabalho de Quachio e Garcia (2014) onde foi desenvolvido um algoritmo para a identificação de modelos caixa-preta com estrutura NARX polinomial, e o trabalho de Pčolka et al. (2016), que utiliza métodos MRI baseados em busca direta para a identificação de modelos caixa cinza.

\subsection{Contribuições da Tese}

A principal contribuição desta tese consiste em demonstrar novos resultados teóricos que mostram a equivalência entre predição múltiplos passos à frente e 1 passo à frente para a estimativa da função estática de modelos de Wiener e de 
Hammerstein. São demonstrados também outros resultados teóricos que mostram como os métodos da identificação MRI linear podem ser utilizados para a identificação de modelos com essas duas estruturas.

Adicionalmente, a partir dos resultados teóricos, também foi possível desenvolver algoritmos SISO para a identificação de modelos com estrutura de Wiener e de Hammerstein e de modelos MIMO com estrutura de Hammerstein. Propriedades estatísticas do algoritmo e a capacidade de predição dos modelos obtidos foram avaliados utilizando conjunto de dados da literatura (coletados em plantas didáticas) e em plantas simuladas. Por fim, foi possível avaliar o desempenho dos modelos obtidos pelo algoritmo em controladores NMPC.

\subsection{Estrutura da Tese}

O presente texto é organizado do seguinte modo:

- Os capítulos 2, 3 e 4 apresentam uma revisão de alguns resultados relevantes para o desenvolvimento da tese. No Capítulo 2 há uma revisão sobre sistemas não lineares. É dado enfoque principalmente a dois aspectos: analisar alguns fenômenos típicos de sistemas não lineares e apresentar quais desses fenômenos podem ser obtidos por modelos com estrutura de Wiener e de Hammerstein. O Capítulo 3 apresenta a estrutura básica do algoritmo MPC e o controlador offset-free. Para esses controladores, é apresentada a extensão relacionada à aplicação de modelos não lineares, notadamente aquelas específicas para modelos com estrutura de Wiener e de Hammerstein. O Capítulo 4 apresenta os algoritmos de identificação de sistemas que servem de base para o desenvolvimento da tese. Desta maneira, são apresentados os algoritmos MRI e em seguida é apresentado o método de identificação de modelos de Wiener e de Hammertein, baseado na identificação de pontos fixos.

- O Capítulo 5 apresenta os novos resultados teóricos que permitem a identificação de modelos de Wiener e de Hammerstein utilizando algoritmos MRI. Estes resultados são utilizados como base para o desenvolvimento de algoritmos para a identificação de modelos SISO e MIMO. 
- Os capítulos 6 e 7 avaliam o desempenho dos algoritmos para a identificação. O capítulo 6 é dedicado a modelos SISO com estrutura de Wiener e de Hammerstein, avaliando suas propriedades estatísticas por meio de análise de Monte Carlo. $O$ desempenho dos algoritmos é também avaliado utilizando dados coletados a partir de plantas didáticas. O Capítulo 7, por outro lado, avalia o desempenho do algoritmo para a identificação de modelos MIMO com estrutura de Hammerstein, a partir de dados obtidos por simulação, e avalia o desempenho do modelo em um controlador NMPC.

- Por fim, o Capítulo 8 apresenta as conclusões desta tese e indica possíveis pesquisas complementares a serem desenvolvidas.

\subsection{Notação}

O trabalho utiliza a seguinte convenção para representar as equações: As variáveis representadas por letras maiúsculas em negrito representam matrizes;

- As variáveis representadas por letras minúsculas em negrito representam vetores coluna; e

- As variáveis representadas por letras maiúsculas ou minúsculas representam valores escalares. 


\section{Sistemas não lineares}

A teoria de sistemas dinâmicos, descrita de modo simplificado, é o nome dado ao ramo da matemática que estuda o comportamento de equações que possuem uma variável independente, que pode ser o tempo. Esse último pode ser uma variável real ou inteira, de maneira a definir a classificação em sistemas dinâmicos em tempo contínuo e em tempo discreto. Para o primeiro tipo, são analisados conjuntos de equações diferenciais, enquanto o segundo se baseia em equações de diferenças.

Para aplicações de engenharia, os sistemas dinâmicos são descritos como modelos matemáticos. Os modelos matemáticos podem ser obtidos via modelagem fenomenológica (conhecida como modelagem caixa branca), por meio de análise estatística dos dados de entrada e saída, constituindo a Identificação de Sistemas (modelagem caixa preta) ou um híbrido destes dois (conhecida como modelagem caixa cinza). O foco deste trabalho é a Identificação de Sistemas usando algoritmos caixa preta. Maiores detalhes sobre modelagem caixa branca e caixa cinza podem ser encontrados em Garcia (2013) e Aguirre (2015), respectivamente.

Um ponto relevante a ser considerado é que os modelos matemáticos, independentemente da metodologia usada, são aproximações dos fenômenos reais, de maneira que os resultados obtidos por eles estão sempre sujeitos a algum erro. Além disso, todo fenômeno pode ser representado por diferentes modelos. De acordo com Pearson (2003), um modelo pode ser avaliado por meio de quatro critérios de utilidade:

1. realizar aproximações acuradas do fenômeno modelado;

2. possuir uma interpretação física;

3. ser adequado para o desenvolvimento de controladores; e

4. simplicidade de desenvolvimento (pequeno número de parâmetros / equações).

Assim, para os métodos de obtenção de modelos, definem-se quais desses fatores são mais relevantes para a aplicação em questão. Para projetar controladores, a geração de modelos caixa preta usualmente busca um compromisso entre os 
critérios 1, 3 e 4. As técnicas clássicas de Identificação de Sistemas se baseiam em sistemas dinâmicos lineares. Próximo ao ponto de operação, esses modelos têm um desempenho satisfatório para estes três itens. No entanto, há um conjunto de comportamentos que não pode ser descrito por modelos lineares. Quando é preciso representá-los, deve-se usar a classe de modelos não lineares. Este é um dos pontos que merece atenção: apesar de os modelos não lineares usualmente representarem superclasses que contêm os modelos lineares, como citado em Pearson, (2006), deve-se considerar o uso de modelos não lineares exclusivamente quando os modelos lineares não forem capazes de representar características desejadas do sistema analisado.

A estrutura de modelos usada nesta tese é a de Wiener e Hammerstein. A partir da discussão feita no capítulo anterior, conclui-se que essa estrutura de modelos foi escolhida por atender bem os critérios de utilidades 3 e 4 . Entretanto, sabendo que a aplicação final é a utilização em controladores NMPC, é importante que os modelos também possam realizar aproximações acuradas do sistema, caso contrário, o desempenho do controlador estará comprometido. Assim, a fim de se compreender se o critério 1 também está sendo atendida, é importante entender quais fenômenos não lineares podem ser corretamente representados por modelos com estrutura de Wiener e Hammerstein.

Neste capítulo citam-se os fenômenos não lineares típicos, baseados em Pearson (2003). Em seguida, são descritas as estruturas de Wiener e Hammerstein e suas capacidades. Também são apresentados modelos com estrutura NARMAX, que possuem uma grande importância para o desenvolvimento desta tese.

\subsection{Fenômenos não lineares}

Existe um conjunto de comportamentos de sistemas reais que não pode ser modelado por meio de sistemas dinâmicos lineares. Sempre que for necessário que o modelo desenvolvido apresente um dos comportamentos listados nesta seção, é preciso considerar o emprego de sistemas não lineares. Pearson (2003) apresenta uma classificação para os diferentes tipos de não linearidades, dividindo-as em não línearidades moderadas (mild), intermediárias (intermediate) e fortes (strong). 
A apresentação é realizada baseando-se em modelos SISO. Tais fenômenos podem, em geral, ser estendidos para sistemas MISO ou MIMO, com algumas ressalvas que são apresentadas ao longo do texto.

\subsubsection{Não linearidades moderadas}

As não linearidades moderadas são as que podem ser geradas por grande parte das estruturas não lineares, incluindo os modelos de Wiener e de Hammerstein.

\subsubsection{Resposta Assimétrica}

Uma das estratégias clássicas de Identificação de Sistemas utilizada em controle de processos consiste em excitar a planta que se deseja identificar utilizando um degrau positivo, seguido de um degrau negativo, isto é, uma excitação simétrica. Para sistemas lineares, a resposta a uma excitação simétrica deve ser simétrica. Entretanto, tal simetria normalmente não é encontrada em sistemas não lineares.

Um exemplo deste fenômeno pode ser observado a seguir: considere um sinal composto por um pulso unitário positivo, seguido de um pulso unitário negativo. Este sinal é aplicado na entrada dos seguintes sistemas:

1) Um sistema linear que possui a função de transferência

$$
G(s)=\frac{1}{5 s+1}
$$

2) Um sistema não linear composto por um bloco linear com função de transferência igual a (1), seguido por um bloco não linear estático com a função $y(t)=w(t)^{2}$, onde $w(t)$ é a saída do bloco linear.

O sinal de entrada assim como as saídas dos sistemas linear e não linear são exibidos na

Figura 2.1. É possível notar que o sinal de entrada e a resposta do modelo linear possuem amplitudes simétricas em relação à origem, enquanto tal fenômeno não é observado no modelo não linear. 
Figura 2.1 - Fenômenos de resposta assimétrica e multiplicidade de entradas.
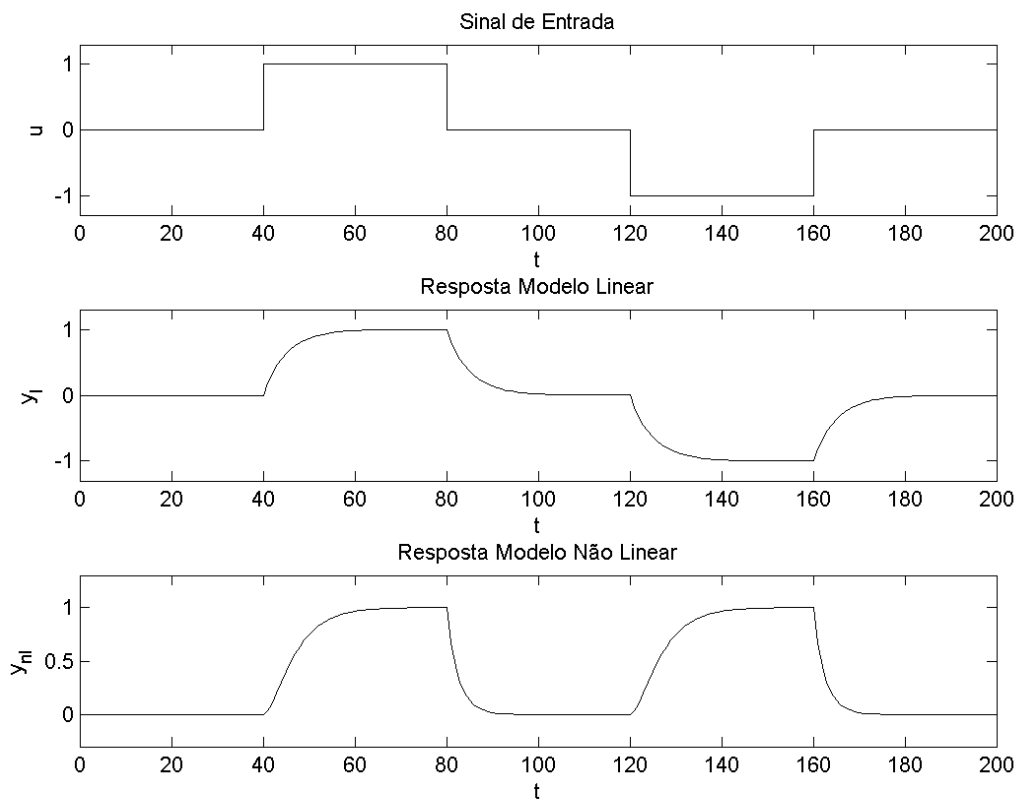

Fonte: Autor.

\subsubsection{Geração de Harmônicos}

Uma propriedade marcante de sistemas lineares consiste na resposta de regime permanente senoidal em que, dado um estímulo senoidal, a saída será senoidal com mesma frequência, com variações na amplitude e na fase. Ao se usar o mesmo sinal de entrada em sistemas não lineares, notam-se harmônicos do sinal original na saída. Para ilustrar esse fato, considere os mesmos sistemas do Item 2.1.1.1, excitados por um sinal senoidal de amplitude unitária e período $100 \mathrm{~s}$. O sinal de entrada e os sinais de saída para os dois sistemas são exibidos na

Figura 2.2 a partir de $t=100 \mathrm{~s}$. 
Figura 2.2 - Fenômeno da geração de harmônicos.
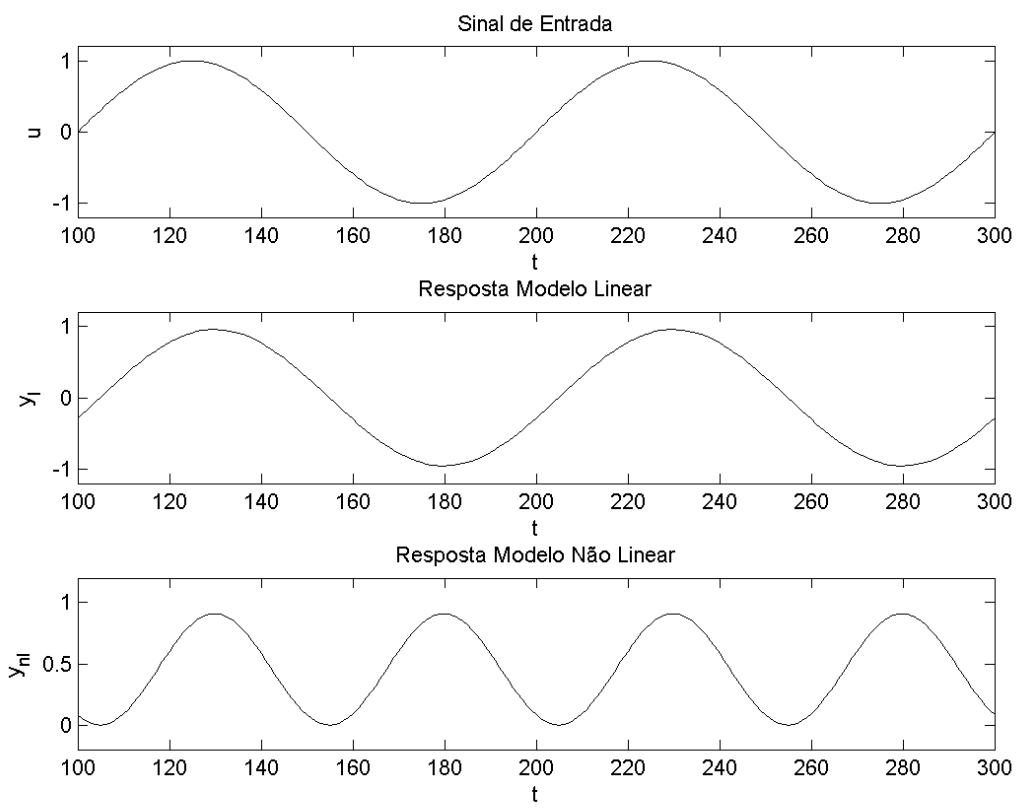

Fonte: Autor.

É possível notar que a resposta gerada pelo sistema não linear gerou frequência duas vezes maior que o sistema linear, indicando a geração de harmônicos.

\subsubsection{Multiplicidade de Entrada}

O fenômeno de multiplicidade de entrada é um fenômeno típico de sistemas não lineares SISO. Ele se caracteriza por uma mesma saída poder ser originada por entradas distintas. Um exemplo deste fenômeno pode ser observado na Figura 2.1, onde é possível notar que tanto o degrau positivo (gerado no instante $40 \mathrm{~s}$ ) quanto o degrau negativo (gerado no instante 120 s) produzem a mesma saída.

É importante notar que a presença da multiplicidade de entradas não implica que o sistema seja não linear quando se está no caso MISO ou MIMO. Isto pode ser facilmente observado caso se considere o sistema MISO descrito por (2).

$$
Y(s)=\left[\begin{array}{ll}
\frac{1}{5 s+1} & \frac{1}{5 s+1}
\end{array}\right]\left[\begin{array}{l}
X_{1}(s) \\
X_{2}(s)
\end{array}\right]
$$


É evidente que as entradas distintas $[h(t) \quad 0]^{T}$ e $\left[\begin{array}{ll}0 & h(t)\end{array}\right]^{T}$, para qualquer sinal $h(t)$, irão produzir a mesma resposta.

\subsubsection{Não linearidades intermediárias}

As não linearidades intermediárias são não linearidades ligeiramente mais complexas, cujo comportamento não pode ser representado por modelos com estrutura de Wiener e de Hammerstein, mas podem ser observados em um grande número de estruturas.

\subsubsection{Estabilidade dependente da entrada}

Usualmente, o conceito de estabilidade é usado indistintamente, como se fosse um conceito único. Entretanto, existem múltiplos conceitos de estabilidade, que podem ser analisados em Teoria de Sistemas. Ao longo deste texto, por motivos de simplificação, sempre que for citado o conceito de estabilidade sem qualquer menção adicional, deve-se remeter ao conceito de estabilidade externa, também conhecido como estabilidade BIBO (bounded input, bounded output).

Em sistemas lineares, um conceito comumente aceito é que a estabilidade é uma característica do sistema. Assim, independente da entrada escolhida, se o sistema for instável, a resposta do sistema será divergente. No entanto, tal fenômeno não é observado em sistemas não lineares. Assim, dependendo da amplitude do sinal aplicado, a resposta poderá ser convergente ou divergente.

Visando ilustrar este fenômeno, utiliza-se o exemplo dado em (Pearson, 2003), correspondente ao modelo quadrático de Lur'e. Seja o sistema não linear em tempo discreto dado por:

$$
y_{n l}(k)=-0,8 y(k-1)+0,2 u(k-1)+0,18 y^{2}(k-1) .
$$

Considere também, para comparação, o seguinte sistema linear:

$$
y_{l}(k)=-0,8 y(k-1)+0,2 u(k-1)
$$


Nestes dois sistemas, para os quais são supostas condições iniciais nulas, são aplicados degraus com amplitude 2.6 e 26 . As repostas são apresentadas na Figura 2.3. Para o sistema linear, é possível observar que as respostas (gráficos (a) e (c)) possuem o mesmo comportamento dinâmico, que se diferenciam pela amplitude dos sinais. Por outro lado, para o sistema não linear, quando excitados pelo mesmo par de entradas, é possível observar que, a resposta do degrau com amplitude 2,6 (gráfico (b)) apresenta uma resposta assintoticamente estável. Por outro lado, para o degrau com amplitude 26, é possível observar que o sistema apresenta resposta instável (gráfico d). Assim, observa-se que para sistemas não lineares, a estabilidade BIBO não é necessariamente uma propriedade do sistema.

Figura 2.3 - Análise do fenômeno de estabilidade dependente da entrada. Em (a) é apresentada a resposta do sistema linear (4) a um degrau com amplitude 2,6. Em (b) é apresentada a resposta do sistema não linear (3) a um degrau com amplitude 2.6. Em (c) é apresentada a resposta do sistema linear (4) a um degrau com amplitude 26 . Em (d) é apresentada a resposta do sistema não linear (3) a um degrau com amplitude 26.

(a)

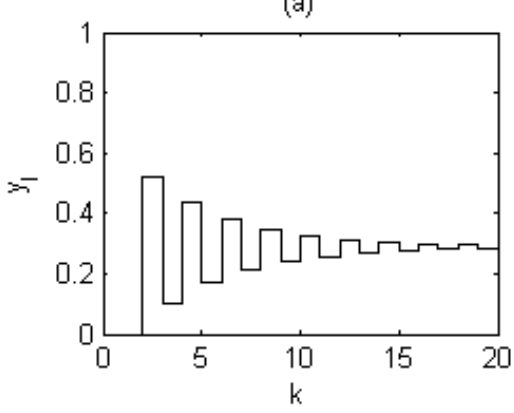

(c)

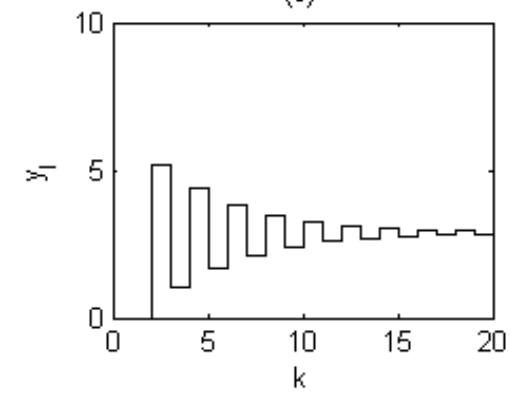

(b)

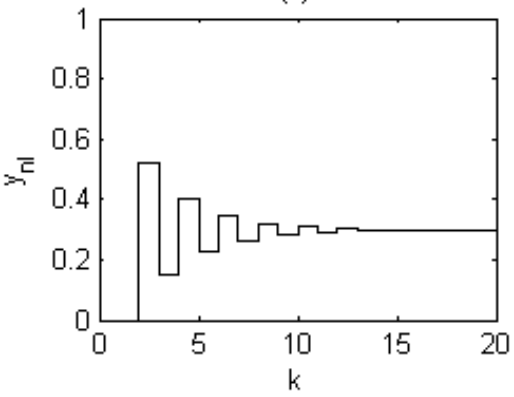

(d)

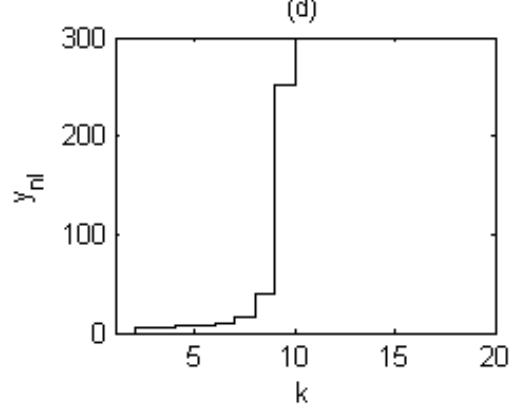

Fonte: Autor.

\subsubsection{Não linearidades fortes}

As não linearidades fortes são aquelas que podem ser geradas por um conjunto mais restrito de estruturas, como aquelas que possuem realimentação não linear da saída, isto é $y(k)=F(y(k-a), u)$, para algum $a \in \mathbb{N}^{*}$, sendo $F$ uma função não 
linear. As estruturas de Wiener e Hammerstein se caracterizam por não exibir este tipo de comportamento.

\subsubsection{Multiplicidade de Saída}

A multiplicidade de saída caracteriza-se pelo fato de um mesmo conjunto de entradas produzir convergência para diferentes atratores. Evidentemente, a convergência para saídas distintas, a partir de uma mesma entrada, decorre diretamente de condições iniciais distintas. $O$ ponto de diferença entre sistemas lineares e sistemas não lineares decorre do fato de sistemas lineares possuírem uma única bacia de atração, isto é, o conjunto das condições iniciais que convergem para um dado atrator é único. Por outro lado, sistemas não lineares podem apresentar diferentes bacias de atração.

É importante ressaltar que o foco não são as respostas transitórias, onde mesmo para sistemas lineares, condições iniciais distintas irão gerar respostas distintas, mesmo para sistemas lineares. Entretanto, se o sistema linear possuir estabilidade externa e interna, isto é, se todos os polos do sistema linear forem estáveis, então os efeitos oriundos das condições iniciais possuirão decaimento exponencial (Kailath, 1980), de forma que seu efeito não será observado na resposta em estado estacionário.

Para ilustrar o cenário onde ocorre multiplicidade de saídas, seja o exemplo dado por:

$$
y(k)=0,9 y(k-1)-0,9 \tan (y(k-2))+0,1 u(k-1)
$$

e a sua linearização na origem, que é dada por:

$$
y(k)=0,9 y(k-1)-0,9 y(k-2)+0,1 u(k-1)
$$

Para esses dois sistemas, é avaliada a resposta ao degrau unitário aplicado no instante zero para os seguintes cenários:

a) Sistema não linear (5) com condições iniciais $y(k-1)=0$ e $y(k-2)=0,498$ 
b) Sistema não linear (5) com condições iniciais $y(k-1)=0$ e $y(k-2)=0,499$

c) Sistema linear (6) com condições iniciais $y(k-1)=0$ e $y(k-2)=0,498$

d) Sistema linear (6) com condições iniciais $y(k-1)=0$ e $y(k-2)=0,499$

O resultado das simulações é apresentado na Figura 2.4.

Figura 2.4 - Fenômeno de multiplicidade de saída.
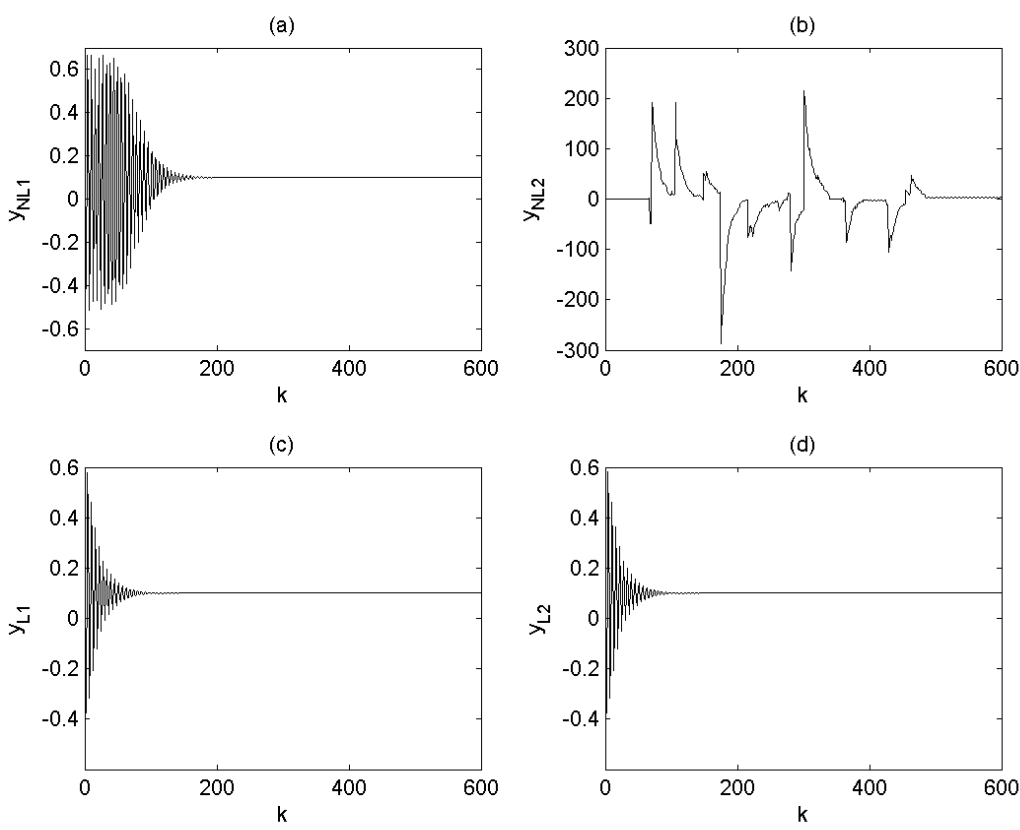

Fonte: Adaptado de Pearson (2003).

A saída em estado estacionário para estas simulações é igual a:

a) $y_{s s}=0,0997$ (cenário "a”);

b) $y_{s s}=2,9415$ (cenário "b");

c) $y_{s s}=0,1$ (cenário “c"); e

d) $y_{s s}=0,1$ (cenário "d").

Nota-se que uma pequena variação na condição inicial, faz com que o sistema não linear, gere respostas em estado estacionário distintas. Apesar de pequena a diferença, as duas condições iniciais pertencem a bacias de atração distintas, produzindo a convergência para atratatores distintos, caracterizando-se como a multiplicidade de saídas. Por outro lado, isto não é observado para sistemas lineares, pelo fato da bacia de atração ser única. 


\subsubsection{Geração de subharmônicos}

A geração de subharmônicos é caracterizada pela seguinte definição: para uma excitação de período $T$, uma resposta será subharmônica se o seu período for igual a $k T, k \in \mathbb{Z}$. Se a geração de harmônicos é um fenômeno consideravelmente comum em sistemas não lineares, o fenômeno de geração de subharmônicos ocorre apenas na presença de termos autoregressivos não lineares.

A fim de ilustrar este fenômeno, é utilizado o exemplo a seguir, extraído de Pearson (2003), em que é considerada a rede neural artificial recorrente:

$$
\begin{gathered}
h_{1}(k)=\tanh (-0,5 y(k-1)+u(k-2)) \\
h_{2}(k)=\tanh (1,3 y(k-2)+u(k-2)) \\
y(k)=\tanh \left(3,2 h_{1}(k)-h_{2}(k)\right)
\end{gathered}
$$

Este sistema é excitado com o sinal $u(k)=0,06(-1)^{k}$, que tem período 2 . O sinal de excitação e o sinal de saída em regime permanente são vistos na Figura 2.5.

Figura 2.5 - Fenômeno de geração de subharmônicos.
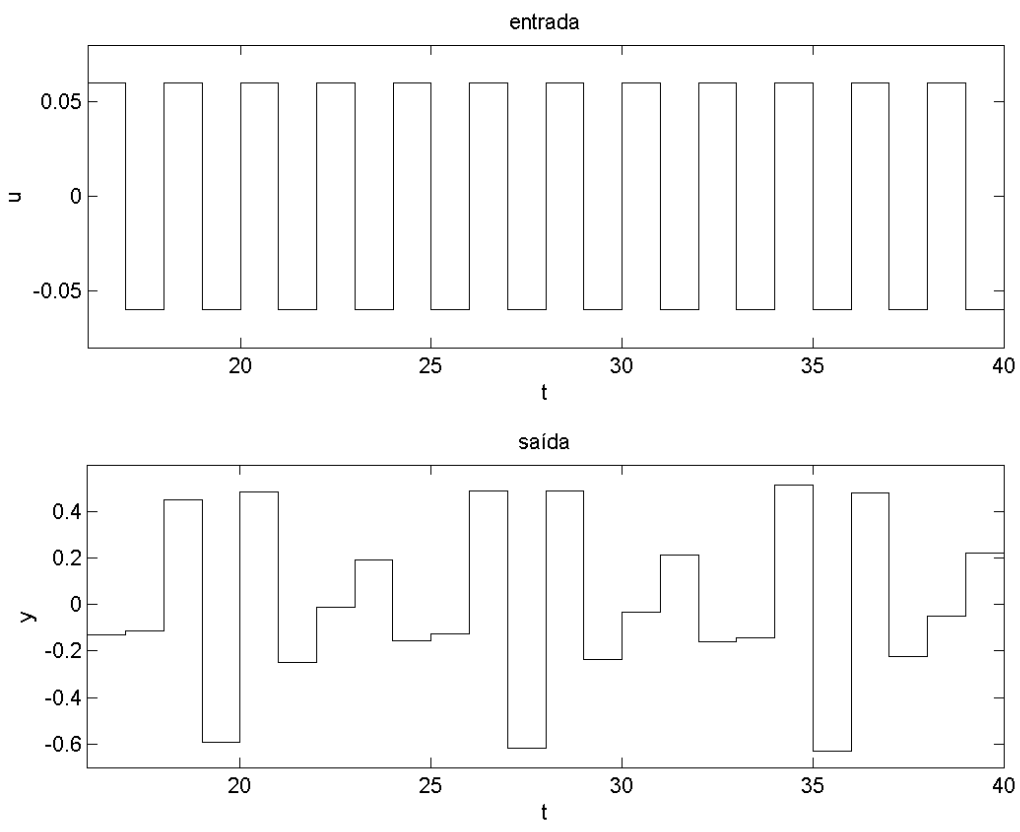

Fonte: Autor. 
É possível notar que o sinal de saída possui período 8, ou seja, quatro vezes o período do sinal de entrada, caracterizando-se assim, a geração de subharmônicos.

\subsubsection{Caos}

Caos é o nome dado a fenômenos típicos de sistemas não lineares, em que é possível observar, entre outras características (AGUIRRE, 1996a), (PEARSON, 2003) e (COELHO; BERNERT, 2009):

a) oscilações não periódicas com amplitude limitada;

b) elevada sensibilidade a condições iniciais;

c) transformada de Fourrier com amplo espectro;

d) propriedades fractais no espaço de fases; $\mathrm{e}$

e) convergência para atratores estranhos.

Conforme apresentado em Aguirre (1996b), muito do comportamento caótico era interpretado exclusivamente como flutuações aleatórias.

A fim de ilustrar este fenômeno, utilizar-se o exemplo apresentado em Aguirre (1996a), que considera o sistema autônomo, descrito por:

$$
y(k)=A[1-y(k-1)] y(k-1)
$$

em que $A$ é uma constante real, que em função do seu valor, o sistema pode apresentar comportamento caótico. Assim, para a condição inicial $y(0)=0,22$, são considerados dois cenários: no primeiro, $A=0,38$, que é conhecido por apresentar comportamento caótico. No segundo, $A=0,22$, não é possível observar caos. Os resultados para as duas simulações para o intervalo $[100,600]$ são apresentados na Figura 2.6.. Esse intervalo foi escolhido para que os efeitos transitórios fossem eliminados. Nos gráficos (a) e (c) são apresentadas as respostas temporais dos dois sistemas, enquanto nos gráficos (b) e (d) são apresentados os mapas de primeiro retorno dos dois sistemas, sendo, assim, possível realizar uma inferência sobre o tipo de atrator.

Por meio da resposta temporal, é possível observar a presença de oscilações não periódicas de amplitude limitada para o sistema caótico, enquanto o sistema não caótico apresenta uma resposta constante. Utilizando os mapas de primeiro retorno, 
por outro lado, é possível observar que o sistema caótico converge para um atrator estranho, enquanto o atrator do sistema não caótico é um ponto.

Figura 2.6 - Resposta temporal e mapa de primeiro retorno de um sistema dinâmico em regime caótico ( $a$ e b) e não caótico (c e d).

(a)

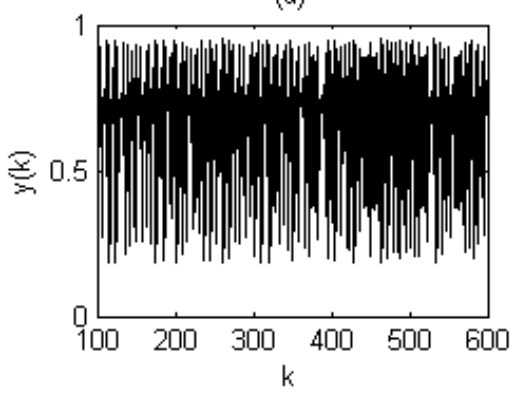

(c)

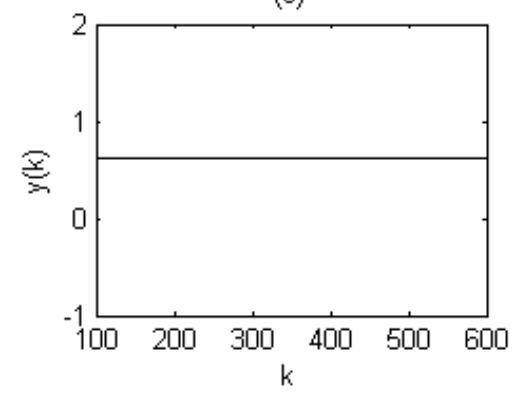

(b)

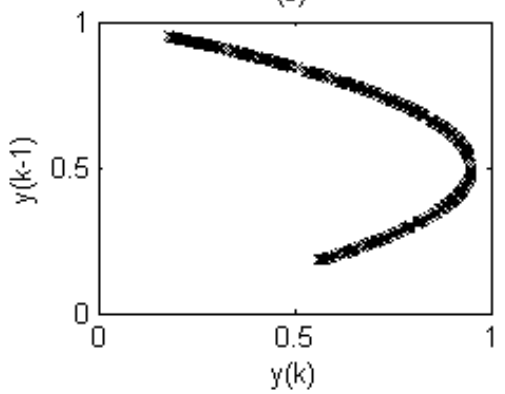

(d)

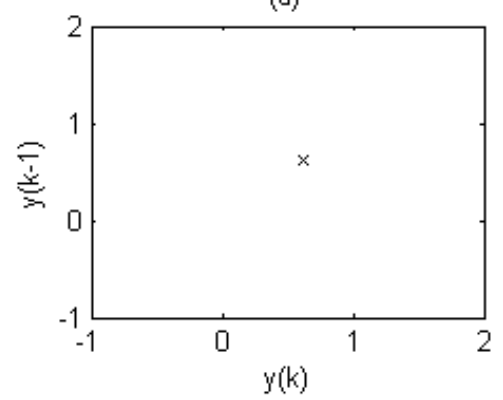

Fonte: Autor.

\subsection{Estruturas de modelos de entrada-saída não lineares}

Nesta seção são apresentadas as estruturas de modelos não lineares NARMAX e de blocos interconectados, sendo os modelos de Wiener e Hammerstein casos particulares da estrutura NARMAX. Apesar de existirem muitas outras estruturas, conforme apresentado em Pearson (2003), a apresentação se limitará a essas duas estruturas que são utilizadas em capítulos posteriores da tese.

\subsubsection{A estrutura NARMAX}

Os sistemas lineares têm uma estrutura geral, a partir da qual as estruturas de modelos lineares clássicas são casos específicos (LJUNG, 1999). Pearson (2003) diz que a estrutura NARMAX (Nonlinear Auto Regressive Moving Average with eXogenous input) pode ser encarada como uma estrutura geral, a partir da qual as demais estruturas são derivadas. A estrutura geral para modelos NARMAX é dada por (9) (LEONTARIS; BILLINGS, 1985a) e (LEONTARIS; BILLINGS, 1985b). 


$$
y(k)=F\left(y(k-1), \ldots, y\left(k-k_{a}\right), u(k), \ldots, u\left(k-k_{b}\right), e(k-1), \ldots e\left(k-k_{c}\right)\right)+e(k)
$$

em que $F: \mathbb{R}^{\left(k_{a}+k_{b}+k_{c}+1\right)} \rightarrow \mathbb{R}$

Um caso particular, são os modelos com estrutura NARX (Nonlinear Auto Regressive with eXogenous input), que se caracteriza por definir a perturbação como sendo um ruído branco. Assim, a forma geral dos modelos NARX é expressa por:

$$
y(k)=F\left(y(k-1), \ldots, y\left(k-n_{a}\right), u(k), \ldots, u\left(k-n_{b}\right)\right)+e(k)
$$

Em problemas de identificação de sistemas, usualmente considera-se que a função $F$ pertença a uma família de funções paramétricas, de maneira que o problema de identificação seja tratado como um problema de estimação paramétrica, para o qual um grande ferramental estatístico pode ser utilizado. Diversas famílias de funções paramétricas podem ser utilizadas, como é o caso de redes neurais artificiais ou polinômios. Grande parte dos resultados apresentados nesta tese utiliza modelos NARX polinomiais, cuja forma geral é apresentada em Aguirre (2015)

$$
\begin{gathered}
y(k)=\sum_{m=0}^{l} \sum_{p=0}^{m} \sum_{n_{1}, n_{m}}^{n_{y}, n_{u}} c_{p, m-p}\left(n_{1}, \ldots, n_{m}\right) \prod_{i=1}^{p}\left(y\left(k-n_{i}\right)\right) \prod_{i=p+1}^{m}\left(u\left(k-n_{i}\right)\right)+e(t) \\
\sum_{n_{1}, n_{m}}^{n_{y}, n_{u}} \equiv \sum_{n_{1}=1}^{n_{y}} \ldots \sum_{n_{m}=1}^{n_{u}}
\end{gathered}
$$

em que $l$ é o grau de não linearidade do modelo, $n_{y}$ é o atraso máximo das saídas, e $n_{u}$ é o atraso máximo das entradas.

É importante notar que os modelos com estrutura NARMAX (de maneira geral) são capazes de representar as não linearidades moderadas e fortes apresentadas na Seção 2.1 (PEARSON, 2003). Particularmente para que as não linearidades fortes possam ser representadas nos modelos, é necessário que a não linearidade possua termos da forma $y(k)=F(y(k-a))$ para $F$ uma função não linear e $a>0$ (PEARSON, 2003). 


\subsubsection{Modelos de Wiener e Hammerstein}

Os modelos com estrutura de Wiener e de Hammerstein pertencem a uma categoria de modelos não lineares, chamada de modelos de blocos interconectados ou modelos de blocos estruturados. Estes modelos são caracterizados por serem compostos pela presença de uma função não linear estática e um modelo dinâmico linear.

A fim de avaliar as estruturas, que por simplicidade serão SISO, considere o modelo linear apresentado em (13) e a função não linear dada por (14).

$$
\begin{gathered}
y_{l}(k)=\sum_{i=1}^{N} a_{i} y_{l}(k-i)+\sum_{i=1}^{M} b_{i} u_{l}(k-i) \\
y_{n l}=f\left(u_{n l}\right), \mathbb{R} \rightarrow \mathbb{R}, \text { invertível }
\end{gathered}
$$

onde $y_{l}$ e $u_{l}$ são respectivamente a saída e entrada do bloco linear e $y_{n l}$ e $u_{n l}$ a saída e entrada do bloco não linear.

As estruturas de blocos interconectados de Wiener e Hammerstein são mostradas a seguir. O diagrama de blocos para cada um destes casos é visto na Figura 2.7, onde $y(k), u(k)$ e $v(k)$ são respectivamente as vaiáveis de saída, entrada e distúrbio do modelo.

Figura 2.7 - Estruturas de modelos de blocos interconectados. (a) Hammerstein e (b) Wiener.
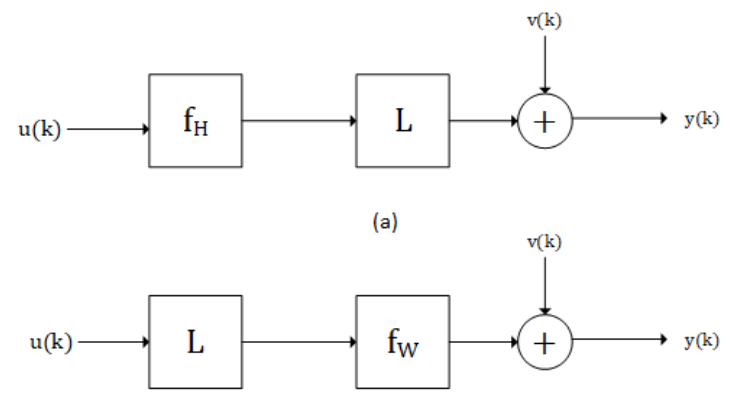

(b)

Fonte: (ROMANO, 2010), adaptado. 
- Modelos de Hammerstein: essa estrutura caracteriza-se pela concatenação da não linearidade estática, seguida pelo modelo dinâmico linear, de maneira que o modelo final seja escrito como:

$$
y(k)=\sum_{i=1}^{N} a_{i} y(k-i)+\sum_{i=1}^{M} b_{i} f_{H}[u(k-i)]+v(k)
$$

- Modelos de Wiener: essa estrutura é muito similar aos modelos de Hammerstein, entretanto a ordem dos blocos é invertida, isto é, o modelo dinâmico é seguido pela não linearidade estática, de maneira que o modelo final é escrito como:

$$
y(k)=f_{W}\left[\sum_{i=1}^{N} a_{i} f_{w}^{-1}[y(k-i)]+\sum_{i=1}^{M} b_{i} u(k-i)\right]+v(k)
$$

Aguirre; Coelho e Correa (2005) mostraram que os autovalores da matriz jacobiana dos modelos de Hammerstein são constantes, ao passo que esses mesmos autovalores dependem do ponto de operação para os modelos de Wiener. Deste modo, é possível observar que os modelos de Wiener apresentam variação no comportamento dinâmico em função do ponto de operação, enquanto este comportamento independe do ponto de operação para os modelos de Hammerstein. Este resultado é fundamental para definir se o sistema é melhor modelado por uma estrutura de Wiener ou de Hammerstein.

\subsection{Aplicabilidade de modelos com estrutura de Wiener e Hammerstein para o controle de processos}

Conforme explicado nas seções anteriores, as estruturas de Wiener e de Hammerstein são capazes de gerar modelos que apresentam apenas os comportamentos não lineares ditos moderados. Assim, um ponto importante a ser avaliado é se os modelos com essas estruturas são capazes de realizar uma boa aproximação de processos industriais para permitir a sua aplicação em controladores NMPC. 
Um primeiro ponto relevante é que em diversos processos na indústria química, é possível encontrar o fenômeno de multiplicidade de saída, denominada multiplicidade de estados estacionários. Alguns processos em que é possível observar esse tipo de multiplicidade são: reatores CSTR - (UPPAL; RAY, 1974), (RAZÓN; SCHMITZ, 1987) e (SINGSTAD, 1992) - colunas de destilação (JACOBSEN; SKOGESTAD, 1991) e (BEKIARIS, et al., 1993) e reatores de leito fluidizado (ARBEL; RINARD; SHINNAR, 1995). Isso pode ser considerado uma indicação para utilizar modelos com estrutura NARMAX. Por outro lado, ao se analisar mais detalhadamente quais são estes estados estacionários, baseando-se principalmente nas análises desenvolvidas por (SINGSTAD, 1992) para reatores de polimerização, observa-se que são encontrados três estados estacionários: o primeiro, estável, corresponde à situação onde o sistema não possui energia suficiente para realizar o processamento. O segundo, instável, consiste no ponto de interesse da atividade industrial. $O$ terceiro, também estável, envolve pressões e temperaturas tão elevadas, que por razões de segurança nunca é alcançado. Assim, para o desenvolvimento de controladores NMPC, que serão utilizados apenas com a planta operando em regime permanente, a multiplicidade de saída não é observada, assim, os modelos com estrutura de Wiener e de Hammerstein podem ser utilizados.

Um segundo ponto é que o modelo não deve introduzir comportamentos que não são observados no sistema real. Como foi mencionado, os modelos com estrutura NARMAX são capazes de apresentar comportamento caótico ou estabilidade dependente da entrada. Se o sistema a ser identificado não apresentar esses fenômenos e a identificação seja baseada em testes que têm sido capazes de reproduzir todas as possíveis dinâmicas da faixa de operação, o modelo resultante também não irá apresentá-los. Entretanto, pensando em aplicações práticas, devese considerar:

1. conforme mencionado por Forbes et al. (2015), mesmo que a identificação inicial de modelos muitas vezes seja realizada por especialistas em controle, que possuem conhecimento sobre o comportamento de modelos não lineares, a reidentificação, realizada durante a manutenção do controlador, é feita por engenheiros de automação, que não necessariamente possuem esse conhecimento; e 
2. a interpretação do comportamento de modelos não lineares não é intuitiva, como um modelo linear de primeira ordem mais tempo morto, por exemplo. Assim, eventuais fenômenos não lineares fortes presentes no modelo e inexistentes na planta podem não ser notados (como por exemplo uma eventual fronteira de bacia de atração na região de operação do controlador). Implementado no controlador, esse erro de modelagem pode produzir comportamentos indesejados, que levariam ao desligamento do controlador.

Por outro lado, apesar de serem capazes de modelar um menor número de fenômenos não lineares, os modelos de Wiener e de Hammerstein, possuem uma interpretação mais simples, evitando assim o erro de modelagem apresentado no exemplo.

Assim, apesar de eventuais limitações, os modelos com estrutura de Wiener e de Hammerstein podem ser utilizados para o desenvolvimento de controladores NMPC, como observado nos trabalhos de Fruzetti, Palazoglu e Mcdonald (1997), Norquay, Palazoglu e Romagnoli (1999), Shi, et al. (2007), Huo, et al. (2008) e Patikirikorala et al. (2012). 


\section{Controladores MPC e NMPC}

$\mathrm{Na}$ indústria de processos, principalmente nos setores petroquímico e de óleo e gás, é possível observar uma elevada aplicação de MPC (QIN; BADGWELL, 2003). Uma extensão direta destes são os controladores NMPC. Diferentemente dos controladores PID, que são utilizados para garantir a estabilidade do processo, os controladores MPC (e NMPC) têm por principal finalidade reduzir a variabilidade do processo, permitindo a operação em condições mais rentáveis. Tendo em vista sua ampla utilização, o objetivo deste capítulo é entender a estrutura geral deste controlador, analisar as particularidades dos casos linear e não linear e, por fim, avaliar algumas estruturas particulares de controladores NMPC.

\subsection{Estrutura Geral}

Não é incomum utilizar a expressão o "controlador MPC" como se fosse um algoritmo de controle único. Em verdade, este nome é uma referência a uma família de controladores que tem por principais características:

1. utilização de um modelo de predição do processo para estimar as saídas e estados futuros do sistema;

2. minimização de uma função para o cálculo da resposta de controle, que considera intervalos de tempo (denominados horizontes) para os quais deve ser considerada a predição e a ação de controle;

3. possibilidade de aplicar restrições ao funcional a ser minimizado; e

4. aplicação apenas da primeira amostra da ação de controle, desprezando todas as demais e minimizando o funcional a cada iteração do algoritmo de controle.

Considerando que o modelo usado seja determinístico, isto é, suas saídas não estão associadas a nenhuma variável aleatória, enquadra-se na classe dos controladores MPC de sistemas determinísticos. Uma ligeira variação da forma geral apresentada por Mayne (2000), ao considerar os modelos por meio de sua representação entrada-saída, em vez da representação em espaço de estados, e desprezando as funções de custo terminal é dada por: 


$$
\min _{\boldsymbol{u}(k), \ldots \boldsymbol{u}(k+N-1)} \sum_{i=1}^{N} \ell(\widehat{\boldsymbol{y}}(k+i), \boldsymbol{u}(k+i-1))
$$

com restrições:

(i) $\hat{\boldsymbol{y}}(k+i)-\boldsymbol{F}\left(\widehat{\boldsymbol{y}}(k+i-1), \ldots, \widehat{\boldsymbol{y}}\left(k+i-n_{a}\right), \boldsymbol{u}(k+i), \ldots, \boldsymbol{u}\left(k+i-n_{b}\right)\right)=0, \forall i$

$$
=1, N
$$

(ii) $\boldsymbol{u}(k+i) \in \boldsymbol{U}_{N}, \forall i=1, N$

(iii) $\widehat{\boldsymbol{y}}(k+i) \in \boldsymbol{y}_{N}, \forall i=1, N$

em que:

$\widehat{\boldsymbol{y}}(k)=\boldsymbol{F}\left(\widehat{\boldsymbol{y}}(k-1), \ldots, \widehat{\boldsymbol{y}}\left(k-n_{a}\right), \boldsymbol{u}(k), \ldots, \boldsymbol{u}\left(k-n_{b}\right)\right)$, a saída obtida com o modelo de predição;

$\ell(\widehat{\boldsymbol{y}}(k+i), \boldsymbol{u}(k+i)): \mathbb{R}^{n_{y}} \times \mathbb{R}^{n_{u}} \rightarrow \mathbb{R}$, um funcional objetivo;

$\boldsymbol{u}_{N} \subseteq \mathbb{R}^{n_{u}}$, o conjunto de entradas admissíveis;

$\boldsymbol{y}_{N} \subseteq \mathbb{R}^{n_{y}}$, o conjunto de saídas admissíveis.

Por essa estrutura ser demasiadamente genérica, é feita uma simplificação em supor este funcional quadrático e os conjuntos de entradas e saídas admissíveis politópicos. Essa simplificação, proposta em Camacho e Bordons (2007), é utilizada em muitos algoritmos MPC apresentados na literatura, e é representada por:

$$
\min _{\boldsymbol{u}(k+1), \ldots, \boldsymbol{u}(k+M), s} \sum_{j=1}^{N}\left\|\hat{\boldsymbol{y}}(k+j)-\boldsymbol{y}_{\boldsymbol{s}}\right\|_{R}^{2}+\sum_{j=0}^{M}\left\|\boldsymbol{u}(k+j)-\boldsymbol{u}_{s}\right\|_{Q}^{2}+\sum_{j=0}^{M}\|\boldsymbol{\Delta u}(k+j)\|_{P}^{2}+\|\boldsymbol{s}\|_{T}^{2}
$$

com restrições:

(i) $\widehat{\boldsymbol{y}}(k+i)-\boldsymbol{F}\left(\widehat{\boldsymbol{y}}(k+i-1), \ldots, \widehat{\boldsymbol{y}}\left(k+i-n_{a}\right), \boldsymbol{u}(k+i), \ldots, \boldsymbol{u}\left(k+i-n_{b}\right)\right)$

$$
=0, \forall j=1, N
$$

(ii) $\boldsymbol{y}_{\min }-\boldsymbol{s} \leq \widehat{\boldsymbol{y}}(k+j) \leq \boldsymbol{y}_{\max }+\boldsymbol{s}, \forall j=1, N$ 
(iii) $\boldsymbol{u}_{\min } \leq \boldsymbol{u}(k+j) \leq \boldsymbol{u}_{\max }, \forall j=1, M-1$

(iv) $\Delta u_{\min } \leq \Delta u(k+j) \leq \Delta u_{\max }, \forall j=1, M-1$

(v) $s \geq 0$

em que:

$\|\cdot\|_{P}^{2}$ são as normas $\mathbb{L}^{2}$, induzidas pelas matrizes real $\boldsymbol{P}$;

$N \in \mathbb{Z}_{+}$é o horizonte de predição utilizado;

$M \in \mathbb{Z}_{+}$é o horizonte de controle utilizado;

$\boldsymbol{\Delta u}(k)=\boldsymbol{u}(k)-\boldsymbol{u}(k-1)$ é a variação da entrada entre duas amostras consecutivas;

$\boldsymbol{y}_{s}$ é o set-point para as variáveis controladas;

$\boldsymbol{R}, \boldsymbol{Q}, \boldsymbol{T}, \boldsymbol{P}$ são matrizes de sintonia;

$\boldsymbol{y}_{\min }, \boldsymbol{y}_{\max }, \boldsymbol{u}_{\min }, \boldsymbol{u}_{\max }, \Delta \boldsymbol{u}_{\min }, \Delta \boldsymbol{u}_{\max }$ são os limites que definem as regiões admissíveis;

$\boldsymbol{s} \in \mathbb{R}_{+}^{N_{y}}$ é uma varável de folga utilizada para garantir que o controlador possua soluções admissíveis.

A partir de (18), é possível obter o controlador MPC linear e não linear, apenas variando a função $F$ da restrição (i). Nas próximas seções, são avaliadas algumas propriedades dos controladores MPC e NMPC.

\subsection{MPC Linear}

Ao supor que $F$ seja descrita por um modelo linear, tem-se um problema de otimização em que a função custo é quadrática e as restrições de igualdade e desigualdade são lineares. A este tipo de problema de otimização dá-se o nome de programação quadrática (em Inglês Quadratic Programming, QP). Desde que as matrizes usadas para o cálculo das normas induzidas sejam simétricas positivas definidas (o que é fácil, visto que elas são matrizes de sintonia do controlador), tem- 
se um problema de otimização convexo (NOCEDAL; WRIGHT, 2006). Deste modo, algumas das vantagens são:

- Existência e unicidade de uma solução ótima global, desde que o conjunto de soluções viáveis seja não nulo.

- Existência de algoritmos para a resolução de problemas de otimização convexa, como o caso do Algoritmo de Restrições Ativas, que convergem para a solução em um número finito de passos.

Apesar da existência dessas vantagens, a resolução não necessariamente é simples, tendo em vista que a quantidade de variáveis envolvidas pode ser consideravelmente grande para problemas com grandes horizontes de predição e controle, ou elevado número de restrições. A essas dificuldades, deve-se acrescentar o fato que a computação deve ocorrer em um tempo restrito.

Somando-se a estas dificuldades, o fato do modelo linear poder ser representado por diferentes estruturas (função de transferência, espaço de estados, resposta ao degrau, etc.), naturalmente, surgiram diferentes implementações de controladores MPC lineares. Assim, alterando a estrutura do modelo e as variáveis de decisão, diferentes características puderam ser exploradas como a incorporação de modelos de perturbação, remoção de erro em regime permanente, etc.

Um dos principais impactos relativos ao erro em regime permanente é obtido por meio da seleção de variável de decisão do MPC. Quando essa é $\boldsymbol{\Delta u}(k)$, diz-se que o controlador está configurado na forma de velocidade (WANG, 2004) e não apresenta erro em regime permanente. Caso contrário, quando a variável decisão é $\boldsymbol{u}(k)$, dizse que o controlador está configurado na forma de posição, que apresenta erro em regime permanente em sua formulação tradicional.

Uma maneira de se obter controladores em forma de posição que não apresentem erro em regime permanente são os controladores offset-free, como apresentado em Pannocchia e Rawlings (2003) e Borrelli e Morari (2007). Estes controladores caracterizam-se pelas seguintes características.

1. São construídos utilizando a formulação em espaço de estados, a seguir: 


$$
\begin{gathered}
\boldsymbol{x}(k+1)=\boldsymbol{A} \cdot \boldsymbol{x}(k)+\boldsymbol{B} \cdot \boldsymbol{u}(k) \\
\boldsymbol{y}(k)=\boldsymbol{C} \cdot \boldsymbol{x}(k),
\end{gathered}
$$

onde $\boldsymbol{A}, \boldsymbol{B}$ e $\boldsymbol{C}$ são matrizes reais, $\boldsymbol{x}(k) \in \mathbb{R}^{n_{x}}$ é o vetor de estados, $\boldsymbol{y}(k)$ é o vetor de saídas e $\boldsymbol{u}(k)$ é o vetor de entradas.

2. Constrói-se um modelo aumentado incluindo as $n_{d}$ variáveis de distúrbio $\boldsymbol{d}(k) \in \mathbb{R}^{n_{d}}$ integradoras, da forma:

$$
\begin{gathered}
{\left[\begin{array}{l}
\boldsymbol{x}(k+1) \\
\boldsymbol{d}(k+1)
\end{array}\right]=\left[\begin{array}{cc}
\boldsymbol{A} & \boldsymbol{B}_{\boldsymbol{d}} \\
\mathbf{0} & \boldsymbol{I}
\end{array}\right] \cdot\left[\begin{array}{l}
\boldsymbol{x}(k) \\
\boldsymbol{d}(k)
\end{array}\right]+\left[\begin{array}{l}
\boldsymbol{B} \\
\mathbf{0}
\end{array}\right] \cdot \boldsymbol{u}(k)} \\
\boldsymbol{y}(k)=\boldsymbol{C} \cdot \boldsymbol{x}(k)+\boldsymbol{C}_{\boldsymbol{d}} \boldsymbol{d}(k),
\end{gathered}
$$

em que $\boldsymbol{B}_{\boldsymbol{d}}$ e $\boldsymbol{C}_{\boldsymbol{d}}$, são matrizes escolhidas tal que

$$
\operatorname{rank}\left[\begin{array}{cc}
\boldsymbol{A}-\boldsymbol{I} & \boldsymbol{B}_{\boldsymbol{d}} \\
\boldsymbol{C} & \boldsymbol{C}_{\boldsymbol{d}}
\end{array}\right]=n_{x}+n_{d}
$$

Alternativamente, conforme mostrado em Pannocchia (2015), pode-se escolher $\boldsymbol{B}_{\boldsymbol{d}}$ como um observador do sistema com matrizes $\boldsymbol{A}, \boldsymbol{B}, \boldsymbol{C}$, fazendo a respectiva alocação de pólos do sistema, e calcular $\boldsymbol{C}_{\boldsymbol{d}}=\boldsymbol{I}-\boldsymbol{C} \cdot \boldsymbol{B}_{\boldsymbol{d}}$.

3. A partir de um observador de estados, estima-se o estado e a perturbação, como sendo igual a:

$$
\begin{gathered}
{\left[\begin{array}{l}
\widehat{\widehat{x}}(k \mid k) \\
\widehat{\boldsymbol{d}}(k \mid k)
\end{array}\right]=\left[\begin{array}{l}
\widehat{\boldsymbol{x}}(k \mid k-1) \\
\widehat{\boldsymbol{d}}(k \mid k-1)
\end{array}\right]+\left[\begin{array}{l}
\boldsymbol{L}_{\boldsymbol{x}} \\
\boldsymbol{L}_{\boldsymbol{d}}
\end{array}\right]\left(\boldsymbol{y}(k)-\boldsymbol{C} \widehat{\boldsymbol{x}}(k \mid k-1)-\boldsymbol{C}_{\boldsymbol{d}} \widehat{\boldsymbol{d}}(k \mid k-1)\right)} \\
{\left[\begin{array}{l}
\widehat{\boldsymbol{x}}(k+1 \mid k) \\
\widehat{\boldsymbol{d}}(k+1 \mid k)
\end{array}\right]=\left[\begin{array}{cc}
\boldsymbol{A} & \boldsymbol{B}_{\boldsymbol{d}} \\
\mathbf{0} & \boldsymbol{I}
\end{array}\right] \cdot\left[\begin{array}{l}
\widehat{\boldsymbol{x}}(k \mid k) \\
\boldsymbol{d}(k \mid k)
\end{array}\right]+\left[\begin{array}{c}
\boldsymbol{B} \\
\mathbf{0}
\end{array}\right] \cdot \boldsymbol{u}(k)} \\
\widehat{\boldsymbol{y}}(k+1 \mid k)=\boldsymbol{C} \cdot \widehat{\boldsymbol{x}}(k+1 \mid k)+\boldsymbol{C}_{\boldsymbol{d}} \cdot \widehat{\boldsymbol{d}}(k+1 \mid k),
\end{gathered}
$$

em que o circunflexo indica que são valores estimados, e $\left[\begin{array}{ll}\boldsymbol{L}_{\boldsymbol{x}}^{T} & \boldsymbol{L}_{\boldsymbol{d}}^{T}\end{array}\right]^{T}$ representa um estimador de estados do sistema aumendado. De acordo com Pannocchia (2015) podem ser escolhidos os valores $\boldsymbol{L}_{\boldsymbol{x}}=\boldsymbol{B}_{\boldsymbol{d}}$ e $\boldsymbol{L}_{\boldsymbol{d}}=\boldsymbol{I}$. 
4. Para o sistema aumentado, a cada iteração, calculam-se os valores de metas para as entradas $\boldsymbol{u}_{\boldsymbol{t}}$ e para os estados $\boldsymbol{x}_{\boldsymbol{t}}$, por meio da resolução do problema de otimização a seguir:

$$
\min _{\boldsymbol{u}_{t}, x_{t}} \boldsymbol{u}_{\boldsymbol{t}} \widetilde{\boldsymbol{R}} \boldsymbol{u}_{\boldsymbol{t}}
$$

com restrições:

(i) $\left[\begin{array}{cc}\boldsymbol{I}-\boldsymbol{A} & -\boldsymbol{B} \\ \boldsymbol{C} & \mathbf{0}\end{array}\right]\left[\begin{array}{l}\boldsymbol{x}_{\boldsymbol{t}} \\ \boldsymbol{u}_{t}\end{array}\right]=\left[\begin{array}{c}\boldsymbol{B}_{\boldsymbol{d}} \cdot \widehat{\boldsymbol{d}}(k \mid k) \\ -\boldsymbol{C} \cdot \widehat{\boldsymbol{d}}(k \mid k)+\boldsymbol{y}_{\boldsymbol{S}}\end{array}\right]$

(ii) $\boldsymbol{y}_{\min } \leq\left[\begin{array}{ll}\boldsymbol{C} & \boldsymbol{C}_{\boldsymbol{d}}\end{array}\right] \cdot\left[\begin{array}{c}\boldsymbol{x}_{t} \\ \boldsymbol{d}(k \mid k)\end{array}\right] \leq \boldsymbol{y}_{\max }$

(iii) $\boldsymbol{u}_{\min } \leq \boldsymbol{u}_{t} \leq \boldsymbol{u}_{\max }$

em que $\widetilde{\boldsymbol{R}}$ é uma matriz simétrica positiva definida utilizada para sintonia. Adicionalmente, pode ser calculada a meta $\boldsymbol{y}_{\boldsymbol{t}}=\boldsymbol{C} \cdot \boldsymbol{x}_{\boldsymbol{t}}+\boldsymbol{C}_{\boldsymbol{d}} \cdot \boldsymbol{d}(k \mid k)$.

5. Por fim, de acordo com Borrelli e Morari (2007), para o cálculo da ação de controle, resolve-se o problema de otimização dado por:

$$
\min _{\boldsymbol{u}(k), \ldots, \boldsymbol{u}(k+M)} \sum_{j=1}^{N}\left\|\hat{\boldsymbol{y}}(k+j)-\boldsymbol{y}_{t}\right\|_{\boldsymbol{Q}}^{2}+\sum_{j=0}^{N}\left\|\boldsymbol{u}(k+j)-\boldsymbol{u}_{t}\right\|_{\boldsymbol{R}}^{2}
$$

com restrições:

(i) $\widehat{\boldsymbol{y}}(k+i \mid k)=\boldsymbol{C} \cdot \widehat{\boldsymbol{x}}(k+i \mid k)+\boldsymbol{C}_{\boldsymbol{d}} \widehat{\boldsymbol{d}}(k+j \mid k), \forall j=1, N$

(ii) $\left[\begin{array}{l}\widehat{\boldsymbol{x}}(k+j+1 \mid k) \\ \widehat{\boldsymbol{d}}(k+j+1 \mid k)\end{array}\right]=\left[\begin{array}{cc}\boldsymbol{A} & \boldsymbol{B}_{\boldsymbol{d}} \\ \mathbf{0} & \boldsymbol{I}\end{array}\right] \cdot\left[\begin{array}{l}\widehat{\boldsymbol{x}}(k+j \mid k) \\ \widehat{\boldsymbol{d}}(k+j \mid k)\end{array}\right]+\left[\begin{array}{c}\boldsymbol{B} \\ \mathbf{0}\end{array}\right] \cdot \boldsymbol{u}(k+j), \forall j=0, N-1$

(iii) $\boldsymbol{y}_{\min } \leq \widehat{\boldsymbol{y}}(k+j) \leq \boldsymbol{y}_{\max }, \forall j=1, N$

(iv) $\boldsymbol{u}_{\text {min }} \leq \boldsymbol{u}(k+j) \leq \boldsymbol{u}_{\max }, \forall j=1, M-1$ 
Pannocchia (2015) demonstrou que o controlador estruturado em forma de velocidade, citado anteriormente, é na verdade um caso particular do controlador offset-free.

\subsection{MPC não linear}

$\mathrm{Na}$ seção anterior, foi mencionado que em função das diferentes estruturas de modelo é possível produzir um grande número de estruturas de controlador. Analogamente, o mesmo ocorre para os controladores MPC não lineares. Entretanto, pelo fato de existirem um número muito maior de estruturas não lineares que de estruturas lineares, a quantidade de técnicas utilizadas para o desenvolvimento do controlador é muito grande. Algumas das técnicas existentes, bem como referências de suas utilizações são listadas a seguir:

- Modelagem Fenomenológica ou caixa branca: (XAUMIER, et al., 1999), (KARACAN, 2003), (UCHOA, et al., 2008), (HUANG et al (2010) e (IDRIS; ENGEL, 2012);

- Modelos de Blocos Interconectados (Wiener e Hammerstein): (FRUZETTI; PALAZOGLU; MCDONALD,1997), (NORQUAY; PALAZOGLU; ROMAGNOLI, 1999), (SHI, et al., 2007), (HUO et al., 2008) e (PATIKIRIKORALA et al., 2012);

- Modelos NARMAX baseados em Redes Neurais Artificiais: (PICHE et al., 2000), (ATUONWU et al., 2010) e (DAMOUR et al., 2010).

Entretanto, independente da técnica utilizada, salvo casos muito particulares, o algoritmo de controle NMPC consiste na resolução de um problema de otimização não convexa. A não convexidade implica que o problema de otimização pode possuir mínimos locais, ao invés de um único mínimo global. Como resultado, em função da inicialização do algoritmo para resolver o problema de otimização, é possível obter a convergência para um mínimo local.

A maneira de tratar este problema, juntamente com as diferentes estruturas de modelos, é o que produz a grande diversidade de algoritmos NMPC existentes. Apesar de muitos controladores resolverem diretamente o problema de otimização 
não linear, vários algoritmos exploram a estrutura do modelo para simplificar a solução. A próxima seção aborda exatamente este tipo de controlador.

\subsubsection{Utilização da estrutura do modelo}

Uma estratégia de resolução dos controladores NMPC consiste em usar o conhecimento sobre a estrutura do modelo para transformá-lo em um MPC linear, mesmo que a solução obtida seja subótima. Um exemplo desta estratégia é citado em Camacho e Bordons (2007) para controladores com modelos de Wiener e Hammerstein.

Para o caso dos modelos de Hammerstein, define-se a variável auxiliar $\boldsymbol{x}_{\boldsymbol{H}}(k)=$ $f_{H}(\boldsymbol{u}(k))$ e resolve-se o problema de MPC linear para a entrada $\boldsymbol{x}_{\boldsymbol{H}}(k)$ e para a saída $\boldsymbol{y}(k)$. Após a resolução do problema de otimização, define-se a ação de controle como $\boldsymbol{u}(k)=f_{H}^{-1}\left(\boldsymbol{x}_{\boldsymbol{H}}(k)\right)$. Como tem-se que $\boldsymbol{\Delta} \boldsymbol{x}_{\boldsymbol{H}}(k) \neq f_{H}(\boldsymbol{\Delta} \boldsymbol{u}(k))$ não é conveniente trabalhar com controladores baseados na forma de velocidade, sendo assim indicada a utilização dos controladores offset-free baseados em posição, apresentados na seção 3.2. Caso exista a necessidade de incluir restrições em $\boldsymbol{\Delta u}(k)$, uma possível solução, aplicável apenas aos modelos não lineares independentes por canais (isto é, a não linearidade estática é um conjunto de funções SISO) seria considerar o menor valor de $\Delta x_{H}(k)$ que seja igual à restrição de $\boldsymbol{\Delta} \boldsymbol{u}(k)$ e escolher este valor como restrição. O problema dessa solução é o fato dela ser muito conservadora, principalmente quando há grande variação da derivada da não linearidade estática. A resposta do controlador, nesse caso, pode ser insatisfatória.

Para modelos de Wiener, define-se a variável auxiliar $\boldsymbol{x}_{W}(t)=f_{W}^{-1}(\boldsymbol{y}(t))$ e resolvese o problema de MPC linear considerando a saída $x_{W}(t)$. Pelo fato do controlador ser implementado como um MPC linear, os problemas relacionados ao tempo limitado para o cálculo da ação de controle tornam-se inexistentes.

Nos algoritmos apresentados acima, supõe-se que a não linearidade estática seja invertível. Para abordar esse problema, algumas possíveis soluções são: 
- Incluir restrições na determinação da função estática para garantir essa hipótese. Dependendo da forma como a não linearidade estática é estimada, esta tarefa pode não ser simples, além de incluir uma restrição não linear a um problema de otimização, muitas vezes linear. Adicionalmente, a função inversa não necessariamente possui uma forma analítica que pode ser facilmente determinada.

- Utilizar uma aproximação da função inversa. Essa estratégia pode implicar eventuais desvios, levando o controlador a operar em uma região não ótima.

Para os modelos com estrutura de Hammerstein, a segunda solução foi aplicada para diversos processos químicos por Fruzetti; Palazoglu e Mcdonald,1997) utilizando um MPC linear na forma de posição. Resultado análogo foi realizado por Norquay; Palazoglu e Romagnoli (1999) para modelos de Wiener.

\subsection{Conclusão}

Neste capítulo foi possível entender o conceito fundamental dos algoritmos MPC que serve como base para o desenvolvimento das técnicas de identificação MRI, descritas no próximo capítulo. Também foi possível notar as dificuldades adicionais inerentes ao controlador NMPC e por fim, foi avaliado como se pode aproveitar as estruturas de Wiener e Hammerstein para simplificar a resolução de algoritmos NMPC, possibilitando a utilização do ferramental existente para algoritmos MPC lineares. 


\section{Identificação de Sistemas}

Após apresentado o conceito do controlador MPC no capítulo anterior, uma das primeiras etapas referentes ao desenvolvimento do controlador consiste em obter o modelo do sistema a ser controlado. Assim, neste capítulo são apresentadas algumas técnicas de identificação de sistemas paramétricas, que poderão ser utilizados em controladores do MPC. Evidentemente, caso o controlador demande como o modelo respostas ao degrau, ou ao impulso, estas, podem ser obtidas por meio de simulação dos modelos paramétricos.

Identificação de Sistemas é um ramo de pesquisas que está em desenvolvimento há mais de 50 anos, conforme pode ser visto no artigo de revisão Åström e Eykhoff (1971). Assim, este capítulo limita-se a apresentar os resultados que são mais relevantes para o entendimento do restante da tese. Assim, o capítulo é estruturado da seguinte maneira: na Seção 4.1 são apresentados os métodos de predição de erro, que consistem em uma das principais famílias de identificação paramétrica existentes. Em sequência, na Seção 4.2, são apresentados os métodos de identificação relevantes para MPC (MRI). Por fim, na Seção 4.3 são apresentados alguns métodos de identificação para modelos não lineares para a estrutura de blocos interconectados.

\subsection{Métodos de erro de predição}

Dentre as técnicas paramétricas de identificação de sistemas lineares, a família que normalmente é a mais utilizada é a dos métodos de predição de erro (Prediction Error Methods, PEM). Estes métodos têm por objetivo a minimização do erro de predição um passo à frente (One Step Ahead Prediction Identification, OSAPI). Isto é, o objetivo é minimizar a função custo dada por:

$$
J_{O S A P I}(k+1)=\|\boldsymbol{y}(k+1)-\widehat{\boldsymbol{y}}(k+1 \mid k)\|^{2}
$$

em que:

$$
\begin{aligned}
& \boldsymbol{y}(k+1) \text { é o vetor que contém o histórico de saídas observadas do } \\
& \text { sistema até a amostra } k+1 \text {; } \\
& \widehat{y}(k+1 \mid k) \text { é o vetor que contém os valores a serem estimados pelo preditor }
\end{aligned}
$$


1 passo à frente.

Apesar de ser um conjunto de métodos de identificação geral, é muito usual utilizar estes métodos para realizar a identificação de modelos lineares baseados em funções de transferência. Ljung (1999) apresenta uma equação geral, que engloba um conjunto de 32 estruturas lineares distintas. Esta equação geral é:

$$
A\left(q^{-1}\right) \hat{y}(k+1 \mid k)=\frac{B\left(q^{-1}\right)}{F\left(q^{-1}\right)} u(k)+\frac{C\left(q^{-1}\right)}{D\left(q^{-1}\right)} e(k),
$$

em que:

$q^{-1} \quad$ Operador de atraso unitário;

$A, C, D, F$ São polinômios mônicos que têm como variável o operador de atraso unitário;

$B \quad$ É um polinômio qualquer que tem como variável o operador de atraso unitário;

$e$ (k) Ruído branco gaussiano.

Dentre as 32 possíveis estruturas, algumas possuem nomes próprios, como é o caso de ARX (Auto Regressive with eXogenous input), ARMAX (Auto Regressive Moving Average with eXogenous input), FIR (Finite Impulse Response) e OE (Output Error). A variação entre essas estruturas reside no fato de selecionar quais polinômios de (26) possuem grau zero.

Dentre essas, apenas as estruturas ARX e FIR podem ser obtidas a partir de métodos de regressão linear. Esse fato implica que apenas os modelos FIR e ARX apresentam uma solução analítica, obtida a partir do método dos mínimos quadrados. Para todas as demais estruturas é necessária a utilização de métodos de otimização não linear, que não possuem garantia de convergência para o mínimo global.

Uma estrutura que é considerada como uma das parametrizações mais naturais, por admitir a completa independência entre os polinômios que modelam o processo e a perturbação, é a estrutura Box-Jenkins (BJ) (Ljung, 1999). Essa estrutura se caracteriza por possuir o polinômio $A$ com grau zero e todos os demais polinômios com grau não nulo. 


\subsection{Métodos de Identificação Relevante para MPC (MRI)}

Uma das principais características dos métodos do erro de predição está no fato que a função custo a ser minimizada é o erro de predição um passo à frente. Por outro lado, os controladores MPC analisados no Capítulo 3 utilizam as predições geradas pelos modelos para um horizonte de predição de $k$ passos, isto é, são consideradas todas as predições no intervalo $[1, k]$. No artigo de Shook et al. (1991) foi apresentada a predição de horizonte amplo (Long Range Prediction Identification, LRPI), cuja função custo é dada por:

$$
J_{L R P I}(l+k)=\sum_{i=1}^{\mathrm{k}}\|\boldsymbol{y}(l+i)-\widehat{\boldsymbol{y}}(l+i \mid l)\|_{2}^{2}
$$

Os modelos fornecidos pela minimização de (27) apresentam melhor desempenho quando aplicados em controladores MPC (Lauri, et al., 2010). Por esta razão, a minimização dessa função é a base para os algoritmos do tipo MRI. Uma desvantagem da função custo (27) em relação à (25) é que, independente da estrutura escolhida para o modelo, não é possível garantir a convexidade do funcional. Assim, a minimização desta função custo requer a resolução de um problema de programação não linear, com todas implicações decorrentes, já mencionadas no Capítulo 3.

Em Stoica e Nehorai (1989) foi realizada uma comparação entre modelos de séries temporais sem entradas exógenas, obtidos para a predição um passo à frente (análogos aos métodos PEM) e para múltiplos passos à frente (análogos aos métodos MRI). Apesar desta análise ter utilizado modelos com estrutura ARMA, esse trabalho mostrou que para predições múltiplos passos à frente o desempenho obtido pelos métodos um passo à frente ou múltiplos passos à frente são equivalentes quando a ordem do modelo é correta ou superdimensionada. Entretanto, nas análises em que a ordem do modelo foi subdimensionada, as identificações para predições múltiplos passos à frente apresentaram melhores resultados.

Por outro lado, em Zhao; Zhu e Patwardhan (2014) os métodos de identificação OSAPI (One Step Ahead Prediction Identification) e LRPI foram comparados para 
realizar a identificação de modelos lineares em que a parcela do erro decorrente da variância (erro decorrente de perturbações não medidas) é maior que a parcela do erro decorrente do viés (erro de submodelagem). Neste cenário, ao comparar o valor oriundo de (27), quando aplicados dados de validação para os modelos obtidos pelos dois métodos, observou-se que o OSAPI obteve desempenho superior.

Apesar de os trabalhos de Stoica e Nehorai (1989) e Zhao; Zhu e Patwardhan (2014) levantarem hipóteses de que não existem ganhos em utilizar algoritmos de identificação do tipo MRI, deve-se lembrar que as plantas de processos químicos em geral apresentam comportamentos não lineares e que só podem ser melhor representadas por modelos a parâmetros distribuídos. Ora, com base nessa premissa, pode-se afirmar que qualquer modelo possui ordem subdimensionada, havendo assim um erro de viés não desprezível.

Para a obtenção de modelos lineares que minimizem (27), diversos métodos foram desenvolvidos nos últimos 25 anos. Uma breve comparação entre os métodos de 2 passos (GOPALUNI; PATWARDHAN; SHAH, 2004), EMPEM (POTTS; ROMANO; GARCIA, 2014), MPEM (HUANG; WANG, 1999) e LRPI (SHOOK; MOHTADI; SHAH, 1991) é apresentada de maneira ilustrativa na Figura 4.1.

Figura 4.1 - Exemplos de métodos MRI.

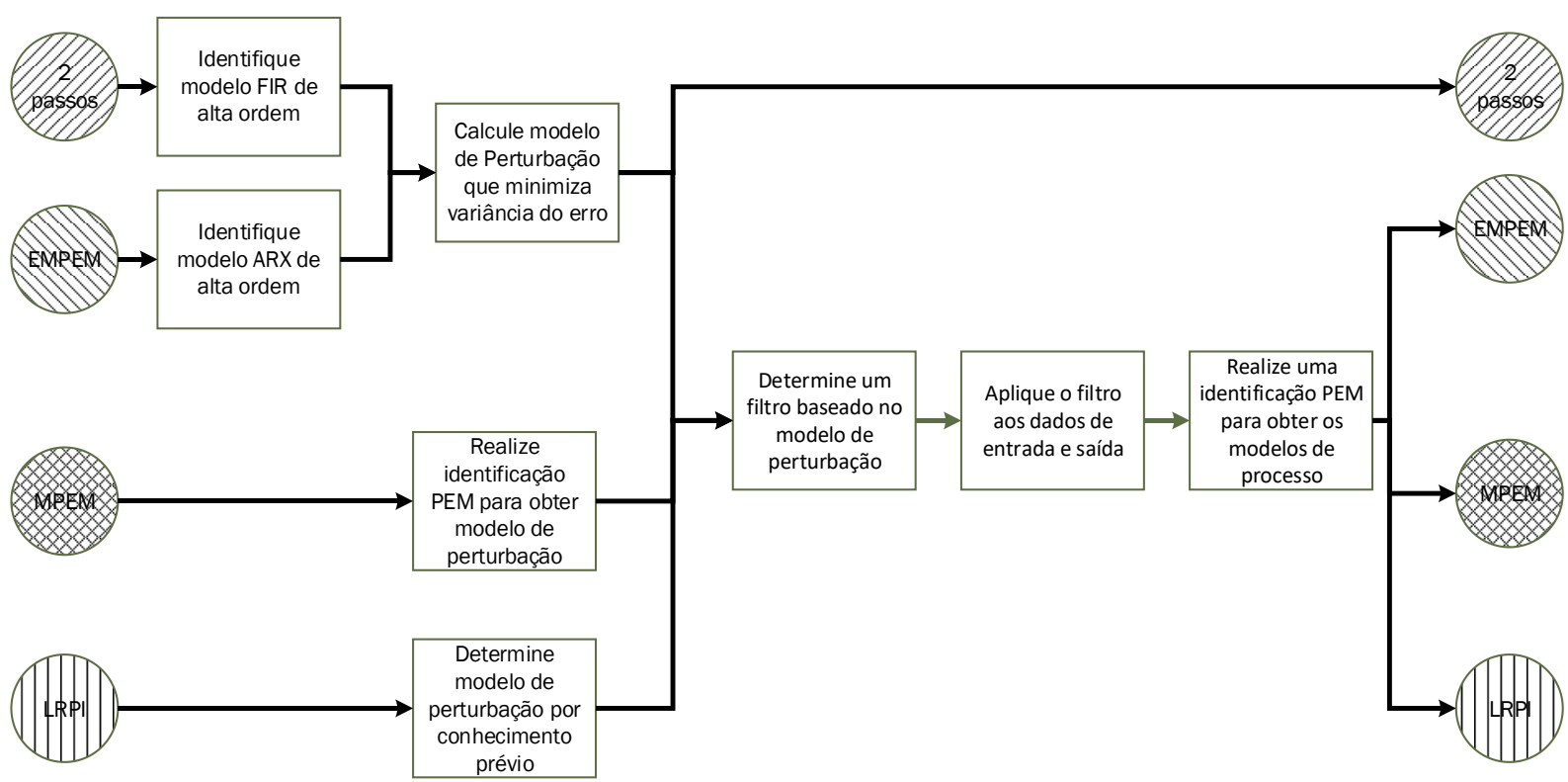

Fonte: Autor 
Dentre os diferentes métodos MRI, é apresentado na sequência a versão SISO do método MPEM (Multistep Prediction Error Method), desenvolvido por Huang e Wang (1999). Esse método se caracteriza por não necessitar que um modelo de perturbação seja fornecido como parâmetro e possuir uma generalização para o caso MISO direta.

1. Com os dados de entrada e saída $u(k)$ e $y(k)$, execute uma identificação utilizando o método do erro de predição (PEM) para obter um modelo da planta $G\left(q^{-1}\right)$ e um modelo de perturbação $H\left(q^{-1}\right)$.

2. Obtenha as novas entradas e saídas $u_{f}(k)=L\left(q^{-1}\right) u(k)$ e $y_{f}(k)=$ $L\left(q^{-1}\right) y(k)$, em que o filtro $L\left(q^{-1}\right)$ é dado pela Equação (28). Este filtro pode ser calculado utilizando algum algoritmo de fatoração espectral, como aqueles descritos no artigo de revisão Sayed e Kailath (2001). Especificamente, nesta tese é usado o método de Wilson, descrito no anexo de Sayed e Kailath (2001),

$$
L\left(q^{-1}\right)=\sum_{j=1}^{\mathrm{N}} \bar{H}_{j}\left(q^{-1}\right)
$$

em que $\bar{H}_{k}\left(q^{-1}\right)$ é dado por

$$
\begin{gathered}
\bar{H}_{j}(q)=\sum_{\ell=0}^{j-1} h_{\ell} q^{-\ell} \\
h_{0}=1
\end{gathered}
$$

3. Execute a identificação de um modelo com estrutura Output Error utilizando os dados filtrados $u_{f}(k)$ e $y_{f}(k)$ para determinar o modelo da planta $G\left(q^{-1}\right)$ que minimize a Função (27).

\subsection{Identificação de sistemas não lineares com estruturas de Wiener e Hammerstein}

A identificação de modelos não lineares com estruturas de Wiener ou de Hammerstein caracterizam-se pela resolução de problemas de dois problemas de estimação: a estimação da função não linear estática e a identificação do modelo 
não linear dinâmico. A ordem em que esses problemas são resolvidos varia em função do método adotado. Por exemplo, o algoritmo desenvolvido por Narendra e Gallman (1965) realiza a identificação dos dois blocos de maneira iterativa enquanto Bai (2004) apresenta outro algoritmo em que inicialmente identifica-se um modelo linear e na sequência é realizada a identificação da não linearidade estática.

Para o desenvolvimento desta tese, possuem papel fundamental os métodos de identificação baseados na análise de pontos fixos. Estes métodos são baseados nos trabalhos de Aguirre e Billings (1995) e Aguirre e Mendes (1996), para a análise de sistemas autônomos. Nesses trabalhos, é realizada, inicialmente a identificação de um modelo com estrutura NARMAX (ou NARX) polinomial. A partir desse modelo, são determinados os pontos fixos do sistema. Para sistemas com entradas exógenas, os pontos fixos serão determinados como funções dos parâmetros de entrada. Tais funções são utilizadas como as não linearidades estáticas dos modelos com estrutura de Wiener e de Hammerstein. É importante ressaltar, que, conforme apresentado em Aguirre e Souza (1998), os pontos fixos podem ser diretamente extraídos a partir dos dados entrada e saída sem a necessidade da identificação intermediária de um modelo com estrutura NARMAX.

Na sequência, tal método é apresentado com a estrutura de um algoritmo conforme a apresentação realizada em Coelho (2002):

1. selecionam-se os regressores e realiza-se a identificação de um modelo com estrutura NARX polinomial;

2. determina-se uma relação estática $\bar{y}=f(\bar{u})$, em que

$$
\bar{y}=y(k-i), i=0, \ldots, n_{y} \text { e } \bar{u}=u(k-j), j=0, \ldots, n_{u}
$$

3. após a determinação da não linearidade estática, calcula-se o sinal intermediário. Para modelos de Hammerstein, calcula-se $x_{H}(k)=f(u(k))$. Para modelos de Wiener, primeiro é definida uma aproximação de $g(\cdot)=$ $f^{-1}(\cdot)$ e, em seguida, se obtém $x_{W}(k)=g(y(k))$. 
4. Com os sinais intermediário e de saída para os modelos de Hammerstein, ou os sinais de entrada e intermediário, calcula-se o modelo dinâmico utilizando regressão linear, obtendo assim um modelo linear com estrutura ARX.

No desenvolvimento deste método, uma das etapas mais relevantes consiste na seleção dos regressores que comporão o modelo NARX polinomial. Algumas propriedades relevantes são:

1. para que o modelo de Wiener e Hammerstein seja único, é necessário que não existam regressores pertencentes aos fatores de agrupamento $\Omega_{y^{a} u^{b}}$ para $a>1$, em que $\Omega_{y^{a} u^{b}}$, para $a, b \in \mathbb{N}$ é o conjunto de todos os monômios de um modelo NARX polinomial com a forma $y^{a}(k-i) u^{b}(k-j)$;

2. para que as características dinâmicas sejam invariantes em função do ponto de operação, não deverão existir regressores pertencentes aos fatores de agrupamento $\Omega_{y^{a} u^{b}}$, para $a>0$, se $b>0$ ou $a=1$, se $b=0$.

Outras propriedades referentes à seleção de regressores, que estão relacionadas à estrutura da não linearidade estática, são avaliadas nos capítulos posteriores.

\subsection{Conclusão}

Nesse capítulo foram apresentados alguns resultados mínimos sobre métodos de identificação MRI lineares e para a identificação de modelos com estrutura de Wiener e de Hammerstein. A relação entre estes métodos é abordada a partir do próximo capítulo. 


\section{Algoritmos de identificação MRI para modelos de Wiener e Hammerstein}

Neste capítulo é apresentada a principal contribuição teórica da tese, que são os teoremas que apresentam a equivalência, em estado estacionário da identificação um passo à frente e múltiplos passos à frente. Este resultado é a base para o desenvolvimento dos algoritmos para a identificação MRI para modelos de Hammerstein e Wiener. Os algoritmos aqui apresentados possuem uma característica comum: eles consideram a identificação de um modelo um passo à frente com uma estrutura mais complexa como primeira etapa. Todo o desenvolvimento é realizado para a identificação de modelos não lineares polinomiais, apesar dos teoremas apresentados serem suficientemente genéricos para permitir a utilização de outras estruturas. A avaliação do desempenho dos algoritmos é realizada nos capítulos posteriores.

\subsection{Resultados Teóricos}

Para permitir a identificação de modelos com estrutura de Wiener ou Hammerstein baseando-se em algoritmos MRI, os seguintes resultados teóricos devem ser considerados:

Lema 1: Em estado estacionário, o mínimo global do funcional de erro de predição 1 passo à frente também é o mínimo global do funcional de erro de predição múltiplos passos à frente.

Demonstração: Seja $\widehat{y_{1}}(k+1 \mid k)=F_{1}(y(k), u(k))$ o modelo que minimiza o funcional de erro de predição 1 passo à frente e $\widehat{y_{2}}(k+1 \mid k)=F_{2}(y(k), u(k))$ o modelo que minimiza o funcional de erro de predição múltiplos passos à frente. Em estado estacionário, é possível definir:

$$
\begin{aligned}
& \overline{y_{1}}=\widehat{y_{1}}(k+1 \mid k)=\widehat{y_{1}}(k+2 \mid k)=\cdots \\
& \overline{y_{2}}=\widehat{y_{2}}(k+1 \mid k)=\widehat{y_{2}}(k+2 \mid k)=\cdots
\end{aligned}
$$

Em estado estacionário, têm-se:

$$
J_{O S A P I}^{*}=E\left[\bar{y}-\overline{y_{1}}\right]^{2},
$$




$$
J_{L R P I}^{*}=\frac{1}{N} \sum_{j=1}^{N} E\left[\bar{y}-\overline{\mathrm{y}_{2}}\right]^{2}
$$

Entretanto, por estar em estado estacionário, (35) pode ser reescrita como:

$$
J_{L R P I}^{*}=E\left[\bar{y}-\overline{y_{2}}\right]^{2}
$$

Dados (34) e (36), é possível notar que tanto $J_{O S A P I}^{*}$ e $J_{L R P I}^{*}$ representam o valor mínimo do funcional de predição de predição 1 passo à frente. Dado que o mínimo global tenha sido obtido por ambos algoritmos, então:

$$
\overline{y_{1}}=\overline{y_{2}}
$$

Este lema apresenta uma maneira de realizar a análise de pontos fixos de modelos obtidos pela minimização do funcional de predição múltiplos passos à frente sem que seja necessário resolver o problema de otimização não linear. Adicionalmente, para modelos não lineares, os algoritmos existentes, provavelmente ficarão presos em um mínimo local.

Até o momento, todas as análises foram realizadas considerando algoritmos hipotéticos. Entretanto, o corolário a seguir apresenta um algoritmo que pode ser utilizado.

Corolário 1: Utilizando mínimos quadrados ortogonais para a identificação de modelo NARX polinomiais, como realizado por Chen, Billings e Luo (1989), é possível obter um modelo com as mesmas características em estado estacionário de um modelo que minimize o funcional de predição múltiplos passos à frente.

Demonstração: Dado que a identificação é realizada utilizando mínimos quadrados ortogonais irrestritos, que é um problema convexo, então o mínimo global é atingido. Aplicando o Lema 1, o comportamento em estado estacionário de um modelo que minimiza a função de predição múltiplos passos à frente também é obtida.

Como consequência do Lema 1 , é possível que os pontos fixos de um modelo que minimize o funcional de predição múltiplos passos à frente pode ser obtida por utilizando um método OSAPI que convirja para o mínimo global. Porém, é necessário ainda assegurar que a análise de pontos fixos pode de fato ser utilizada 
para a obtenção da função não linear estática de modelos MRI com estrutura de Wiener e Hammerstein. Para tal, considere a seguinte definição.

Definição 1: Considere a representação geral de modelos NARMAX originalmente definida em Leontaritis e Billings (1984a, b).

$$
y(k)=F\left(y(k-1), \ldots, y\left(k-n_{a}\right), u\left(k-n_{d}\right), \ldots, u\left(k-n_{b}-n_{d}\right), e(k), \ldots, e\left(k-n_{c}\right)\right),
$$

em que e $(k)$ é um ruído branco e $F$ é uma função não linear.

O valor em estado estacionário do modelo é definido como:

$$
\bar{y}=\mathrm{E}\left[F\left(\bar{y}, \bar{u}, e(k), \ldots, e\left(k-n_{c}\right)\right)\right],
$$

em que $E[\cdot]$ é a esperança matemática com respeito ao ruído branco.

A partir da Definição 1, é então possível avaliar os pontos fixos mesmo quando as estruturas de modelo apresentam termos estocásticos. Para identificar a função não linear estática de um modelo de Hammerstein, considere o Teorema 1.

Teorema 1: A função não linear estática de um modelo de Hammerstein obtida por um algoritmo que minimiza OSAPI também minimiza o funcional de predição múltiplos passos à frente.

Demonstração: Seja (40) o modelo de com estrutura de Hammerstein que minimizem a função de predição múltiplos passos à frente.

$$
\hat{y}(k)=G\left(q^{-1}\right) f(u(k))+H\left(q^{-1}\right) e(k),
$$

em que $G\left(q^{-1}\right)$ e $H\left(q^{-1}\right)$ são as partes dinâmicas do modelo, com respeito ao sinal de entrada e o ruído, respectivamente.

Dado que $e(k)$ é um ruído branco e $H\left(q^{-1}\right)$ é linear, então, o valor esperado do termo de distúrbios será igual a zero. Utilizando a Definição 1, é possível escrever:

$$
\bar{y}=G_{s s} f(\bar{u}),
$$

Em que $G_{s s}$ é o ganho do termo dinâmico linear $G\left(q^{-1}\right)$.

Assumindo, sem perda de generalidade, que $G_{s s}=1$, o modelo que minimiza $\circ$ funcional de predição múltiplos passos à frente em estado estacionário, para modelos com estrutura de Hammerstein é: 


$$
\operatorname{Argmin}\left(J_{L R P I}^{*}\right)=\bar{y}=f(\bar{u}) .
$$

Entretanto, a partir do Lema 1, está função é a mesma obtida pela minimização do funcional de predição 1 passo à frente, provando assim que ambos métodos são equivalentes.

Desta maneira, o Teorema 1 garante que para a identificação MRI de modelo com estrutura de Hammerstein, a função não linear estática pode ser identificada utilizando uma técnica de identificação 1 passo à frente. Para obter resultados similares para modelos com estrutura da Wiener, é necessário avaliar primeiramente um caso particular, apresentado no Lema 2.

Lema 2: Seja $f$ uma função estática linear por partes definida em um intervalo limitado $A$. Se $f$ é a função estática de um modelo de Wiener que minimiza o funcional de predição 1 passo à frente, então, esta função também irá minimizar o funcional de predição múltiplos passos à frente.

Demonstração: Seja (43) ser um modelo com estrutura de Wiener que minimiza o funcional de predição múltiplos passos à frente

$$
\hat{y}(k)=f\left(G\left(q^{-1}\right) u(k)+H\left(q^{-1}\right) e(k)\right) .
$$

Dado que $f$ foi definida linear por partes, a função não linear estática pode ser escrita como:

$$
f(x)=\sum_{i=1}^{n}\left(a_{i} x+b_{i}\right) \cdot \mathbb{I}_{A_{i}}
$$

em que $A_{i}$ são intervalos tais que $\cup A_{i}=A$ e $A_{i} \cap A_{j}=\emptyset, i \neq j$ e $\mathbb{I}_{A_{i}}$ são suas funções indicatrizes.

Substituindo (42) em (41), tem-se:

$$
\hat{y}(k)=\sum_{i=1}^{n}\left(a_{i}\left(G\left(q^{-1}\right) u(k)+H\left(q^{-1}\right) e(k)\right)+b_{i}\right) \cdot \mathbb{I}_{A_{i}},
$$

como $a_{i}$ e $b_{i}$ são escalares, então, (43) pode ser reescrita como: 


$$
\hat{y}(k)=\sum_{i=1}^{n}\left(a_{i}\left(G\left(q^{-1}\right) u(k)\right)+b_{i}\right) \cdot \mathbb{I}_{A_{i}}+\sum_{i=1}^{n} a_{i}\left(H\left(q^{-1}\right) e(k)\right) \cdot \mathbb{I}_{A_{i}}
$$

utilizando a Definição 1, é possível escrever:

$$
\bar{y}=f\left(G_{s S} \bar{u}\right)
$$

em que $G_{s S}$ é o ganho do sistema linear $G\left(q^{-1}\right)$.

Assumindo, sem perda de generalidade, que $G_{s s}=1$ minimiza o functional de predição multiplos passos à frente, em estado estacionário para estruturas de Wiener lineares por partes, então:

$$
\operatorname{Argmin}\left(J_{L R P I}^{*}\right)=\bar{y}=f(\bar{u}) .
$$

Mas, a partir do Lema 1, esta função também é obtida pela minimização do funcional de predição 1 passo à frente, provando que ambos métodos são equivalentes.

Embora o Lema 2 apresente um caso específico, esse pode ser generalizado, conforme apresentado no Teorema 2.

Teorema 2: Seja g uma função não linear continua e limitada. Se g é a função não linear estática obtida pela minimização do funcional de predição um passo à frente, então ela também será a função não linear estática que minimiza o funcional de predição múltiplos passos à frente.

Demonstração: Dado que $g$ é continua, ela pode ser escrita como

$$
g(x)=\lim _{n \rightarrow \infty} \sum_{i=1}^{n}\left(a_{i} x+b_{i}\right) . \mathbb{I}_{A_{i}}
$$

A partir de (49), é possível aplicar uma análise similar àquela empregada durante a demonstração do Lema 2. Adicionalmente, como $g$ é limitada, é possível aplicar o teorema da convergência dominada quando determinando o comportamento em estado estacionário, de maneira que

$$
\bar{y}=g\left(G_{s s} \bar{u}\right)
$$


tal que, como observado na demonstração do Lema 2, é uma condição necessária para que o valor mínimo obtido do funcional de predição múltiplos passos à frente seja igual ao valor mínimo obtido pelo funcional de predição 1 passo à frente.

\subsection{Algoritmo de identificação MRI para modelos de Wiener e de Hammerstein polinomiais}

Nesta seção são apresentados os algoritmos para a identificação de modelos com estrutura de Wiener e Hammerstein polinomiais. É importante notar que os resultados teóricos apresentados na seção 5.1 também são aplicáveis à não linearidades estáticas que não sejam polinomiais.

\subsubsection{Caso SISO - modelos de Hammerstein e de Wiener}

Utilizando o resultado dos Teoremas 1 e 2, é proposto o seguinte algoritmo para identificação MRI de modelos com estrutura de Wiener e de Hammerstein e não linearidade polinomial para modelos SISO.

1. Identifique um modelo NARX polinomial utilizando técnicas de mínimos quadrados ortogonais;

2. Calcule a função de não linearidade estática assumindo $y(k-1)=y(k-2)=$ $\cdots=\bar{y}$ e $u(k-1)=u(k-2)=\cdots=\bar{u}$;

3. Utilizando a não linearidade estática, calcule o sinal intermediário do modelo:

3.1. Para modelos com estrutura de Hammerstein, é necessário apenas aplicar o sinal $u(k)$ na não linearidade encontrada.

3.2. Para modelos com estrutura de Wiener, é necessário inverter a função estática. Caso a função não seja invertível, deve ser identificada uma função aproximada. Em seguida, aplica-se o sinal de saída $y(k)$ na função de saída para se obter o sinal intermediário;

4. Com o sinal intermediário, é possível determinar o modelo linear utilizando qualquer algoritmo MRI.

Os passos de 1 a 3 desse algoritmo são exatamente iguais as primeiras etapas do algoritmo desenvolvido por Coelho (2002), descrito na Seção 4.3. Entretanto, 
quando combinado com o quarto passo, o modelo obtido minimiza o funcional de predição múltiplos passos a frente, e não o funcional de predição um passo à frente, como no método original. A alteração do último passo, que é a inovação do método, é possível apenas em função dos resultados teóricos demonstrados na Seção 5.1 .

As estruturas dos modelos identificados com este algoritmo são apresentadas na Figura 5.1 e na Figura 5.2. Essas figuras são ligeiramente diferentes dos modelos apresentados na Figura 2.7, pois abaixo são representados tanto o modelo de processo quanto o modelo de perturbação que compõe a parte linear dos modelos.

Figura 5.1 - Estrutura do modelo de Hammerstein SISO identificado pelo algoritmo proposto.

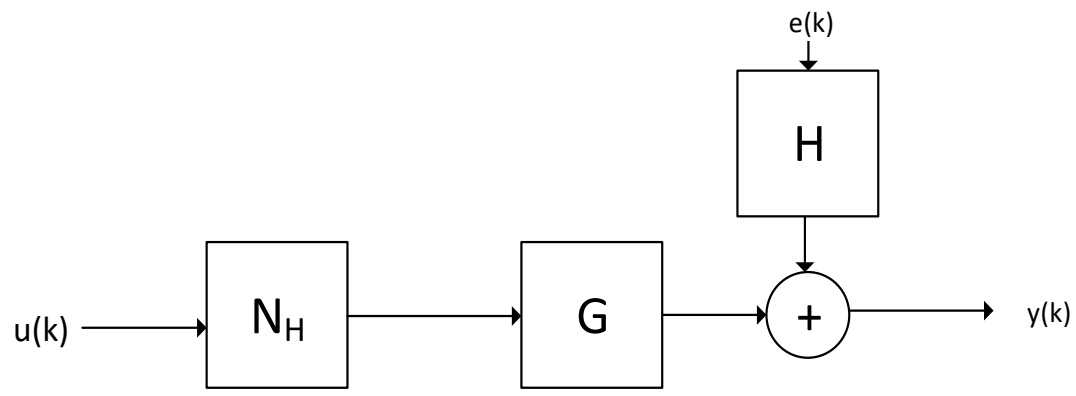

Fonte: Autor.

Na Figura $5.1 N_{H}$ é a não linearidade estática, $G$ é o modelo dinâmico de processo e $H$ é o modelo dinâmico de distúrbio. O sinal $e(k)$ é ruído branco.

Figura 5.2 - Estrutura do modelo de Wiener SISO identificado com o algoritmo proposto.

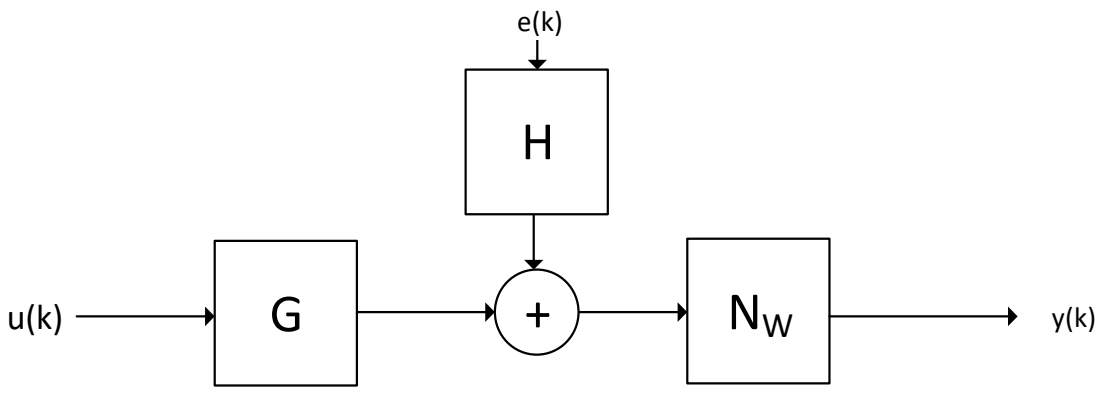

Fonte: Autor.

Na Figura $5.2 N_{W}$ é a não linearidade estática, $G$ é o modelo dinâmico de processo e $H$ é o modelo dinâmico de distúrbio. $O$ sinal $e(k)$ é ruído branco. 
É importante notar que a posição do sinal de distúrbio indicada na Figura 5.2, pode ser considerada pouco usual, pois conforme afirmado por Haggenblad, Ljung e Wills (2008), grande parte dos artigos sobre identificação de modelos de Wiener considera exclusivamente a perturbação aditiva de medição na saída da não linearidade estática. A perturbação apresentada na Figura 5.2 é denominada perturbação de processo por esse mesmo artigo. Nos modelos identificados pelo algoritmo proposto, assume-se, portanto, a hipótese que a perturbação de medição é nula e a perturbação de processo é não nula.

Considerando que as perturbações de processo representam as diferenças entre a planta e o modelo, e que as perturbações de medição usualmente representam ruídos na medição, espera-se que os ruídos de medição possam ser reduzidos por meio de substituição ou manutenção dos sensores. Assim, esta hipótese é aceitável para o desenvolvimento de controladores para a indústria de processos.

\subsubsection{Caso MIMO - modelos de Hammerstein}

O algoritmo apresentado na subseção anterior para modelos de Hammerstein pode ser generalizado para o caso MIMO, com a identificação de múltiplos modelos MISO. Entretanto, conforme mostrado por Ribeiro e Aguirre (2014), para modelos com estrutura de Hammerstein, é necessário introduzir restrições a quais regressores são considerados na identificação do modelo NARX, para selecionar a estrutura das não linearidades estáticas. Desta maneira, as seguintes restrições são consideradas:

1. Não inclusão de regressores da forma $y^{i}(k-a) u^{j}(k-b)$, para $i \geq 1$ e $j \geq 0$, de maneira que a não linearidade seja polinomial;

2. Não inclusão de regressores da forma $y^{l}(k-a) u_{p}^{i}(k-b) u_{q}^{j}(k-c)$, para $p \neq$ $q$, de maneira que não existam termos cruzados na não linearidade estática, sendo assim representados por um conjunto de funções monovariáveis.

Desta maneira, na Figura 5.3 é apresentado o diagrama de blocos de um modelo MIMO 2x2 com estrutura de Hammerstein. Para simplificar a representação, os modelos de perturbação identificados pelo algoritmo foram omitidos, sendo representado apenas o ruído colorido resultante $v_{l}(k)$. 
Figura 5.3 - Estrutura de modelo de Hammerstein MIMO 2x2 identificada pelo algoritmo proposto.

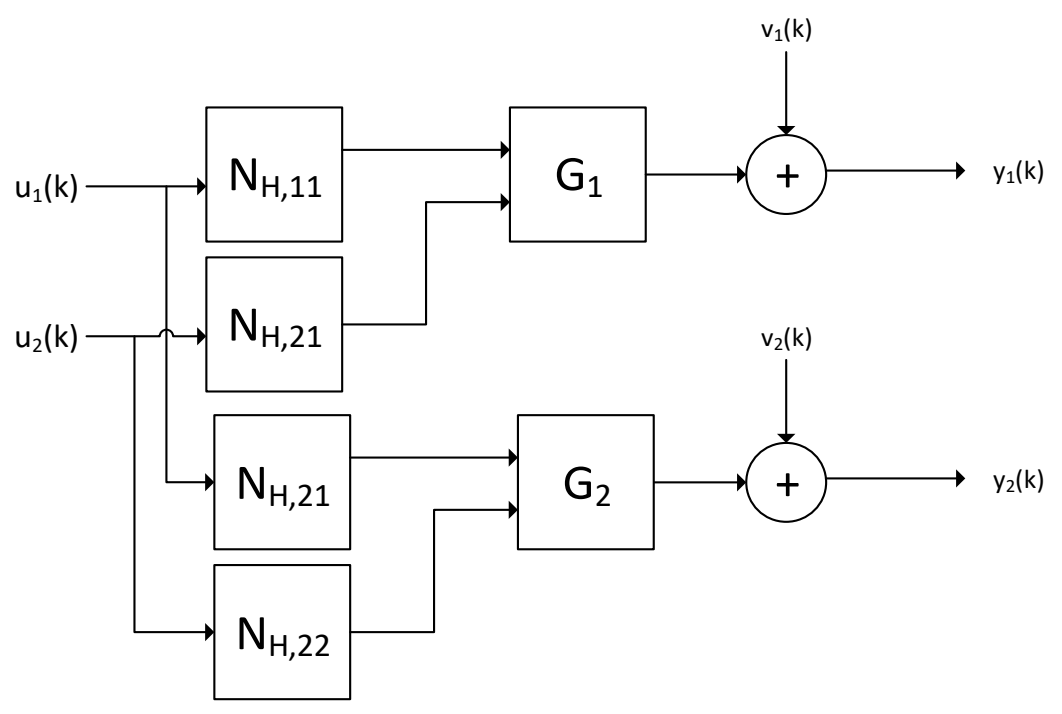

Fonte: Autor.

Na Figura $5.3 N_{H, i j}$ são não linearidades estáticas SISO e $G_{j}$ são modelos lineares MISO.

É importante notar que para os modelos com estrutura de Hammerstein, as restrições 1 e 2 são necessárias para garantir que a representação seja unívoca, conforme apresentado por Ribeiro e Aguirre (2014). Assim, para o caso MIMO, os algoritmos são escritos da seguinte maneira:

1. Para cada saída $y_{i}$, identifique um modelo NARX polinomial MISO utilizando técnicas de mínimos quadrados ortogonais, restringindo os regressores a serem inclusos no modelo;

2. Calcule as funções de não linearidade estática, assumindo $y_{i}(k-1)=$ $y_{i}(k-2)=\cdots=\bar{y}_{l}$ e $u_{j}(k-1)=u_{j}(k-2)=\cdots=\bar{u}_{j} ;$

3. Utilizando as não linearidades estáticas, calcule o sinal intermediário do modelo aplicando os sinais de identificação de $u_{j}(k)$ a cada uma das funções de não linearidade estática encontradas.

4. Com o sinal intermediário, é possível determinar o modelo linear utilizando qualquer algoritmo MRI. É importante notar que para identificação de estruturas de Hammerstein, é necessário utilizar um algoritmo MISO. 
É importante notar que a generalização do modelo de Wiener para o caso MIMO, não é uma extensão direta como ocorre para os modelos de Hammerstein. Como foi mencionado no Capítulo 2, os modelos de Wiener caracterizam-se pela sua dinâmica variar em função do ponto operacional. Por outro lado, ao assumir a hipótese para que o modelo NARX seja polinomial para que as não linearidades sejam independentes por canal, faz-se com que o modelo NARX não apresente variação da dinâmica em função do ponto de operação (Aguirre, 2015). Como resultado, a função não linear estática para o caso de um modelo MIMO Wiener é multivariável. Assim, para calcular o sinal intermediário, é necessário realizar a aproximação da função não linear inversa. Essa estimação pode ser realizada utilizando redes neurais artificiais, conforme apresentado por Ferrari e Stengel (2005).

\subsection{Conclusão}

A equivalência do comportamento em estado estacionário entre os modelos identificados por algoritmos MRI e OSAPI, demonstrada nesse capitulo, permite que, na identificação MRI de modelos com estrutura de Wiener e Hammerstein, a identificação da função não linear estática seja realizada de maneira independente do modelo dinâmico linear. Tal independência permite que os arcabouços, já desenvolvidos, para a identificação de funções não lineares estática para modelos de Wiener e Hammerstein e modelos MRI lineares sejam combinados de maneira a permitir que diversos métodos de identificação MRI de modelos com estrutura de Wiener e Hammerstein sejam desenvolvidos. Assim, os algoritmos apresentados, devem ser vistos como um primeiro exemplo de aplicação dos resultados apresentados. 


\section{Aplicações da identificação com estrutura de Hammerstein e de Wiener SISO}

Visando analisar o desempenho dos algoritmos de identificação MRI SISO para modelos com estrutura de Wiener e Hammerstein, descritos no capítulo anterior, são apresentados os resultados de um conjunto de experimentos que tiveram por objetivo:

- verificar que os modelos obtidos pelo algoritmo proposto possuem melhor capacidade de predição múltiplos passos à frente que os modelos obtidos pela combinação entre identificação da não linearidade estática e a identificação utilizando métodos PEM;

- avaliar a acurácia dos modelos identificados, por meio de análises baseadas no método de Monte Carlo.

\subsection{Avaliação da capacidade de predição múltiplos passos à frente}

Para avaliar os modelos com estrutura de Wiener e de Hammerstein identificados pelo algoritmo proposto, foram realizados dois experimentos de identificação: para o primeiro foram utilizados os dados obtidos em um experimento de identificação de um sistema térmico com dissipação, apresentado em (CASSINI, 1999) e para o segundo foram utilizados os dados de um experimento de identificação de um forno elétrico, apresentado em (RODRIGUES et al., 1996). Existem dois pontos que devem ser destacados sobre estes experimentos:

1. os dados utilizados foram extraídos da literatura, de maneira, que não é possível realizar qualquer análise sobre a seleção dos sinais de excitação;

2. os dados foram coletados a partir de sistemas reais, para os quais não é possível determinar a estrutura de modelo correta.

\subsubsection{Identificação de sistema térmico com dissipação}

Conforme descrito em (CASSINI, 1999), o sistema utilizado neste experimento consiste em um ferro de solda, acoplado a um termopar. Adicionalmente, existe um ventilador operando em velocidade constante, para realizar a dissipação térmica. 
Neste sistema, é possível modular e medir a tensão de alimentação do ferro de solda e é possível medir a tensão no termopar. Para as séries de dados utilizadas neste experimento, foi usado um período de amostragem de $12 \mathrm{~s}$.

Os dados utilizados para este experimento foram centrados e escalados e são apresentados na Figura 6.1.

Figura 6.1 - Dados de entrada e saída de identificação e validação para o sistema térmico com dissipação.
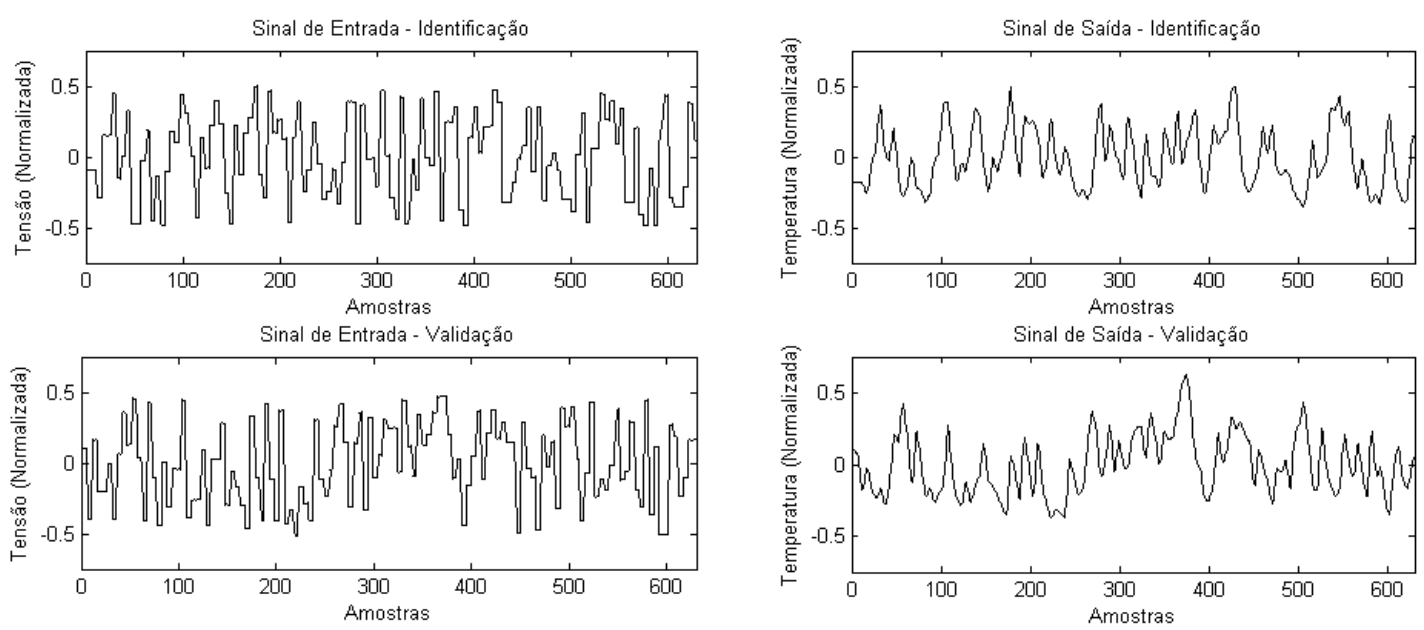

Fonte: Cassini (1999), adaptado.

A fim de definir se a estrutura de Wiener ou de Hammerstein deveria ser utilizada, foi realizada a avaliação dos autovalores da matriz Jacobiana, conforme mencionado na Subseção 2.2.2. Para tal, foi identificado um modelo NARX polinomial com os termos da forma $y^{a} u^{b}, a \leq 1, a+b<N L$, onde $N L$ é o grau de não linearidade do modelo, com os parâmetros apresentados na Tabela 6.1. Tal escolha baseou-se nas estruturas selecionadas por Cassini (1999).

Tabela 6.1 - Parâmetros utilizados para avaliação dos autovalores da matriz Jacobiana do sistema térmico com dissipação.

\begin{tabular}{lc}
\hline Parâmetro & Valor \\
\hline Grau de não linearidade $(\mathrm{NL})$ & 3 \\
Máximo atraso na entrada & 2 \\
Máximo atraso na saída & 2 \\
Valor mínimo de ERR residual & $5.10^{-4}$ \\
\hline
\end{tabular}

Fonte: Autor. 
Em função da utilização do valor do Error Reduction Ratio (ERR) residual apresentado, o modelo NARX polinomial considerado na identificação utilizou todos os 22 parâmetros possíveis. A partir do modelo NARX polinomial, foi possível calcular os autovalores da matriz Jacobiana, para diferentes estados estacionários em uma faixa de valores de entrada iguais aos utilizados na identificação. Os autovalores da matriz são apresentados na Figura 6.2.

Figura 6.2 - Autovalores da matriz Jacobiana para 20 pontos de operação distintos do sistema térmico com dissipação. Os primeiros autovalores de cada par são indicados como "+" e os segundos autovalores de cada par são indicados como "x".

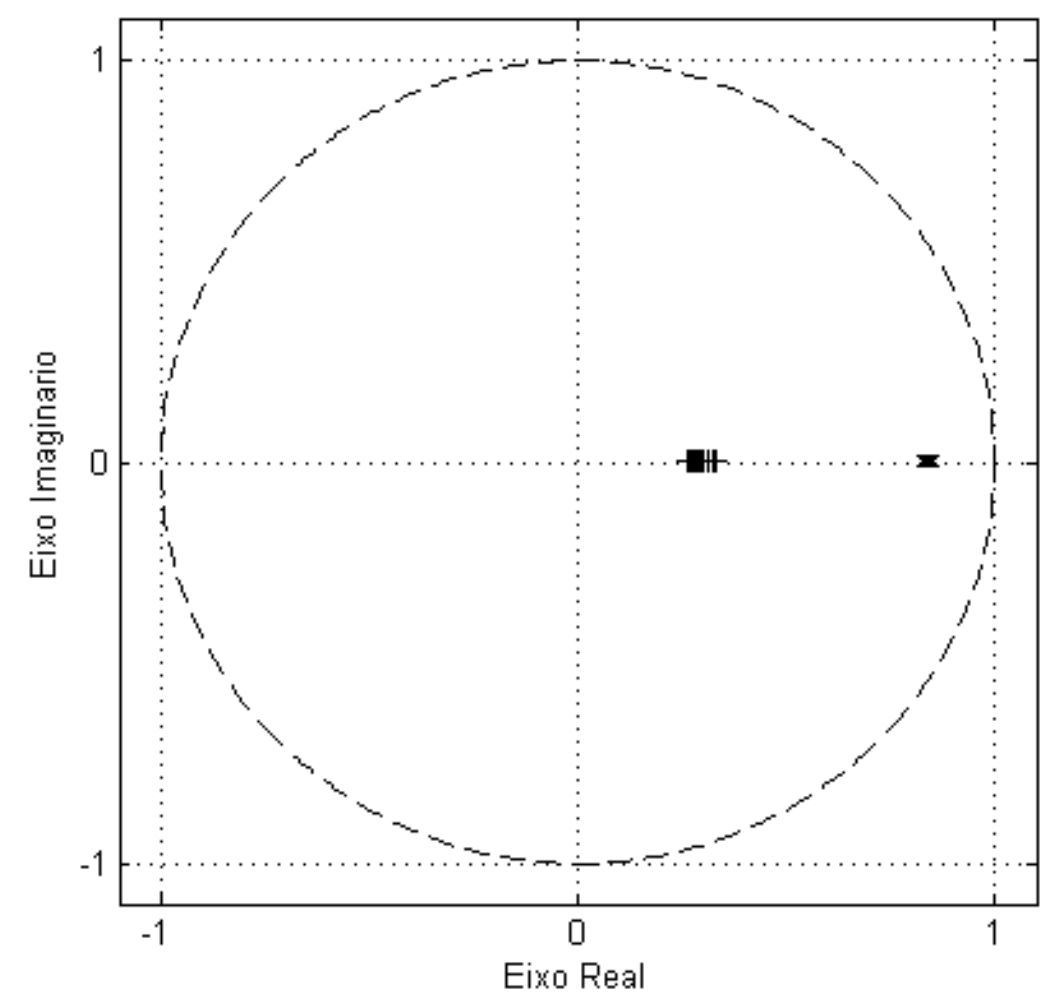

Fonte: Autor.

Na Figura 6.2, para cada ponto de operação o primeiro autovalor é indicado por '+', e localiza-se mais próximo a origem, e o segundo autovalor é indicado por ' $x$ ' e localiza-se mais próximo do círculo unitário. É possível observar na Figura 6.2 que os autovalores da matriz Jacobiana apresentaram uma pequena variação, indicando, desta maneira, que a estrutura de Hammerstein é mais apropriada para a identificação do modelo. 
Para a identificação do modelo de Hammerstein, os dados foram divididos em dois conjuntos: as primeiras 630 amostras foram utilizadas para a identificação, enquanto as 630 amostras subsequentes foram usadas para a validação do modelo.

Além dos parâmetros listados na Tabela 6.1, para a identificação do modelo de Hammerstein, foi fixado o horizonte de predição igual a 10. Adicionalmente, permitiuse que alguns parâmetros variassem de maneira a possibilitar que fossem encontrados os parâmetros que minimizam o funcional de predição múltiplos passos à frente. As faixas de variação desses parâmetros são indicadas na Tabela 6.2.

Tabela 6.2 - Faixa de variação de alguns parâmetros utilizados na identificação do modelo de Hammerstein.

\begin{tabular}{lcc}
\hline Parâmetro & Valor Mínimo & Valor Máximo \\
\hline Grau do polinômio B & 1 & 2 \\
Grau do polinômio C & 1 & 2 \\
Grau do polinômio D & 1 & 2 \\
Grau do polinômio F & 1 & 2 \\
Atraso da entrada & 1 & 2 \\
\hline
\end{tabular}

Fonte: Autor.

Utilizando os parâmetros listados, foram identificados dois modelos com estrutura de Hammerstein: o primeiro utilizando o algoritmo MRI descrito no capítulo anterior (considerando o algoritmo MPEM para a identificação da dinâmica linear) e o segundo usando um modelo cuja parte linear possui estrutura de Box-Jenkins e que minimizasse o funcional de predição um passo à frente. Para os dois modelos, foi empregada a mesma não linearidade estática, identificada a partir do comportamento em estado estacionário do modelo NARX polinomial.

A fim de simplificar o texto, na sequência é utilizado um abuso de linguagem, em que os modelos obtidos pelo algoritmo de identificação MRI são denominados modelos MRI e os modelos cujo bloco linear foi identificado utilizado o algoritmo PEM com estrutura Box-Jenkins são intitulados modelos BJ.

Para avaliar o desempenho dos modelos identificados, as seguintes comparações foram feitas: 
- o valor da função custo ponderada para a predição múltiplos passos à frente, conforme definido por (51).

$$
W_{L R P I}(N)=\frac{1}{N} \sum_{k=i}^{n-N} \sum_{i=1}^{N}\|\boldsymbol{y}(k+i)-\widehat{\boldsymbol{y}}(k+i \mid k)\|_{2}^{2}
$$

- a comparação entre a saída do sistema utilizada para a validação e as predições 1 passo à frente e 10 passos à frente, utilizando o parâmetro fit, que é calculado por (LJUNG, 1999):

$$
f i t=100 \cdot\left(1-\frac{\|y-\hat{y}\|_{2}}{\|y-\operatorname{mean}(y)\|_{2}}\right) .
$$

Os resultados destas comparações são apresentados nas figuras a seguir.

Figura 6.3 - Comparação do valor função custo ponderada para a predição múltiplos passos em função da variação do horizonte de predição para o modelo MRI e o modelo BJ.

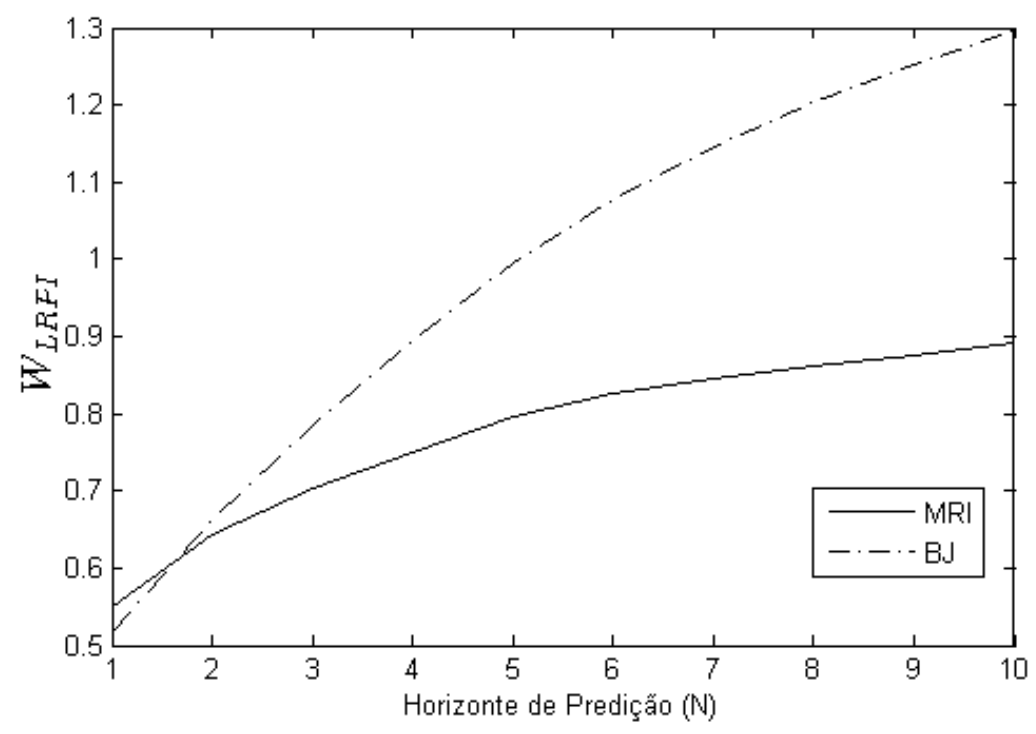

Fonte: Autor. 
Figura 6.4 - Comparação entre a saída real da planta (dados centrados e escalados) e a predição 1 passo à frente obtida pelos modelos MRI e BJ.

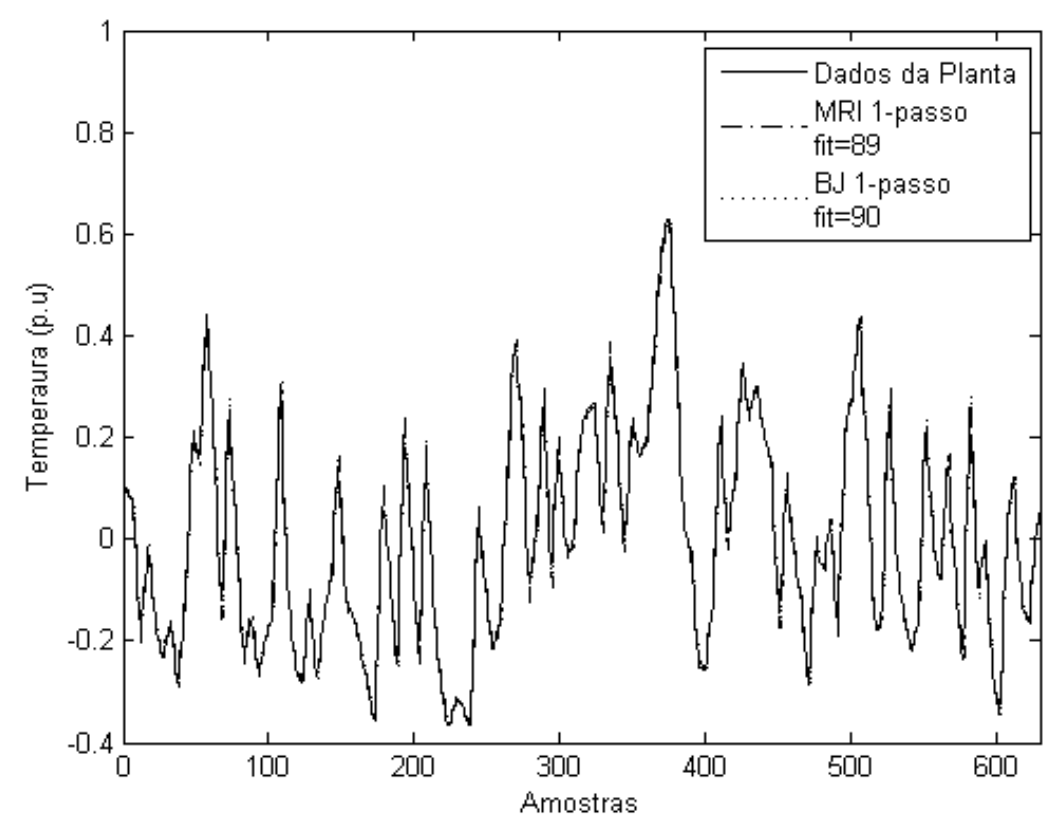

Fonte: Autor.

Figura 6.5 - Comparação entre a saída real da planta (dados centrados e escalados) e a predição 10 passos à frente obtida pelos modelos MRI e BJ.

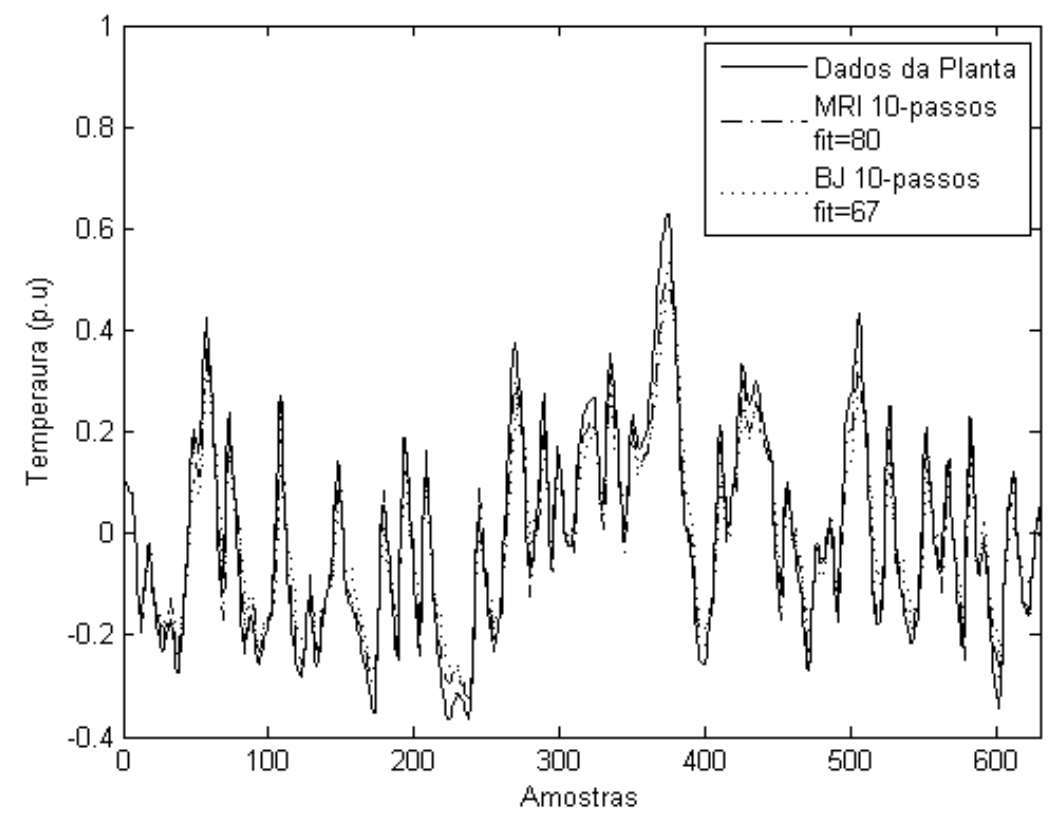

Fonte: Autor. 
Avaliando-se a Figura 6.3, é possível observar que, com o aumento do horizonte de predição $(N)$, o valor de $W_{L R P I}$ aumenta com uma taxa superior para o modelo BJ. Assim, para qualquer horizonte de predição superior a 2, o erro de predição obtido pelo modelo MRI será inferior ao erro de predição obtido pelo modelo BJ. Uma consequência direta desta constatação é o valor do parâmetro fit calculado para o modelo MRI ser superior ao do modelo BJ na Figura 6.5.

Outro ponto que pode ser constatado a partir da Figura 6.3 é o fato do valor de WLRPI obtido pelo algoritmo MRI ser superior ao do modelo $B J$ para $\mathrm{N}=1$. Este fato decorre diretamente do fato de o modelo BJ ser o resultado de uma minimização do funcional de erro de predição 1 passo à frente, enquanto o modelo MRI ser resultado da minimização do funcional de erro para o intervalo de 1 a 10 passos à frente. Este ponto pode ser constatado pelo fato do parâmetro fit do modelo BJ ser ligeiramente superior ao modelo MRI na Figura 6.4

\subsubsection{Identificação de forno elétrico}

No experimento a seguir, foram utilizados os dados de um forno elétrico (RODRIGUES et al., 1996). Para este sistema é possível modular a porcentagem da potência total fornecida à resistência elétrica e é possível medir a temperatura no interior do forno, sendo estas respectivamente as variáveis de entrada e saída do sistema.

Os dados usados para este experimento foram centrados e escalados e são vistos na Figura 6.6. 
Figura 6.6- Dados de entrada e saída de identificação e validação para o forno elétrico.
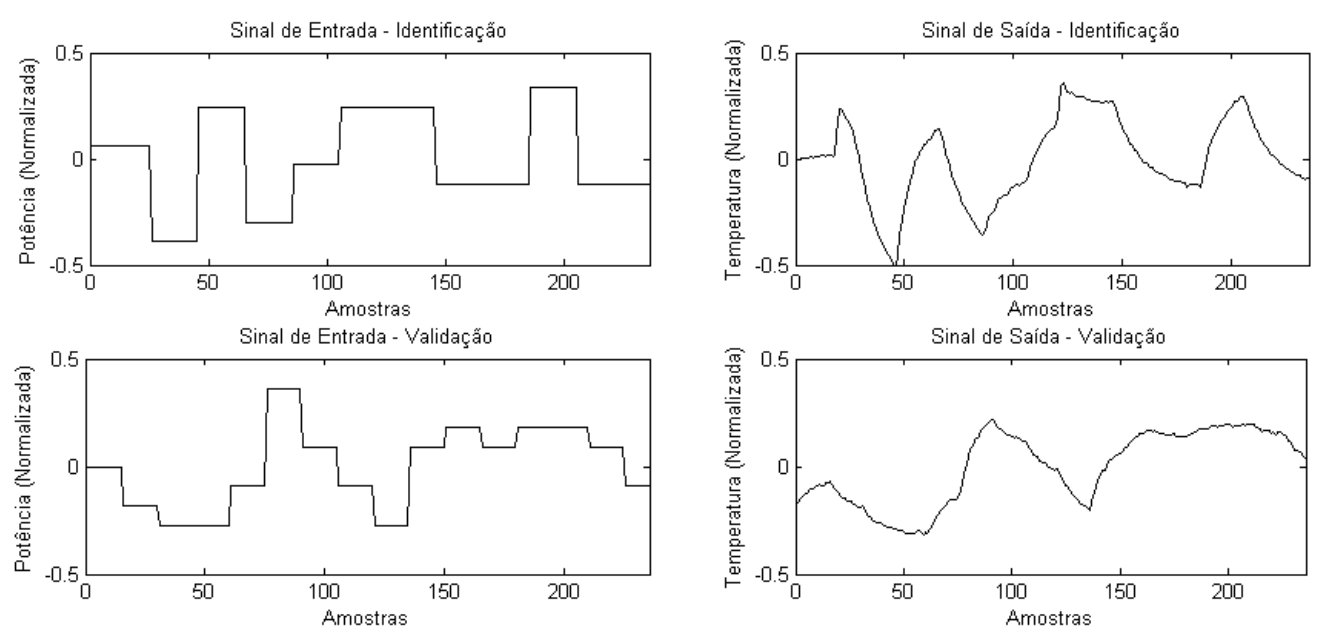

Fonte: Rodrigues et al (1996) adaptado.

De maneira análoga à realizada na subseção anterior, para determinar se o modelo deve ser identificado por uma estrutura de Wiener ou de Hammerstein, foram calculados os autovalores da matriz Jacobiana. O modelo NARX polinomial identificado possui termos da forma $y^{a} u^{b}, a \leq 1, a+b<N L$, com os parâmetros apresentados na Tabela 6.3. Esses parâmetros foram escolhidos com base nos modelos identificados em Rodrigues et al (1996). Para a identificação, os dados foram centrados e escalados.

Tabela 6.3 - Parâmetros utilizados para avaliação dos autovalores da matriz Jacobiana do forno elétrico.

\begin{tabular}{lc}
\hline Parâmetro & Valor \\
\hline Grau de não linearidade $(\mathrm{NL})$ & 3 \\
Máximo atraso na entrada & 2 \\
Máximo atraso na saída & 2 \\
Valor mínimo de ERR residual & $5.10^{-4}$ \\
\hline
\end{tabular}

Fonte: Autor.

Em função do valor mínimo de ERR residual usado, todos os 22 parâmetros da estrutura NARX polinomial foram utilizados na análise. A partir deste modelo, os autovalores da matriz Jacobiana foram determinados para 20 pontos uniformemente distribuídos para a faixa de valores de entrada. Estes autovalores são exibidos na Figura 6.7. 
Figura 6.7- Autovalores da matriz Jacobiana para 20 pontos de operação distintos do forno elétrico. Os primeiros autovalores de cada par são indicados como "+" e os segundos autovalores de cada par são indicados como " $x$ ".

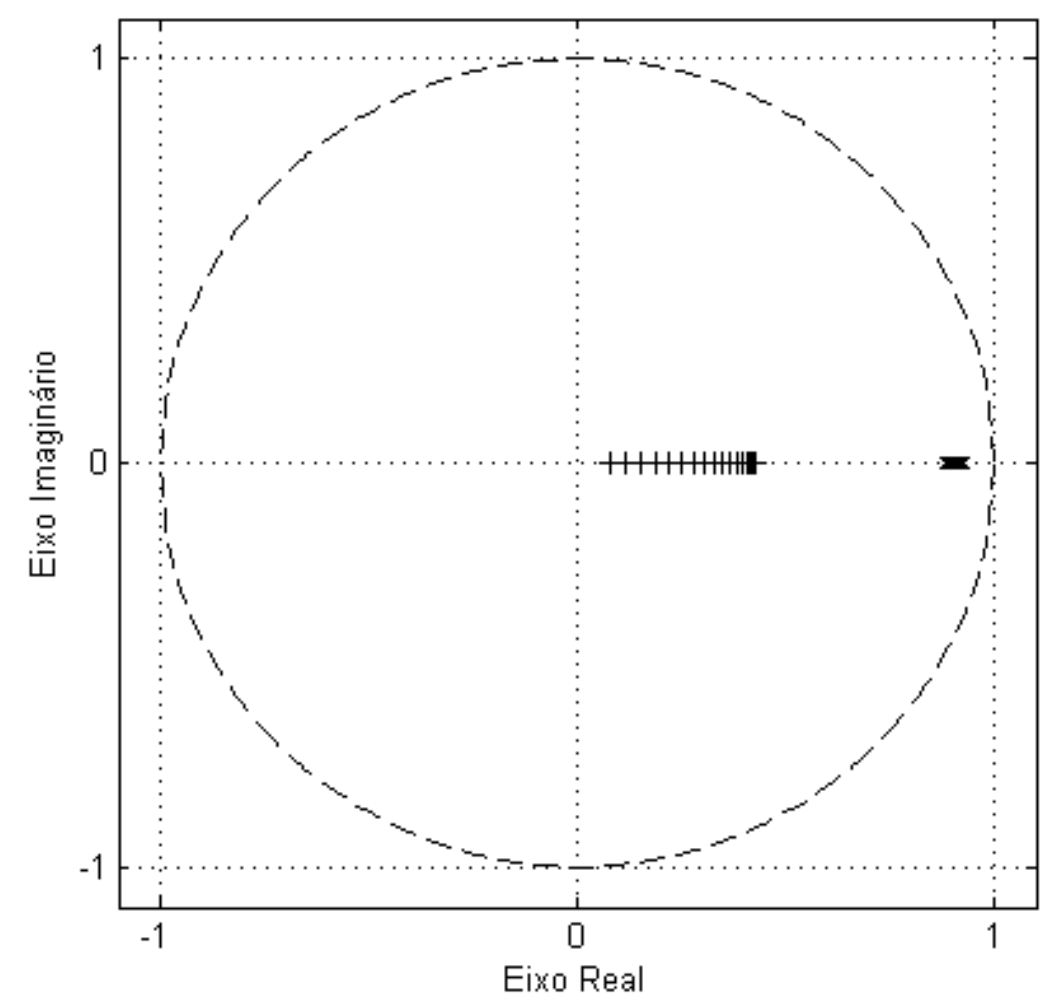

Fonte: Autor.

Na Figura 6.7, para cada ponto de operação o primeiro autovalor (mais próximo da origem) é indicado por '+' e o segundo autovalor (mais próximo do círculo unitário) por ' $x$ '. É possível notar que os autovalores apresentam uma variação significativa, notadamente o primeiro autovalor ("+"). Por este motivo, optou-se por realizar a identificação considerando modelos com estrutura de Wiener.

Para realizar a identificação usando o algoritmo MRI, além dos parâmetros apresentados na Tabela 6.3, definiu-se o horizonte de predição igual a 10 e o máximo grau do polinômio que aproxima a não linearidade estática inversa igual a 6 . Para a determinação da não linearidade estática inversa, foi adotado o seguinte procedimento:

1. Após a determinação da não linearidade estática $f$, foram escolhidos $N$ valores $u$ uniformemente distribuídos na faixa dos dados de entrada utilizados para a identificação; 
2. Foram calculadas as respostas das não linearidades $y=f(u)$;

3. Para cada grau de polinômio $n_{p}$ entre 1 e o grau máximo, foi determinado o melhor polinômio $g_{n_{p}}$ que aproxima $f^{-1}$;

4. Por fim, foi selecionado o polinômio que minimiza o Critério de Informação de Akaike (AIC).

$$
\operatorname{AIC}\left(n_{p}\right)=\operatorname{Nln}\left(\left\|u-g_{n_{p}}(y)\right\|_{2}^{2}\right)+2\left(n_{p}+1\right)
$$

Ademais, da mesma forma que foi feito na subseção anterior, permitiu-se que os parâmetros associados aos modelos lineares variassem, de modo a possibilitar a seleção do melhor modelo. As faixas para tais parâmetros estão listadas na Tabela 6.4 .

Tabela 6.4 - Faixa de variação de alguns parâmetros utilizados na identificação do modelo de Wiener.

\begin{tabular}{lcc}
\hline Parâmetro & Valor Mínimo & Valor Máximo \\
\hline Grau do polinômio B & 1 & 2 \\
Grau do polinômio C & 1 & 2 \\
Grau do polinômio D & 1 & 2 \\
Grau do polinômio F & 1 & 2 \\
Atraso da entrada & 1 & 2 \\
\hline
\end{tabular}

Fonte: Autor.

A partir desses parâmetros, foi realizada a identificação de um modelo com o algoritmo MRI (denominado modelo MRI) e de um modelo com estrutura BoxJenkins, que minimiza o erro de predição 1 passo à frente (intitulado modelo $\mathrm{BJ}$ ). Para a identificação MRI do bloco linear, foi utilizado o algoritmo MPEM. A identificação da não linearidade estática, assim como da não linearidade estática inversa foi comum para os dois modelos. De maneira análoga à subseção anterior, para os dois modelos identificados foram avaliados:

- o valor da função custo ponderada para a predição múltiplos passos à frente dividido pelo horizonte de predição em função da variação desse último; e

- a comparação entre a saída do sistema utilizada para a validação e as predições 1 passo à frente e 10 passos à frente, usando o parâmetro fit.

Os resultados destas análises são representados nas figuras a seguir: 
Figura 6.8- Comparação do valor função custo ponderada para a predição múltiplos passos à frente em função da variação do horizonte de predição para o modelo MRI e o modelo BJ.

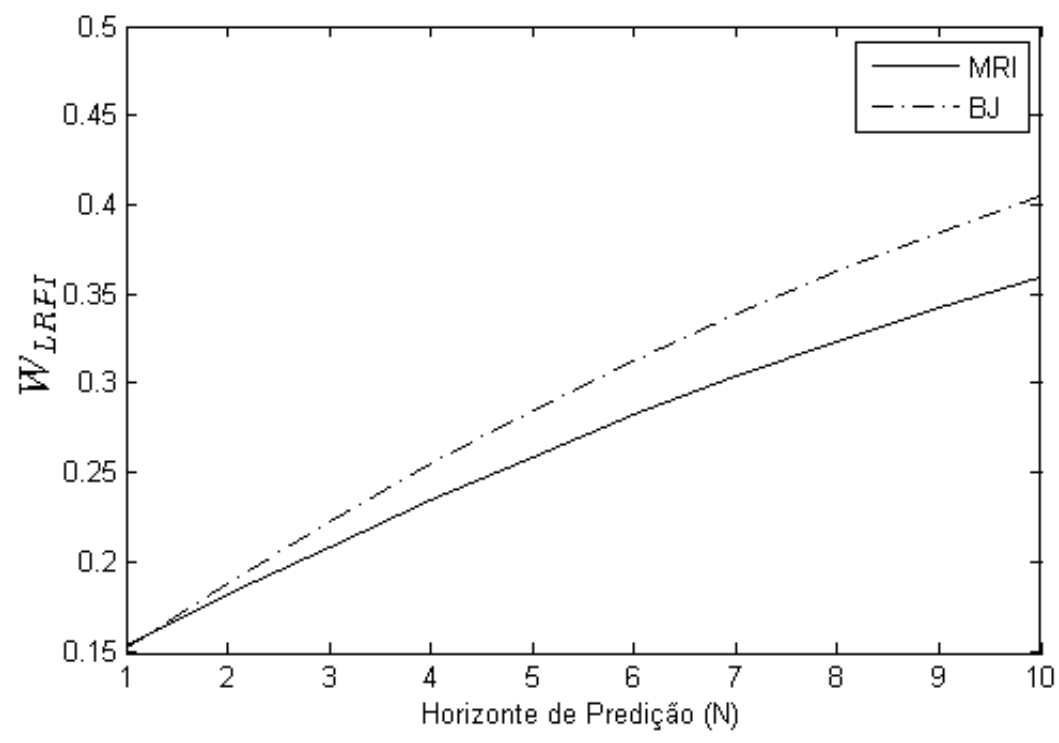

Fonte: Autor.

Figura 6.9 - Comparação entre a saída real da planta (dados centrados e escalados) e a predição 1 passo à frente obtida pelos modelos MRI e BJ.

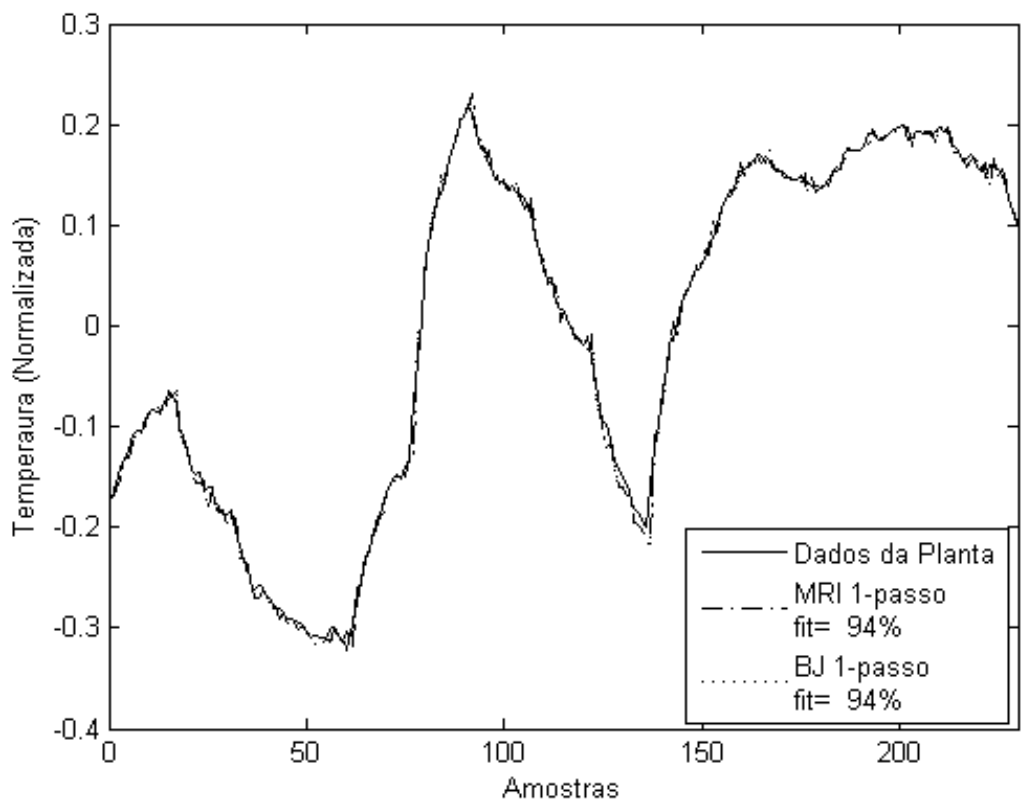

Fonte: Autor. 
Figura 6.10 - Comparação entre a saída real da planta (dados centrados e escalados) e a predição 10 passos à frente obtida pelos modelos MRI e BJ.

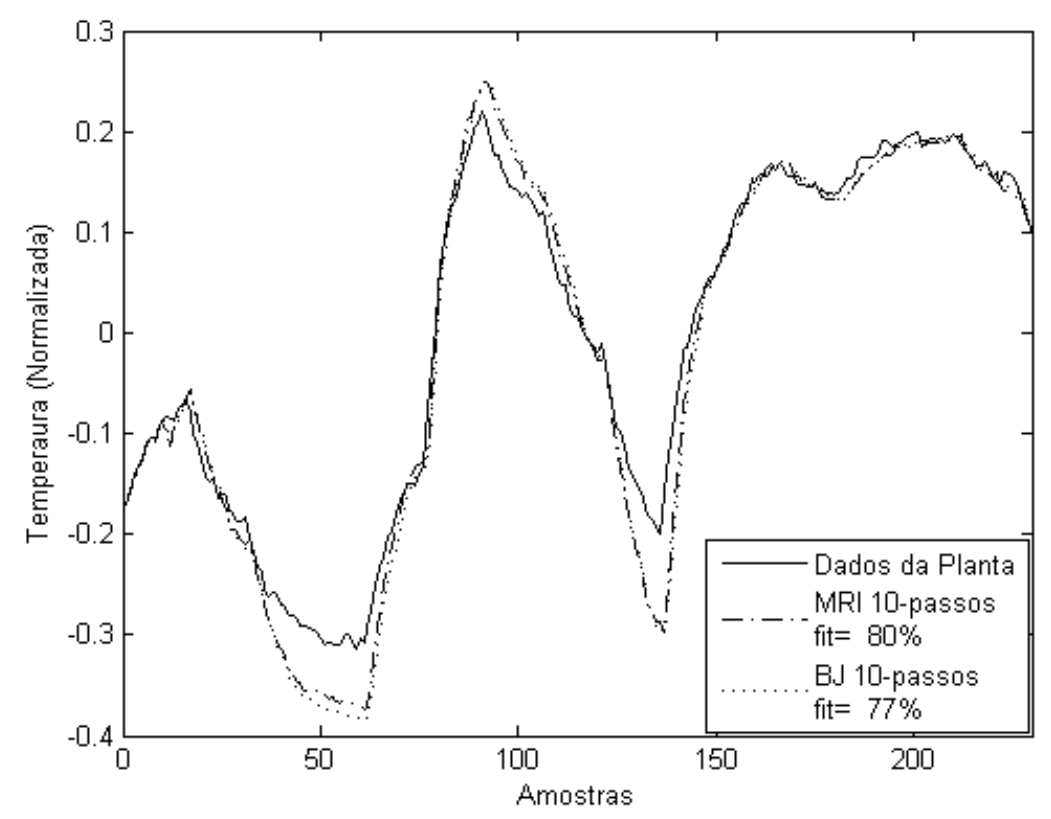

Fonte: Autor.

Nota-se que, assim como ocorreu com o modelo de Hammerstein, com o aumento do horizonte de predição, o modelo MRI tem um valor de $W_{L R P I}$ inferior e um valor de fit para a predição 10 passos à frente superior aos do modelo BJ. Com relação à predição 1 passo à frente, o valor de $W_{L R P I}$ para o modelo MRI foi 0,1533 , enquanto para o modelo BJ foi 0,1517 , ao passo que os respectivos índices fit foram $94,096 \%$ e 94,157\%, indicando que ainda que marginalmente, o modelo BJ teve um desempenho superior ao modelo MRI para predição 1 passo à frente, como esperado.

\subsection{Avaliação da acurácia e precisão dos modelos obtidos}

Visando avaliar a capacidade de estimar corretamente os parâmetros dos modelos identificados, foram realizadas análises utilizando o método de Monte Carlo para um modelo de Hammerstein e para um modelo de Wiener.

É relevante notar que para os modelos de Wiener e de Hammerstein, a forma de identificá-los não é única. Para eles, é viável mudar arbitrariamente o ganho do modelo linear e ajustar a não linearidade estática, de modo que as saídas do 
sistema não mudem. Assim, para as análises com o método de Monte Carlo, devese supor uma hipótese adicional para assegurar a unicidade do modelo. Uma opção é fixar algum parâmetro do modelo linear, supondo, por exemplo, que o polinômio do numerador seja mônico. Outra opção é definir que o modelo linear tenha um ganho específico.

\subsubsection{Estrutura de Hammerstein}

Para realizar a análise de Monte Carlo para o método MRI, usou-se o seguinte modelo (ZHU, 2000):

$$
\begin{gathered}
y(k)=\frac{1+0,5 q^{-1}+0,4 q^{-2}+2 q^{-3}}{1+0,5 q^{-1}-0,4 q^{-2}-0,26 q^{-3}-0,03 q^{-4}}\left[u(k)+3 u^{2}(k)+2 u^{3}(k)\right] \\
+v(k)
\end{gathered}
$$

onde:

$$
v(k)=\frac{\alpha}{1-0,9 q^{-1}} e(k)
$$

sendo $e(k)$ ruído branco gaussiano com variância unitária e $\alpha$ um parâmetro usado para ajustar a relação sinal-ruído. A locação dos polos e zeros deste sistema é vista na Figura 6.11, onde é se observa que o sistema é estável, mas de fase não mínima. 
Figura 6.11 - Gráfico de polos e zeros do sistema linear da planta utilizada para a análise de Monte Carlo de um modelo de Hammerstein.

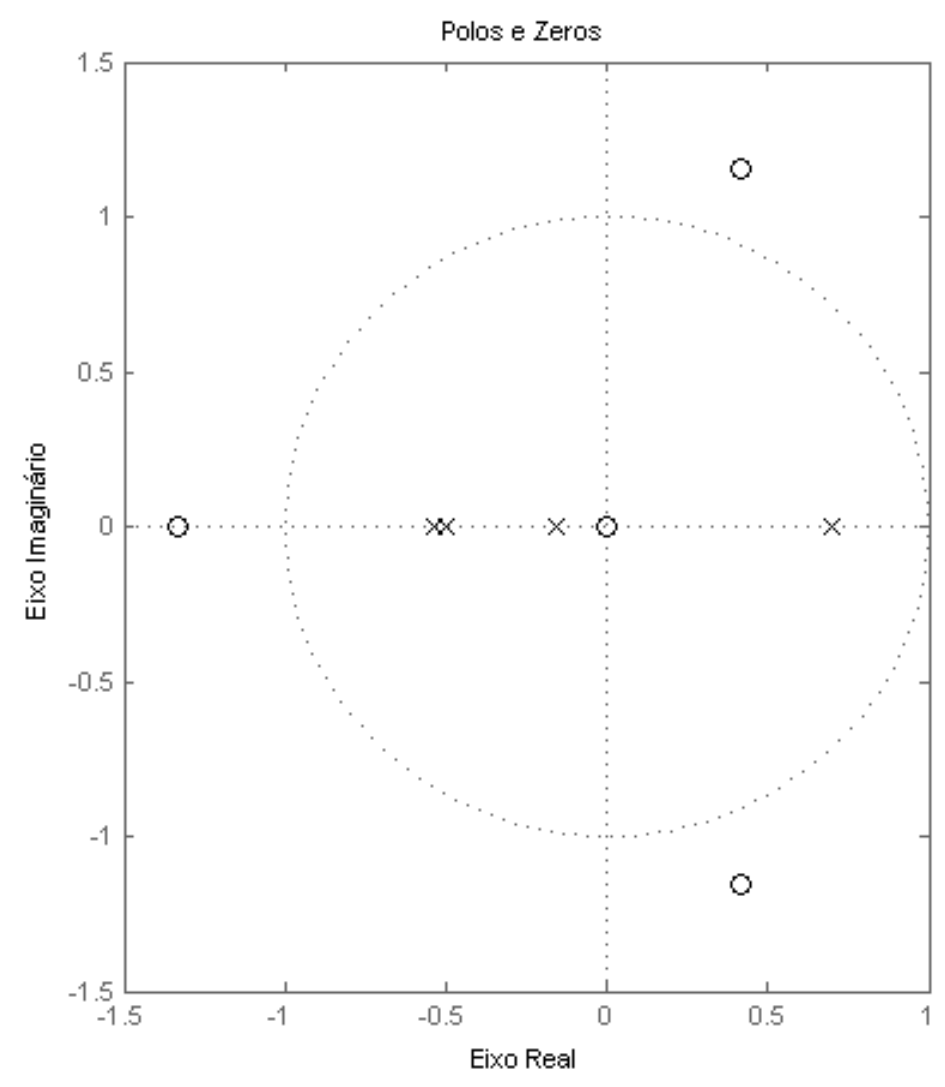

Fonte: Autor.

Para excitar este sistema usou-se um sinal PRMS (Pseudo-Random Multipleamplitude Sequence), que consiste em uma generalização para múltiplos níveis do sinal GBN (ZHU, 2000). Para definir os níveis, optou-se por utilizar uma distribuição gaussiana ao invés de uniforme, como descrito em Zhu (2000). O motivo para tal alteração decorre do fato que, durante a operação do controlador, espera-se que as variáveis manipuladas operem a maior parte do tempo próximas ao ponto de operação do sistema, de modo que grandes desvios tendam a ser eventos mais raros. Assim, com o uso de um sinal PRMS excitado por um sinal gaussiano, é esperado um número maior de amostras em torno do ponto de operação, melhorando a identificação em torno deste ponto. A distribuição gaussiana usada nesse experimento possui média nula e variância 0,5 e o número mínimo de amostras para a mudança de nível foi 20 .

Para avaliar o impacto de diferentes relações sinal-ruído (em variância), foram feitas simulações com valores SNR de $10 \mathrm{~dB}, 30 \mathrm{~dB}$ e $40 \mathrm{~dB}$ e com ausência de ruído. 
Para cada uma destas relações foram realizados 100 experimentos com duração de $10^{5}$ amostras. Para garantir a unicidade do modelo identificado, foi feito um ajuste para que o numerador fosse um polinômio mônico, assim o parâmetro $b_{0}$ foi fixado em 1 para ajustar os ganhos das partes dinâmica e estática do modelo.

Ao realizar a identificação, observou-se que o termo constante da parte não linear era usualmente identificado com um valor ordens de grandeza superior ao valor real. No entanto, como os modelos obtidos pelo algoritmo MRI serão usados em controladores MPC, cujos dados de entrada e saída são centrados no ponto de operação do sistema, é preciso que o termo constante seja nulo. Caso contrário, para uma entrada constante igual ao ponto de operação, o modelo apresentaria uma saída distinta do ponto de operação. Por esta razão, o termo constante da parte não linear não é identificado e definido como sendo constante e nulo.

As médias, desvios padrão e coeficientes de variação (desvio padrão dividido pela média) dos parâmetros para os diferentes cenários são apresentados na Tabela 6.5.

Tabela 6.5 - Média, desvio padrão e coeficiente de variação (entre parênteses) dos parâmetros identificados pelo algoritmo MRI para o modelo de Hammerstein para diferentes intensidades de perturbação.

\begin{tabular}{|c|c|c|c|c|c|}
\hline \multirow[t]{2}{*}{ Parâmetro } & \multirow{2}{*}{$\begin{array}{c}\text { Valor } \\
\text { real }\end{array}$} & \multicolumn{4}{|c|}{ Valor Estimado } \\
\hline & & SNR $10 \mathrm{~dB}$ & SNR $30 \mathrm{~dB}$ & SNR $40 \mathrm{~dB}$ & Sem distúrbio \\
\hline$c_{0}$ & 0 & \multicolumn{4}{|c|}{ Não Identificado } \\
\hline$c_{1}$ & 1 & $\begin{array}{c}-0,1470 \pm 1,8757 \\
(1 E+1)\end{array}$ & $\begin{array}{c}1,1170 \pm 0,4182 \\
(4 \mathrm{E}-1)\end{array}$ & $\begin{array}{c}1,0199 \pm 0,1182 \\
(1 \mathrm{E}-1)\end{array}$ & $\begin{array}{c}1,0012 \pm 0,1161 \\
(1 \mathrm{E}-1)\end{array}$ \\
\hline$c_{2}$ & 3 & $\begin{array}{c}1,7874 \pm 1,4356 \\
(8 \mathrm{E}-1)\end{array}$ & $\begin{array}{c}2,9602 \pm 0,5766 \\
(2 \mathrm{E}-1)\end{array}$ & $\begin{array}{c}3,0149 \pm 0,1169 \\
(4 \mathrm{E}-2)\end{array}$ & $\begin{array}{c}2,9994 \pm 0,1169 \\
(4 \mathrm{E}-2)\end{array}$ \\
\hline$c_{3}$ & 2 & $\begin{array}{c}1,8921 \pm 1,1311 \\
(6 \mathrm{E}-1)\end{array}$ & $\begin{array}{c}1,8799 \pm 0,4328 \\
(2 \mathrm{E}-1)\end{array}$ & $\begin{array}{c}1,9956 \pm 0,0172 \\
(9 E-3)\end{array}$ & $\begin{array}{c}2,0003 \pm 0,0017 \\
(9 \mathrm{E}-4)\end{array}$ \\
\hline$a_{1}$ & 0,5 & $\begin{array}{c}0,1024 \pm 0,8220 \\
(8 \mathrm{E}+0)\end{array}$ & $\begin{array}{c}0,4786 \pm 0,2143 \\
(4 \mathrm{E}-1)\end{array}$ & $\begin{array}{c}0,49997 \pm 0,00002 \\
(4 \mathrm{E}-5)\end{array}$ & $\begin{array}{c}0,49998 \pm 0,00003 \\
(6 \mathrm{E}-5)\end{array}$ \\
\hline$a_{2}$ & $-0,4$ & $\begin{array}{c}-0,1582 \pm 0,5038 \\
(3 E+0)\end{array}$ & $\begin{array}{c}-0,3864 \pm 0,1359 \\
(4 \mathrm{E}-1)\end{array}$ & $\begin{array}{c}-0,40005 \pm 0,00004 \\
(1 \mathrm{E}-4)\end{array}$ & $\begin{array}{c}-0,40003 \pm 0,00005 \\
(1 \mathrm{E}-4)\end{array}$ \\
\hline$a_{3}$ & $-0,26$ & $\begin{array}{c}-0,3080 \pm 0,1139 \\
(4 \mathrm{E}-1)\end{array}$ & $\begin{array}{c}-0,2622 \pm 0,0219 \\
(8 \mathrm{E}-2)\end{array}$ & $\begin{array}{c}-0,25999 \pm 0,00005 \\
(2 E-4)\end{array}$ & $\begin{array}{c}-0,25998 \pm 0,00001 \\
(6 E-5)\end{array}$ \\
\hline$a_{4}$ & $-0,03$ & $\begin{array}{c}0,0234 \pm 0,1179 \\
(5 \mathrm{E}+0)\end{array}$ & $\begin{array}{c}-0,0278 \pm 0,0217 \\
(8 \mathrm{E}-1)\end{array}$ & $\begin{array}{c}-0,02996 \pm 0,00004 \\
(1 \mathrm{E}-3)\end{array}$ & $\begin{array}{c}-0,02997 \pm 0,00003 \\
(1 \mathrm{E}-3)\end{array}$ \\
\hline$b_{0}$ & 1 & \multicolumn{4}{|c|}{ Não Identificado } \\
\hline$b_{1}$ & 0,5 & $\begin{array}{c}0,0678 \pm 0,8894 \\
(1 \mathrm{E}+1)\end{array}$ & $\begin{array}{c}0,4770 \pm 0,2303 \\
(5 \mathrm{E}-1)\end{array}$ & $\begin{array}{c}0,49998 \pm 0,00014 \\
(3 E-4)\end{array}$ & $\begin{array}{c}0,49998 \pm 0,00003 \\
(7 \mathrm{E}-5)\end{array}$ \\
\hline$b_{2}$ & 0,4 & $\begin{array}{c}0,7681 \pm 0,7638 \\
(1 \mathrm{E}+0)\end{array}$ & $\begin{array}{c}0,4197 \pm 0,1972 \\
(5 \mathrm{E}-1)\end{array}$ & $\begin{array}{c}0,39993 \pm 0,00010 \\
(2 E-4)\end{array}$ & $\begin{array}{c}0,39997 \pm 0,00008 \\
(2 \mathrm{E}-4)\end{array}$ \\
\hline$b_{3}$ & 2 & $\begin{array}{c}1,3354 \pm 1,3717 \\
(1 \mathrm{E}+0)\end{array}$ & $\begin{array}{c}1,9655 \pm 0,3445 \\
(2 \mathrm{E}-1)\end{array}$ & $\begin{array}{c}1,99994 \pm 0,00023 \\
(1 \mathrm{E}-4)\end{array}$ & $\begin{array}{c}2,00002 \pm 0,00006 \\
(3 E-5)\end{array}$ \\
\hline
\end{tabular}

Fonte: Autor. 
Com exceção do parâmetro $a_{2}$ no cenário com SNR igual a $40 \mathrm{~dB}$, todos os valores reais dos parâmetros ficaram dentro do intervalo de 1 desvio padrão. Apesar de não ser uma demonstração rigorosa, este é um indício que o estimador é não polarizado. Entretanto, é importante dizer que para os cenários de SNR igual a $10 \mathrm{~dB}$ e $30 \mathrm{~dB}$, a identificação apresentou baixa precisão. Isso pode ser verificado por meio dos coeficientes de variação dos parâmetros. De acordo com Mendenhall e Sincich (2014) uma regra prática para determinar que uma estimação o coeficiente de variação deve ser inferior a 0,1. Para os cenários de $40 \mathrm{~dB}$ e com ausência de perturbação, esta regra foi respeitada.

Outro experimento feito usando o método de Monte Carlo com a identificação MRI consistiu em fixar a relação sinal-ruído como sendo igual a $10 \mathrm{~dB}$ e realizou-se a identificação utilizando $10^{3}, 10^{4}, 10^{5}$ e $10^{6}$ amostras. Para cada cenário, foram realizadas 100 identificações e a média e o desvio padrão de cada um dos parâmetros foram identificados. Os resultados das identificações são apresentados nas figuras a seguir.

Figura 6.12 - Média e desvio padrão dos parâmetros da não linearidade estática identificados em experimentos de Monte Carlo para diferentes valores de amostras.
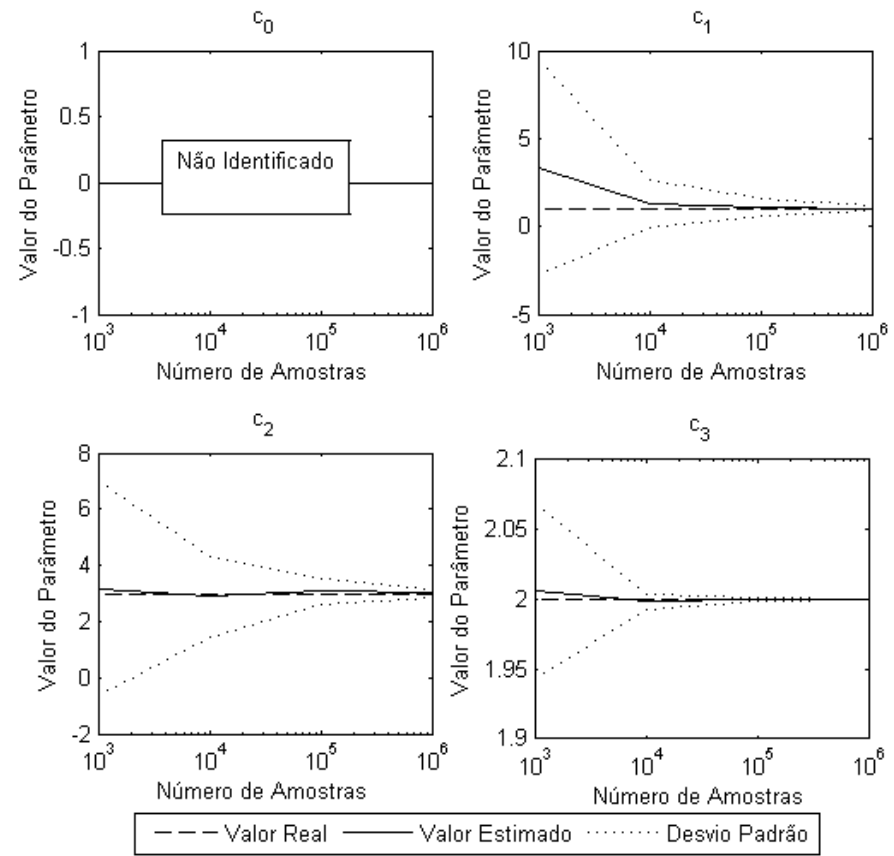

Fonte: Autor. 
Figura 6.13- Média e desvio padrão dos parâmetros do denominador da função de transferência identificados em experimentos de Monte Carlo para diferentes valores de amostras.
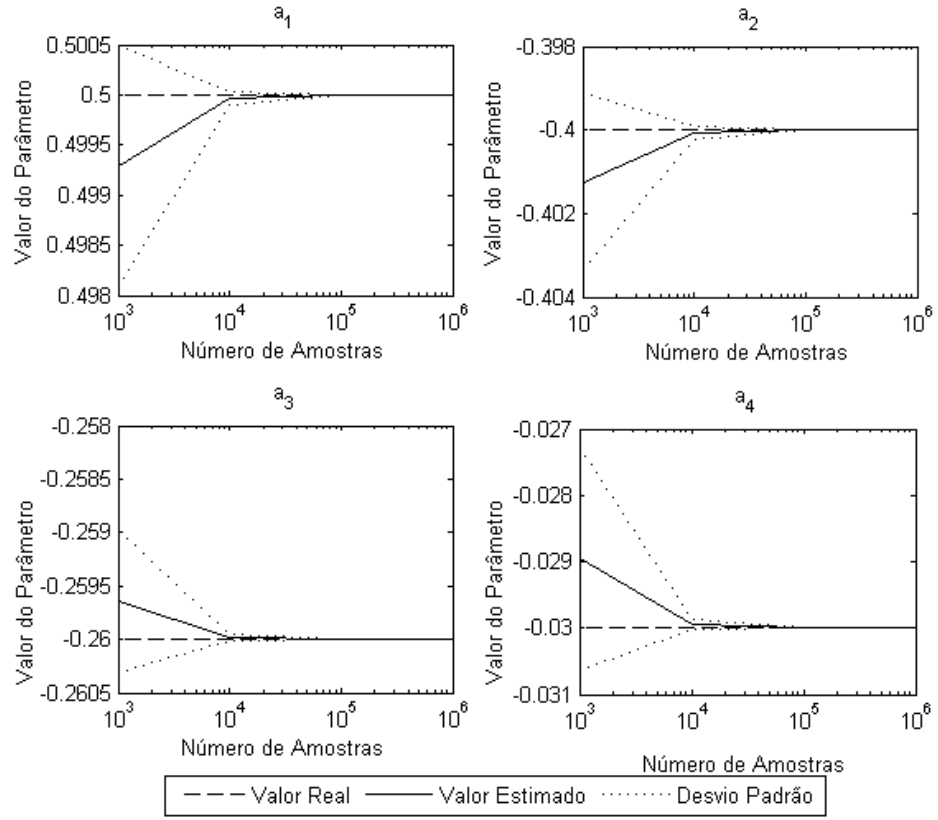

Fonte: Autor.

Figura 6.14 - Média e desvio padrão dos parâmetros do numerador da função de transferência identificados em experimentos de Monte Carlo para diferentes valores de amostras.
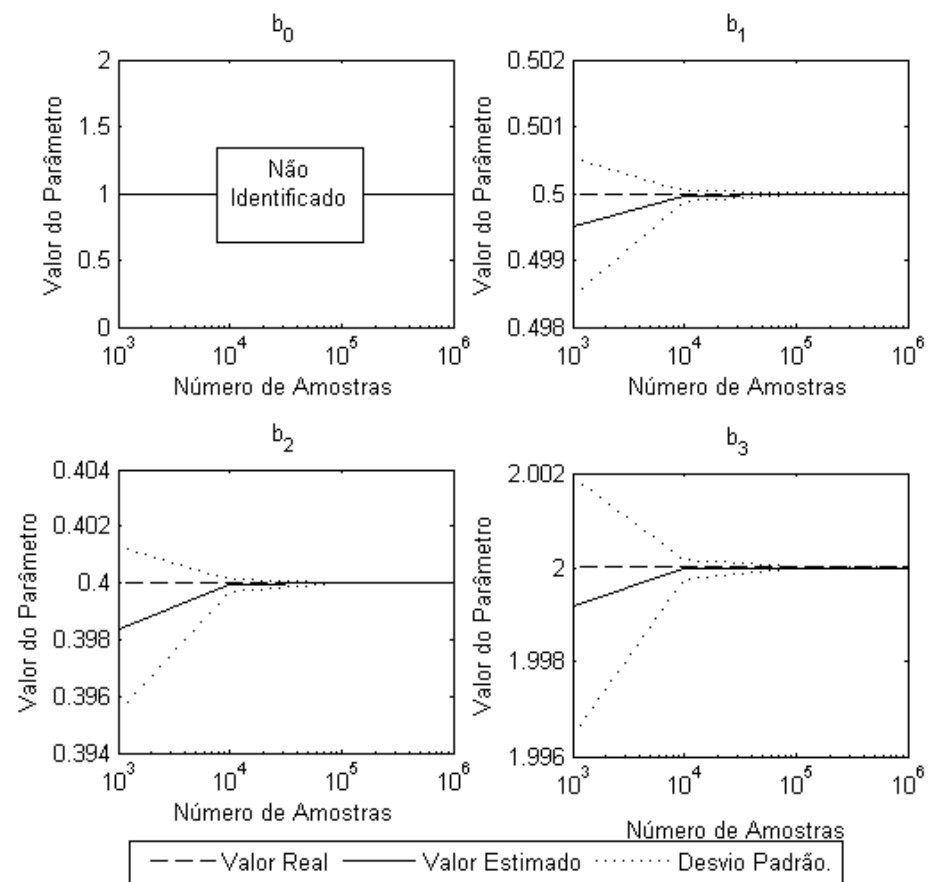

Fonte: Autor. 
Nota-se nas Figuras 6.12 a 6.14 que ao aumentar o número de amostras usadas na identificação, a média se aproxima do valor real e é possível perceber uma redução do desvio padrão. Apesar de não ser uma demonstração formal, este resultado gera um indício que o estimador MRI para os modelos com estrutura de Hammerstein seja consistente.

\subsubsection{Estrutura de Wiener}

Para realizar o ensaio de Monte Carlo para o algoritmo MRI identificar modelos com estruturas de Wiener, foi utilizado o seguinte modelo SISO:

$$
\begin{gathered}
y(k)=27 x(k)-x^{3}(k) \\
x(k)=\frac{0,2077+0,1038 q^{-1}+0,08308 q^{-2}+0,4154 q^{-3}}{1+0,5 q^{-1}-0,4 q^{-2}-0,26 q^{-3}-0,03 q^{-4}} u(k) \\
+\frac{\alpha}{1-0,9 q^{-1}} e(k)
\end{gathered}
$$

onde $\alpha$ é um parâmetro para ajustar a relação sinal ruído e e(k) é ruído branco gaussiano com variância unitária.

É importante notar que a parte correspondente ao modelo de processo na Equação (57) é a versão com ganho unitário da parte linear do modelo de processo da Equação (54). Assim, este modelo contém o mesmo conjunto de polos e zeros apresentado na Figura 6.11, possuindo, portanto, parte linear estável e de fase não mínima.

Para excitar o sistema foi usado um sinal PRMS com tempo de chaveamento de 20 amostras. Sabe-se que para a identificação do modelo de Wiener é preciso calcular uma aproximação para a função inversa da não linearidade estática. Dado que a Função (56) é invertível no intervalo ]-3,3[ e que a relação sinal-ruído considerada no experimento será sempre positiva, então, para garantir que a probabilidade de encontrar níveis fora da faixa desejada fosse inferior a $0,5 \%$, a variância da distribuição de probabilidade dos níveis do sinal PRMS foi selecionada igual a 0,35. O número mínimo de amostras para a mudança de nível utilizado neste experimento foi igual a 20 . 
Nos primeiros testes de identificação, observou-se que quando a intensidade do ruído era comparável à intensidade do sinal, o algoritmo não era capaz de identificar os parâmetros. Assim, foram selecionados os níveis de sinal-ruído $10 \mathrm{~dB}, 30 \mathrm{~dB}$ e $100 \mathrm{~dB}$, além do cenário sem ruído. Para cada um destes cenários foram realizados 100 experimentos de identificação, usando $10^{5}$ amostras em cada um. Para garantir a unicidade do modelo, foi incluída a hipótese de que o modelo linear possui ganho unitário. Assim como para a identificação dos modelos com estrutura de Hammerstein da subseção anterior, o termo constante da não linearidade estática foi definido como nulo.

As médias dos parâmetros, os respectivos desvios padrão e coeficientes de variação para os diferentes valores de SNR e ausência de ruído obtidos no experimento são apresentados na Tabela 6.6 .

Tabela 6.6 - Médias e desvios padrão dos parâmetros identificados pelo algoritmo MRI para o modelo de Wiener para diferentes relações sinal-ruído.

\begin{tabular}{|c|c|c|c|c|c|}
\hline \multirow{3}{*}{$\begin{array}{c}\text { Parâmetro } \\
c_{0}\end{array}$} & \multirow{3}{*}{$\begin{array}{c}\text { Valor } \\
\text { Real } \\
0\end{array}$} & \multicolumn{4}{|c|}{ Valor Estimado } \\
\hline & & SNR $10 \mathrm{~dB}$ & SNR $30 \mathrm{~dB}$ & SNR $100 \mathrm{~dB}$ & Sem distúrbio \\
\hline & & \multicolumn{4}{|c|}{ Não Identificado } \\
\hline$c_{1}$ & 27 & $\begin{array}{c}-18,0869 \pm 105,9141 \\
(6 \mathrm{E}+0)\end{array}$ & $\begin{array}{c}23,2491 \pm 29,3342 \\
(1 E+0)\end{array}$ & $\begin{array}{c}26,6684 \pm 0,0633 \\
(2 E-3)\end{array}$ & $\begin{array}{c}26,68170 \pm 0,06740 \\
(3 E-3)\end{array}$ \\
\hline$c_{2}$ & 0 & 0 & 0 & 0 & 0 \\
\hline$c_{3}$ & -1 & $\begin{array}{c}17,4432 \pm 76,2543 \\
(4 \mathrm{E}+0)\end{array}$ & $\begin{array}{c}-1,72209 \pm 4,91950 \\
(3 E+0)\end{array}$ & $\begin{array}{c}-0,95528 \pm 0,01457 \\
(2 E-2)\end{array}$ & $\begin{array}{c}-0,95508 \pm 0,01440 \\
(2 \mathrm{E}-2)\end{array}$ \\
\hline$a_{1}$ & 0,5 & $\begin{array}{c}-0,15313 \pm 0,00000 \\
(0 E+0)\end{array}$ & $\begin{array}{c}0,48818 \pm 0,14402 \\
(3 E-1)\end{array}$ & $\begin{array}{c}0,49982 \pm 0,00009 \\
(2 \mathrm{E}-4)\end{array}$ & $\begin{array}{c}0,49982 \pm 0,00009 \\
(2 \mathrm{E}-4)\end{array}$ \\
\hline$a_{2}$ & $-0,4$ & $\begin{array}{c}-0,03826 \pm 0,85917 \\
(2 E+1)\end{array}$ & $\begin{array}{c}-0,40280 \pm 0,01139 \\
(3 E-2)\end{array}$ & $\begin{array}{c}-0,39989 \pm 0,00009 \\
(2 E-4)\end{array}$ & $\begin{array}{c}-0,39989 \pm 0,00007 \\
(2 E-4)\end{array}$ \\
\hline$a_{3}$ & $-0,26$ & $\begin{array}{c}-0,22735 \pm 0,38479 \\
(2 E+0)\end{array}$ & $\begin{array}{c}-0,24978 \pm 0,12745 \\
(5 E-1)\end{array}$ & $\begin{array}{c}-0,25983 \pm 0,00009 \\
(4 E-4)\end{array}$ & $\begin{array}{c}-0,25982 \pm 0,00009 \\
(4 E-4)\end{array}$ \\
\hline$a_{4}$ & $-0,03$ & $\begin{array}{c}0,02216 \pm 0,16666 \\
(8 E+0)\end{array}$ & $\begin{array}{c}-0,03461 \pm 0,03797 \\
(1 E+0)\end{array}$ & $\begin{array}{c}-0,02995 \pm 0,00004 \\
(1 E-3)\end{array}$ & $\begin{array}{c}-0,02996 \pm 0,00002 \\
(8 E-4)\end{array}$ \\
\hline$b_{0}$ & 0,2077 & $\begin{array}{c}0,22056 \pm 0,28517 \\
(1 \mathrm{E}+0)\end{array}$ & $\begin{array}{c}0,22941 \pm 0,19875 \\
(9 E-1)\end{array}$ & $\begin{array}{c}0,20760 \pm 0,00006 \\
(3 E-4)\end{array}$ & $\begin{array}{c}0,20759 \pm 0,00006 \\
(3 E-4)\end{array}$ \\
\hline$b_{1}$ & 0,1038 & $\begin{array}{c}-0,07404 \pm 0,66942 \\
(9 E+0)\end{array}$ & $\begin{array}{c}0,08659 \pm 0,18708 \\
(2 E+0)\end{array}$ & $\begin{array}{c}0,10371 \pm 0,00005 \\
(5 E-4)\end{array}$ & $\begin{array}{c}0,10371 \pm 0,00005 \\
(4 E-4)\end{array}$ \\
\hline$b_{2}$ & 0,0831 & $\begin{array}{c}0,15642 \pm 0,62986 \\
(4 \mathrm{E}+0)\end{array}$ & $\begin{array}{c}0,04535 \pm 0,35847 \\
(8 E+0)\end{array}$ & $\begin{array}{c}0,08319 \pm 0,00006 \\
(8 E-4)\end{array}$ & $\begin{array}{c}0,08320 \pm 0,00006 \\
(7 E-4)\end{array}$ \\
\hline$b_{3}$ & 0,4154 & $\begin{array}{c}0,30048 \pm 0,40242 \\
(1 \mathrm{E}+0)\end{array}$ & $\begin{array}{c}0,43965 \pm 0,28094 \\
(6 \mathrm{E}-1)\end{array}$ & $\begin{array}{c}0,41565 \pm 0,00013 \\
(3 E-4)\end{array}$ & $\begin{array}{c}0,41565 \pm 0,00012 \\
(3 E-4)\end{array}$ \\
\hline
\end{tabular}

Fonte: Autor.

Avaliando-se a Tabela 6.6, é possível observar que o parâmetro $c_{2}$ foi identificado identicamente nulo em todos os ensaios. Isso ocorre, pois, os termos do tipo 
$u^{2}(k-i)$ possuem uma ERR muito baixa, não sendo portanto incluídos nos modelos NARX polinomiais utilizados para a identificação das não linearidades estáticas.

Analisando-se os resultados para os diferentes níveis de relação sinal-ruído, é possível notar que para os menores valores, o valor real de cada parâmetro está localizado no intervalo $[\mu-\sigma, \mu+\sigma]$, onde $\mu$ é a média calculada e $\sigma$ o desvio padrão calculado. Entretanto, isto decorre principalmente pelas identificações terem sido pouco precisas, como pode ser observado em função dos elevados coeficientes de variação. Tal regra foi observada apenas para o parâmetro $a_{1}$.

Para as estimativas com menor intensidade de perturbação, entretanto, é possível observar que os coeficientes de variação foram significativamente menores, indicando que as estimações foram precisas. Entretanto, avaliando-se a Tabela 6.6, é possível notar que os valores reais ficaram localizados fora do intervalo $[\mu-\sigma, \mu+$ $\sigma]$. Desta maneira, existe um forte indício que o algoritmo MRI seja um estimador polarizado.

\subsection{Conclusão}

A partir das análises realizadas neste capítulo, é possível verificar que o algoritmo MRI é mais capaz de identificar modelos que gerem menores erros para a predição múltiplos passos à frente do que a estimação da não linearidade estática somada à identificação do bloco linear utilizando o algoritmo PEM. Assim, essa é uma indicação que este método seja útil para a identificação de modelos para controladores MPC.

Ao avaliar as propriedades estatísticas do estimador, experimentos indicam que o algoritmo MRI produza estimadores não polarizados e consistentes para modelos de Hammerstein. Por outro lado, a análise similar realizada em modelos identificados com estrutura de Wiener, indicou que a identificação ocorreu corretamente apenas para cenários com relação sinal-ruído baixa. Mesmo assim, para estes cenários, os experimentos indicaram que o algoritmo MRI produziu um estimador com viés. 


\section{Aplicação da identificação com estrutura de Hammerstein MIMO}

Com o objetivo de avaliar a capacidade que o algoritmo proposto na Subseção 5.2.2 de identificar modelos MIMO com estrutura de Hammerstein, este capítulo apresenta um experimento de identificação de um sistema simulado com estrutura de Hammerstein. A fim de avaliar o desempenho do algoritmo, os modelos obtidos na identificação MRI e OSAPI são utilizados em um controlador NMPC com offset-free.

\subsection{Sistema proposto e experimento de identificação}

O sistema simulado utilizado neste experimento é dado por:

$$
\begin{gathered}
{\left[\begin{array}{l}
y_{1}(s) \\
y_{2}(s)
\end{array}\right]=\left[\begin{array}{cc}
\frac{1}{5 s+1} & \frac{2}{6 s+1} \\
\frac{2}{5 s+1} & \frac{2}{3 s+1}
\end{array}\right]\left[\begin{array}{l}
n_{1}(s) \\
n_{2}(s)
\end{array}\right]+\left[\begin{array}{cc}
\frac{1}{2 s+1} & 0 \\
0 & \frac{1}{2 s+1}
\end{array}\right]\left[\begin{array}{l}
e_{1}(s) \\
e_{2}(s)
\end{array}\right]} \\
n_{1}(s)=-0,25 u_{1}^{3}(s)+u_{1}(s) \\
n_{1}(s)=-0,5 u_{1}^{3}(s)+2 \cdot u_{1}(s)
\end{gathered}
$$

onde $e_{1}(s)$ e $e_{2}(s)$ são dois ruídos brancos independentes com variância 0,01.

Para a realização do experimento de identificação, este sistema foi simulado considerando o modelo discretizado com passo de amostragem de 0,1 s. Para os sinais de entrada foram considerados dois sinais PRMS com os níveis sendo definidos por uma distribuição gaussiana com variância 0,16. Os intervalos mínimos de mudança de nível são iguais e foram definidos como sendo iguais a 7 e 8 amostras para $u_{1}(k)$ e $u_{2}(k)$, respectivamente.

Para o experimento de identificação foram coletadas 800 amostras. As primeiras 400 amostras foram utilizadas para a identificação enquanto as demais foram utilizadas para a validação. Estes sinais estão apresentados na Figura 7.1. Para a realização da identificação, os dados foram centrados e escalados. Desta maneira, considerando os parâmetros apresentados na Tabela 7.1 e as faixas de variação dos parâmetros apresentados na Tabela 7.2, foi realizada a identificação do modelo utilizando o algoritmo MRI, com a parte linear sendo identificada por um algoritmo MPEM. 
Figura 7.1 - Variáveis de entrada e saída utilizadas para a identificação do sistema MIMO.
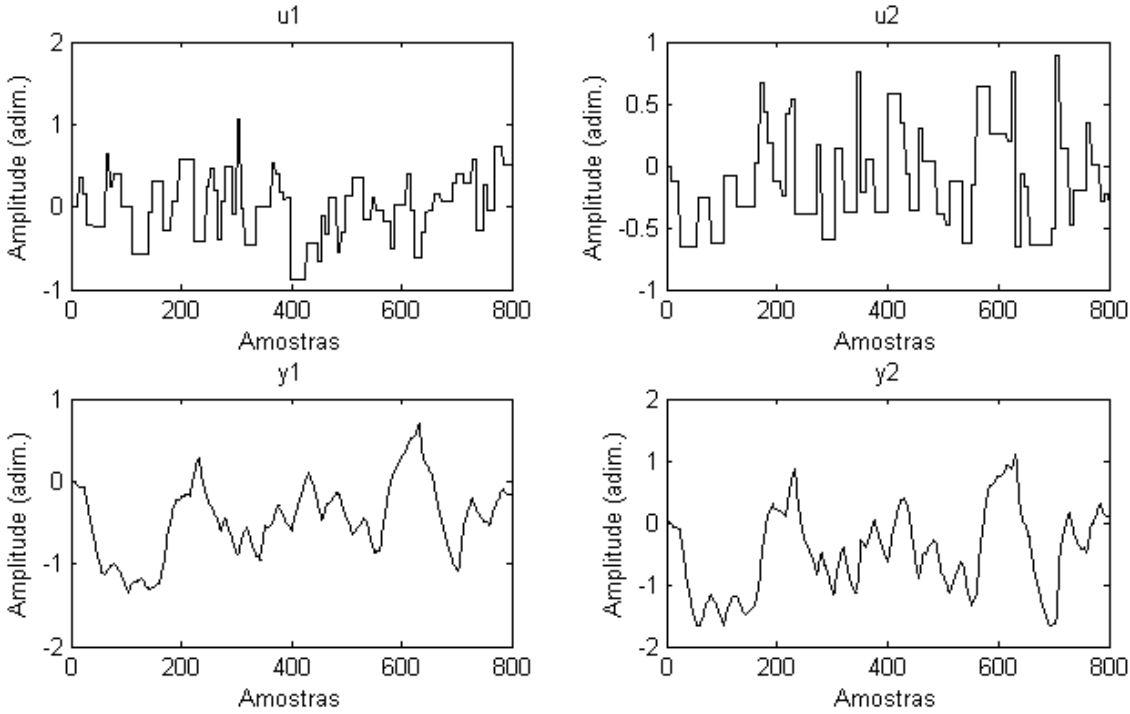

Fonte: Autor.

Utilizando a não linearidade estática identificada pelo modelo MRI, também foi realizada a identificação de um modelo linear com estrutura $B J$, que minimiza o erro de predição 1 passo à frente, para ser utilizada como comparação. Os resultados destas identificações são apresentados nas Figuras 7.2, 7.3 e 7.4.

Tabela 7.1 - Parâmetros utilizados para a identificação do sistema MIMO.

\begin{tabular}{lc}
\hline Parâmetro & Valor \\
\hline Grau de não linearidade $(\mathrm{NL})$ & 3 \\
Máximo atraso na entrada & 3 \\
Máximo atraso na saída & 3 \\
Valor mínimo de ERR residual & $10^{-8}$ \\
\hline
\end{tabular}

Fonte: Autor.

Tabela 7.2 - Faixa de variação de alguns parâmetros utilizados na identificação do modelo de Hammerstein.

\begin{tabular}{lcc}
\hline Parâmetro & Valor Mínimo & Valor Máximo \\
\hline Grau dos polinômios B & 1 & 2 \\
Grau dos polinômios C & 0 & 2 \\
Grau dos polinômios D & 1 & 2 \\
Grau dos polinômios F & 1 & 2 \\
Atraso da entrada & 0 & 2 \\
\hline
\end{tabular}

Fonte: Autor. 
Figura 7.2 - Valores de $W_{L R P I}$ para diferentes horizontes de predição para os modelos MRI e BJ.

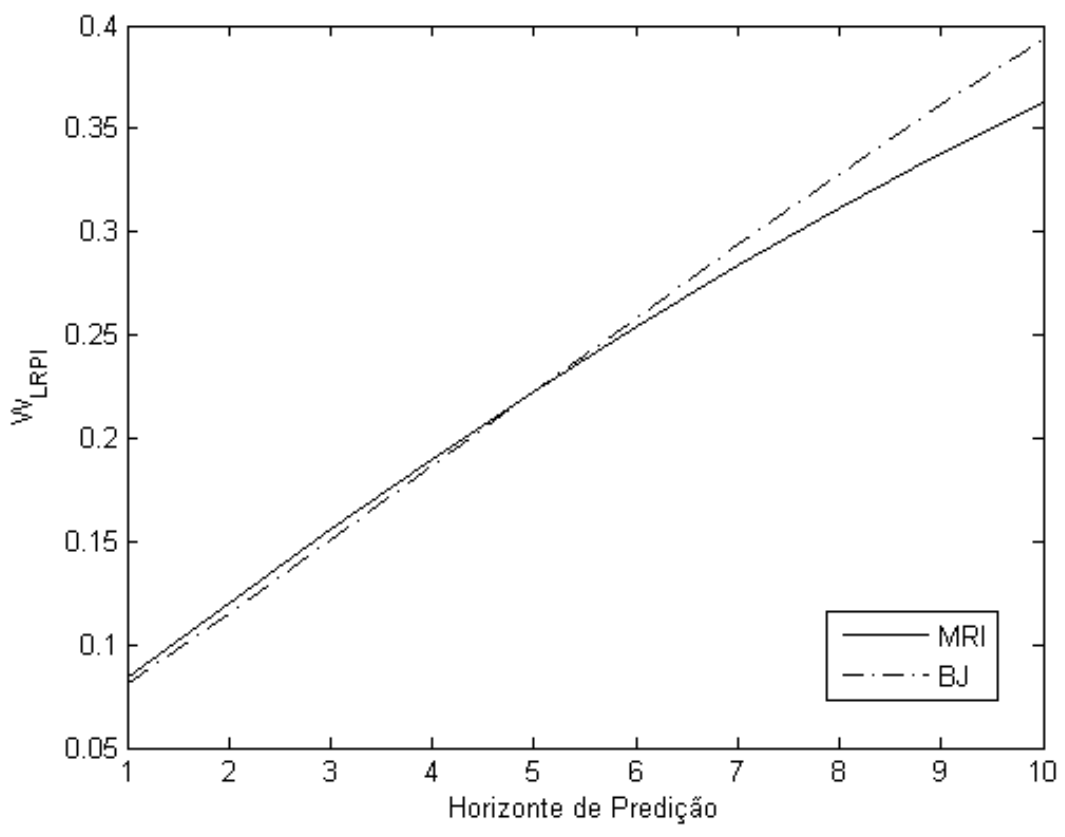

Fonte: Autor.

Figura 7.3 - Predição 1 passo à frente para o conjunto de dados de validação para os modelos MRI e BJ, assim como os respectivos valores dos parâmetros fit.
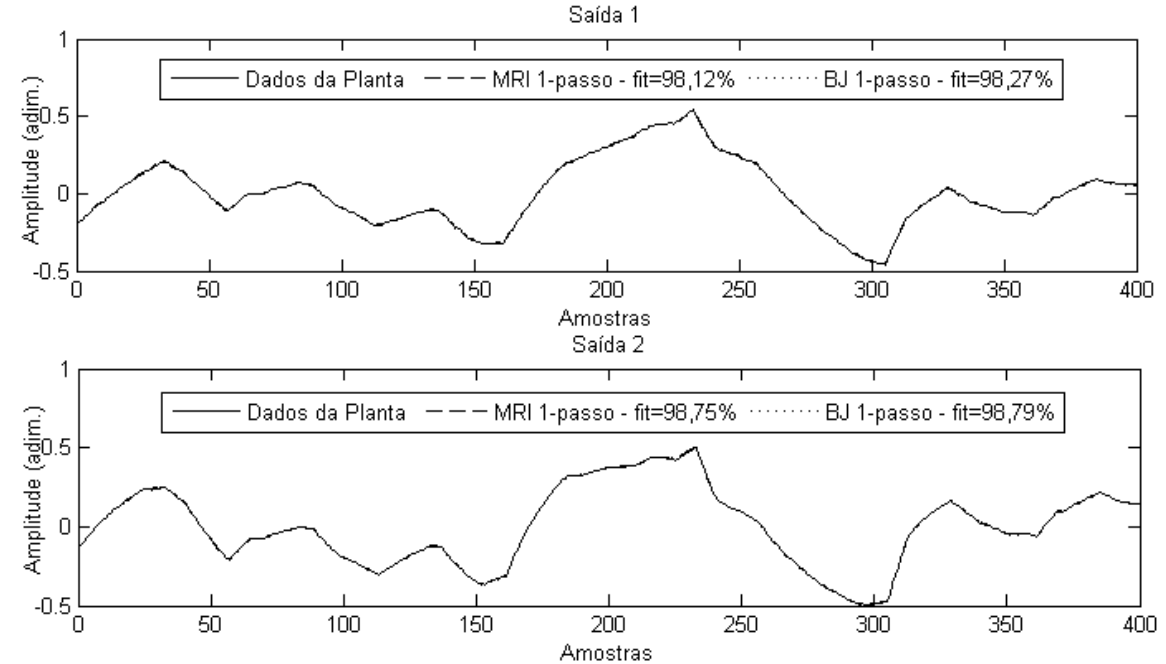

Fonte: Autor.

Figura 7.4 - Predição 10 passos à frente para o conjunto de dados de validação para os modelos MRI e BJ, assim, como os respectivos valores do índice fit. 

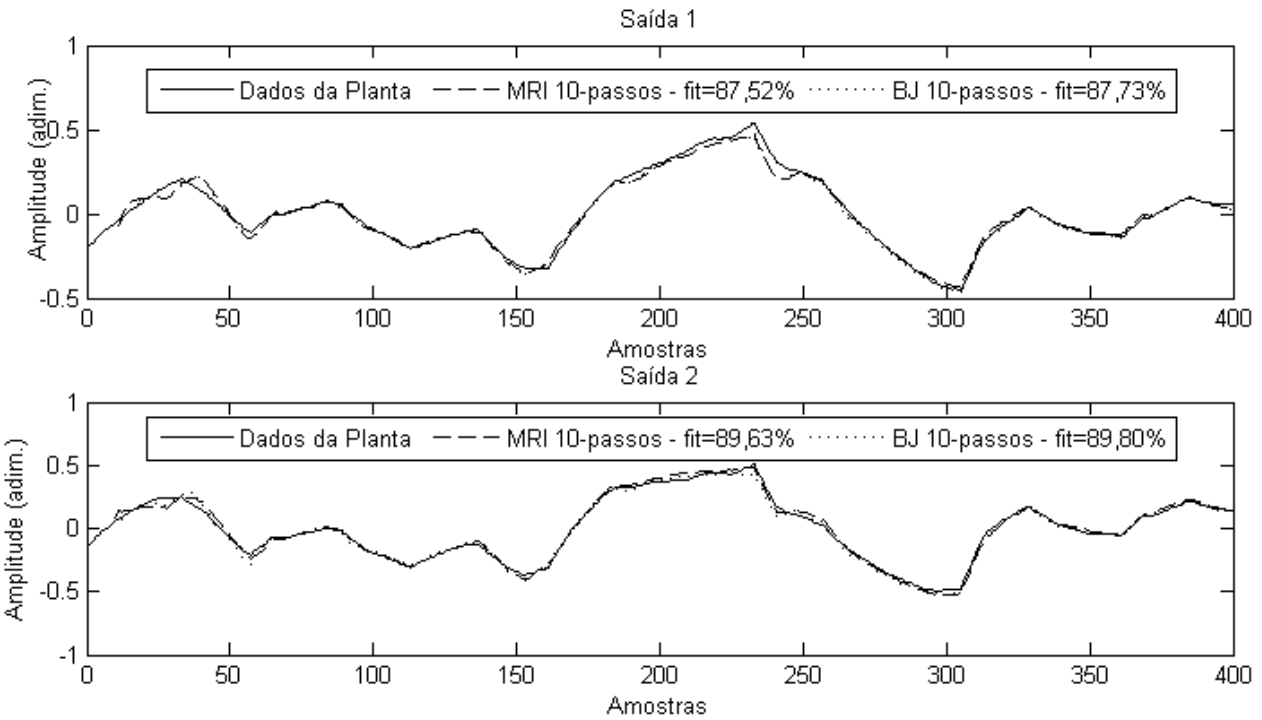

Fonte: Autor.

Ao comparar os valores de $W_{L R P I}$ entre o modelo $\mathrm{MRI}$ e o modelo $\mathrm{BJ}$, é possível observar que para os horizontes de predição inferiores a 5 o modelo BJ apresenta um desempenho superior. Entretanto, para horizontes de predição maiores, é possível notar que a função custo ponderada passa a ser menor, indicando que para horizontes maiores o modelo obtido pelo algoritmo MRI possui melhor desempenho.

Ao avaliar as figuras 7.3 e 7.4 , é possível observar que tanto para a simulação 1passo à frente quanto para a simulação 10-passos à frente, o desempenho do modelo MRI foi praticamente igual àquele do modelo $\mathrm{BJ}$, inclusive, com o primeiro apresentando menores valores de fit em todos os cenários. Desta maneira o resultado das figuras 7.3 e 7.4 podem parecer entrar em conflito com o resultado da Figura 7.2, o que não é necessariamente verdade, pois a função custo ponderada considera a contribuição de todas os passos de predição a frente, enquanto as demais figuras apresentam considerações isoladas.

Por fim, é importante notar que o sistema identificado, pode ser perfeitamente representado pelos parâmetros escolhidos para a modelagem, não havendo assim o viés entre o sistema e o modelo, de maneira que o resultado obtido pelos algoritmos de predição 1 passo à frente e múltiplos passos à frente é similar, conforme mostrado por Zhao, Zhu e Patwardhan (2014). 


\subsection{Aplicação em controlador NMPC}

A base da identificação MRI consiste na utilização dos modelos obtidos para controladores MPC. Assim, os modelos baseados nas identificações MRI e OSAPI da seção anterior foram aplicados em um controlador NMPC, aplicado ao sistema descrito por (56), (57) e (58).

Para o projeto do controlador, considerou-se a proposta descrita na subseção 3.3.1, onde o conhecimento da função estática foi combinado a um controlador offset-free linear, conforme descrito na seção 3.2.

Assim, para a implementação do controlador foram considerados os seguintes pontos:

1. Para cada não linearidade estática inversa, foram amostrados 20 valores no intervalo $\left[u_{\text {Min }}, u_{\text {Max }}\right]$, que são as restrições do esforço de controle. Em sequência, com esses valores foi estimada a função não linear inversa escolhendo o polinômio de ordem 1 a 10 que minimizasse o critério de informação de Akayke. A escolha tanto da ordem polinomial máxima quanto do número de amostras foi arbitrária;

2. Para o cálculo das matrizes $B_{d}$ e $C_{d}$, conforme sugestão apresentada em Pannochia (2015), a matriz $\left[\begin{array}{l}B_{d} \\ C_{d}\end{array}\right]$ foi determinada de maneira a ser composta pelas colunas de uma base ortonormal de $\operatorname{Ker}\left(\left[\begin{array}{c}A-I \\ C\end{array}\right]\right)$;

3. Para a sintonia do controlador, os seguintes parâmetros foram utilizados:

a. Os horizontes de predição e controle foram iguais a 10;

b. Foram determinados os limites máximos e mínimos para as variáveis manipuladas e controladas iguais a -1,5 e 1,5;

c. As matrizes de ponderação das variáveis controladas e manipuladas foram selecionadas como matrizes diagonais com todos os valores da diagonal iguais a 100 para a matriz das variáveis controladas e 1 para a matriz de variáveis manipuladas.

Utilizando o controlador proposto, e ajustando as perturbações para que a variância do ruído branco fosse igual a $10^{-5}$, de maneira a tornar sua influência desprezível, foi 
realizado um experimento, onde a primeira saída deveria acompanhar um sinal de referência composto por um pulso positivo seguido por um pulso negativo, ambos com amplitude 0,85 , enquanto a segunda saída deveria acompanhar um sinal similar com amplitude 1,2. Os resultados das simulações utilizando os modelos baseados em identificação MRI e em identificação OSAPI são apresentados nas figuras 7.5 e 7.6 a seguir.

Figura 7.5 - Resposta da saída 1 do sistema simulado, considerando a utilização de controladores NMPC utilizando os modelos oriundos da identificação MRI e OSAPI.

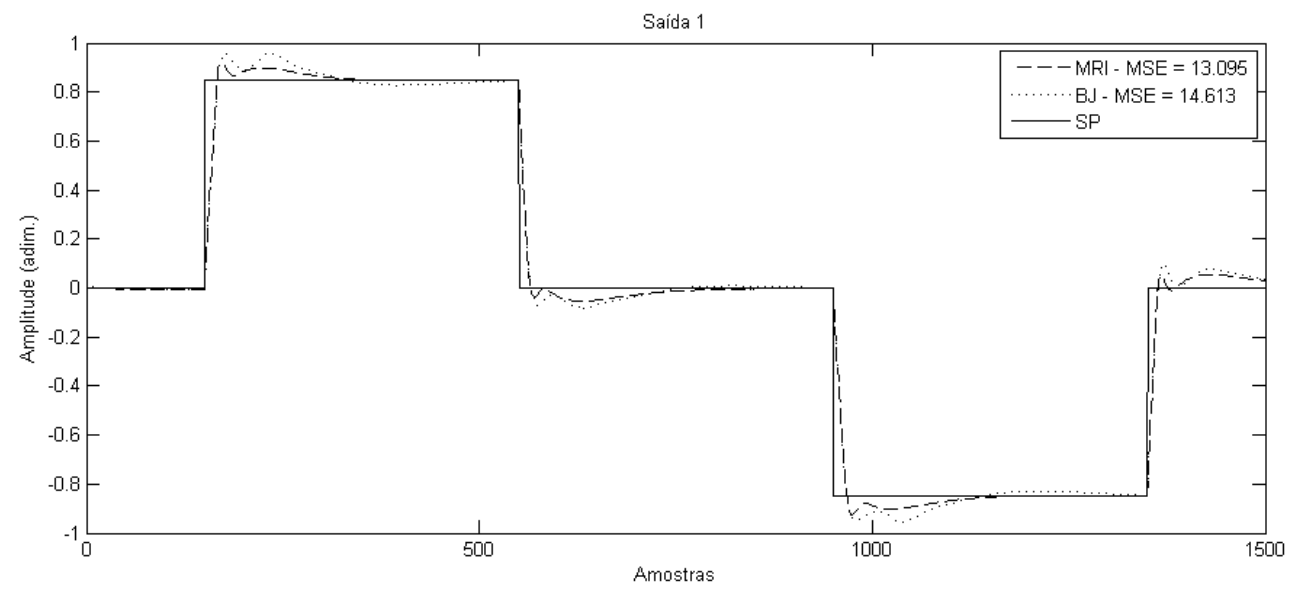

Fonte: Autor.

Figura 7.6 - Resposta da saída 2 do sistema simulado, considerando a utilização de controladores NMPC utilizando os modelos oriundos da identificação MRI e OSAPI.

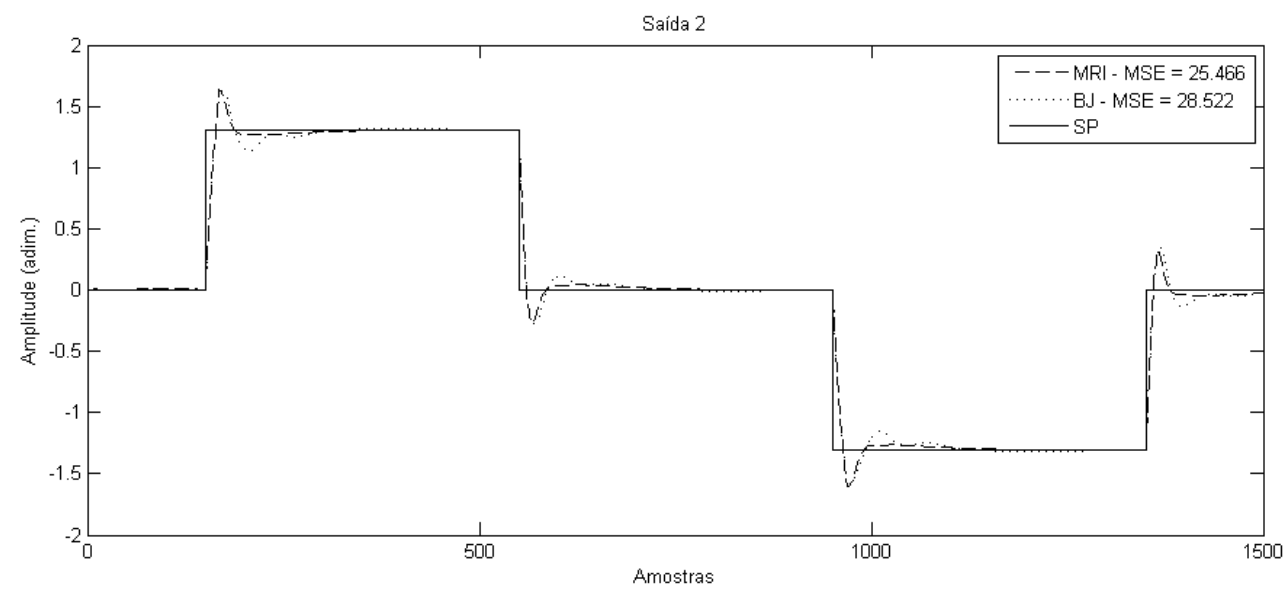

Fonte: Autor.

Apesar de os resultados obtidos para os dois controladores ser similar, é possível observar que os valores de erro médio quadrátrico (mean square error, MSE) foram 
menores quando foi utilizado o modelo obtido pelo algoritmo MRI no controlador. Isto indica, conforme esperado, um desempenho ligeiramente melhor quando é utilizado o modelo MRI ao invés do modelo obtido pela predição um passo à frente.

Vale salientar que para os dois modelos para a saída 2, ocorreram violações das restrições de limite superior e inferior da saída. Tais violações devem-se pelo fato de os modelos utilizados nos controladores serem obtidos em experimentos de identificação, onde são esperadas divergências entre o modelo simulado e a planta real.

\subsection{Conclusão}

Nesse capítulo, foi possível observar que mesmo em um cenário de identificação onde tanto o algoritmo para predição 1-passo à frente quanto o algoritmo MRI possuem desempenhos similares, foi possível observar um resultado ligeiramente superior para o algoritmo MRI. Adicionalmente, conforme esperado na teoria, o desempenho obtido pelo modelo identificado pelo algoritmo MRI em um controlador NMPC foi superior àquele obtido pelos métodos de predição 1 passo à frente.

Desta maneira, o algoritmo MRI Hammerstein torna-se fortemente recomendado para a identificação de modelos para a aplicação em controladores NMPC com estrutura de Hammerstein. 


\section{Conclusão}

A partir do que foi exposto ao longo dos últimos capítulos, é possível notar que, por meio do algoritmo proposto, é possível identificar modelos com estrutura de Hammerstein (casos SISO e MIMO) e Wiener (caso SISO) que são capazes de minimizar o erro de predição múltiplos passos à frente. Desta maneira, mostra-se possível a identificação MRI de modelos com estrutura de Wiener e de Hammerstein para a utilização em controladores NMPC. Adicionalmente, foi possível observar no caso MIMO, em uma implementação de NMPC que o desempenho obtido utilizando o modelo obtido pelo algoritmo MRI foi ligeiramente superior ao

Alguns pontos devem ser notados sobre a relação entre o resultado teórico e o algoritmo desenvolvido:

- apesar de o algoritmo utilizado ao longo da tese realizar a identificação não linear MRI por meio do método MPEM, qualquer outro método MRI linear pode ser utilizado;

- a seleção de funções polinomiais para a representação da não linearidade, não implica que esta seja a única possibilidade. A identificação polinomial foi selecionada pelo fato de possuir um grande volume de teoria já definida, principalmente em relação à obtenção de modelos com estrutura de Wiener e de Hammerstein a partir de modelos NARX polinomiais.

Em relação ao emprego de outras estruturas não lineares, existem indícios que a estrutura Linear AutoRegressive Nonlinear Moving Average with eXogenous inputs (LARNMAX) apresentada em Pearson (1999) possa ser utilizada. Com essa estrutura seria possível utilizar outras famílias de funções não lineares, como é o caso de redes neurais feedforward. A desvantagem desta abordagem, entretanto, é que ela ainda carece da fundamentação já desenvolvida para modelos com estrutura NARX polinomial.

Os resultados apresentados para modelos de Hammerstein foram satisfatórios, indicando não apenas a capacidade de identificar modelos SISO e MIMO, mas também a ausência de viés e a consistência dos estimadores. Tais propriedades, 
entretanto, foram avaliadas apenas por meio de simulações baseadas no método de Monte Carlo. É necessária uma demonstração formal destas propriedades.

Para os modelos de Wiener, as identificações realizadas com dados de plantas didáticas apresentaram um desempenho satisfatório, embora o estimador tenha se mostrado com viés. Adicionalmente, este método precisa ser estendido para o caso MIMO.

Desta maneira, alguns dos próximos passos relativos a este trabalho seriam:

- explorar a utilização do algoritmo com outras estruturas não lineares capazes, eventualmente, de melhor aproximar não linearidades estáticas existentes nas plantas;

- demonstrar formalmente as propriedades estatísticas dos estimadores desenvolvidos; e

- estender os algoritmos para a identificação de modelos MIMO com estruturas de Wiener e estruturas de blocos interconectados mais sofisticadas, como por exemplo, estruturas de Hammerstein-Wiener ou Wiener-Hammerstein. 


\section{REFERÊNCIAS}

AGUIRRE, L. A. A Tutorial Introduction to Nonlinear Dynamics and Chaos, Part I: Tools and Benchmarks. Controle \& Automação, v.7, n.1, p. 29-49, 1996.

AGUIRRE, L. A. A Tutorial Introduction to Nonlinear Dynamics and Chaos, Part II: Modeling and Control. Controle \& Automação, v.7, n.1, p. 50-66, 1996.

AGUIRRE, L. A. Introdução à identificação de Sistema: Técnicas lineares e nãolineares aplicadas a sistemas. Teoria e Aplicação. $4^{a}$ ed. Belo Horizonte: Editora UFMG, 2015, $730 \mathrm{p}$.

AGUIRRE, L. A.; BILLINGS, S. A. Retrieving dynamical invariants from chaotic data using NARMAX models, International Journal of Bifurcation and Chaos. v.5, n.2, p. 449-474, 1995.

AGUIRRE, L. A.; COELHO, M. C. S.; CORREAA, M. V. On interpretation and practice of dynamical differences between Hammerstein and Wiener models. IEE Proceedings on Control Theory and Applications, v.152, n.4, p. 349-356, 2005.

AGUIRRE, L. A.; MENDES, E. M. A. M. Global nonlinear polynomial models: Structure, term clusters and fixed points. International Journal of Bifurcation and Chaos. v.6, n.2, p. 279-294, 1996.

AGUIRRE, L. A.; SOUZA, A. V. An algorithm for estimating fixed points of dynamical systems from time series. International Journal of Bifurcation and Chaos, v.8, n. 11, p. 2203-2213, 1998.

ARBEL, A.; RINARD, I. H.; SHINNAR, R. Dynamics and control of fluidized catalytic crackers. 2. Multiple steady states and instabilities. Industrial \& Engineering Chemistry Research, v. 34, n.9, p. 3014-3026, 1995.

ÅSTRÖM, K. J.; EYKHOFF, P. System identification - A survey. Automatica, v.7, n.2, p. 123-162, 1971. 
ATUONWU, J. C. et al. Identification and Predictive Control of a multistage evaporator. Control Engineering Practice, v.18, n.12, p. 1418-1428, 2010.

BAI, E. W. Decoupling the Linear and Nonlinear Parts in Hammerstein Model Identification. Automatica, v.40, n.4, p. 671-676, 2004.

BEKIARIS, N. et al. Multiple steady states in homogeneous azeotropic distillation. Industrial \& Engineering Chemistry Research, v.32, n.9, p. 2023-2038, 1993.

BORRELLI, F; MORARI, M. Offset Free Model Predictive Control, In: IEEE Conference on Decision and Control, 46., 2007, New Orleans. Proceendings. New Orleans, 2007. 1245-1250.

CAMACHO, F. E.; BORDONS, C. Model Predictive Control. $2^{\text {a }}$ ed. Londres: Springer-Verlag, 2007, $405 \mathrm{p}$.

CAMPOS, M. C. M. M.; TEIXEIRA, H. C. Controle Típicos de Equipamentos e Processos Industriais. $1^{\mathrm{a}}$ ed. São Paulo: Edgard Blucher, 2006, 396 p.

CASSINI, C. C. S. Estimação recursiva de características estáticas não lineares utilizando modelos polinomiais NARMAX. Dissertação (Mestrado). Universidade Federal de Minas Gerais. Belo Horizonte, 1999.

COELHO, L. S.; BERNERT, D. L. A. An improved harmony search algorithm for synchronization of discrete-time chaotic systems. Chaos, Solitons \& Fractals, v.41, n.5, p. 2526-2532, 2009.

COELHO, M. C. S. Modelos de Hammerstein e de Wiener: conexões com modelos NARX e sua aplicação em identificação de sistemas não-lineares. Dissertação (Mestrado). Universidade Federal de Minas Gerais. Belo Horizonte, 2002.

DAMOUR, C. et al. NMPC of an industrial crystallization process using model-based observers. Journal of Industrial and Engineering Chemistry, v.16, n.5, p. 708716, 2010. 
FERRARI, S.; STENGEL; R. F. Smooth functions approximation using neural networks. IEEE Transactions on Neural Networks, v.16, n. 1, p. 24-38, 2005.

FORBES, M. G. et al. Model Predictive Control in Industry: Challenges and Opportunities. IFAC-PapersOnLine, v. 48, n. 8, p. 531-538, 2015.

FRUZETTI, R. P.; PALAZOGLU, A.; MCDONALD, K. A. Nonlinear Model Predictive control using Hammerstein models. Journal of Process Control, v.7, n.1, p. 31-41, 1997.

GARCIA, C., 2013. Modelagem e Simulação de Processos Industriais e de Sistemas Eletromecânicos. $2^{a}$ ed. São Paulo: Edusp, 688 p.

GOPALUNI, R. B.; PATWARDHAN, R. S.; SHAH, S. L.. The MPC relevant identification - tuning the noise models. Journal of Process Contol, v.14, n.6, p. 699-714, 2004

HAGGENBLAD, A.; LJUNG; L.; WILLS, A. Maximum likelihood identification of Wiener models. Automatica, v.44, n.11, p. 2697-2705, 2008.

HUANG, B. ; WANG, Z. The role of data prefiltering for integrated identification and model predictive control. In: WORLD CONGRESS OF IFAC, 14. Beijing, Proceedings Beijing, 1999.

HUO, H. B. et al. Nonlinear model predictive control of SOFC based on a Hammerstein model. Journal of Power Sources, v.185, n.1, p. 338-344, 2008.

IDRIS, E. A. N.; ENGEL, S. Economics-based NMPC strategies for the operation and control of a continuous catalytic distillation process. Journal of Process Control, v.22, n.10, p. 1832-1843, 2012.

JACOBSEN, E. W.; SKOGESTAD, S. Multiple Steady States in Ideal Two-Product Distillation. AlChE Journal, 37(4), pp. 499-511, 1991.

KAILATH, T. Linear Systems. Englewood Cliffs: Prentice-Hall, 1980, 682 p. 
KARACAN, J. K. Application of a non-linear long range predictive control to a packed distillation collumn. Chemical Engineering and Processing, v.42, n.12, p. 943-953, 2003.

LEONTARITIS, I.J.; BILLINGS, S.A. Input-output parametric models for non-linear systems Part I: deterministic non-linear systems, International Journal of Control. v.41 n. 2 p. 303-328, 1985.

LEONTARITIS, I.J.; BILLINGS, S.A. Input-output parametric models for non-linear systems Part II: stochastic non-linear systems, International Journal of Control. v. 41 n. 2 p. 329-344, 1985.

LAURI, D. et al. PLS-based model predictive control relevant identification: PLS-PH algorithm. Chemometrics and Intelligent Laboratory Systems, v.100, n.2, p. 118126, 2010.

LJUNG, L. System Identification: Theory for the User. $2^{\mathrm{a}}$ ed. Upper Saddle River: Prentice Hall, 1999, 672 p.

MAHMOODI, S. et al. Nonlinear model predictive control of a $\mathrm{pH}$ neutralization process based on Wiener-Laguerre model. Chemical Engineering Journal, v.146, n.3, p. 328-337, 2009.

MAYNE, D. Q. Model Predictive Control: Recent developments and future promise. Automatica, v.50, n.12, p. 2967-2986, 2014.

MENDENHALL, W.; SINCICH, T. A Second Course in Statistics: Regresion Analysis. $7^{\text {a }}$ ed. Essex: Pearson, 2014. 744 p.

NARENDRA, K. S.; GALLMAN, P. G. An Itherative Method for Identification of Nonlinear System Using Hammerstein Model. IEEE Transactions on Automatic Control, v.11, n.3, p. 546-550, 1966.

NOCEDAL, J.; WRIGHT. S. J. Numerical Optimization. Nova York: SpringerVerlag, 2006, $664 \mathrm{p}$. 
NORQUAY, S. J.; PALAZOUGLU, A.; ROMAGNOLI, J. A. Model Predictive Control based on Wiener Models. Chemical Engineering Science, v.53, n.1, p. 75-84, 1998.

PANNOCHIA, G.; RAWLINGS, J.B. Disturbance Models for Offset-Free ModelPredictive Control. AIChE Journal, v.49, n.2, p. 426-437, 2003.

PANNOCCHIA, G. Offset-free tracking MPC: A tutorial review and comparison of different formulations, In: European Control Conference, 2015, Linz. Proceendings. Linz, 2015. 527-532.

PATIKIRIKORALA, T. et al. Hammerstein-Wiener nonlinear model predictive control for relative QoS performance and resource management of software systems. Control Enginnering Practice, v.20, n.1, p. 49-61, 2012.

PČOLKA, M. et al. Bridging the gap between the linear and nonlinear predictive control: Adaptations for efficient building climate control, Control Engineering Practice, v.53 p. 124-138, 2016.

PEARSON, R. K. Discrete-Time Dynamic Models. Nova York: Oxford University Press, 1999. 466 p.

PEARSON, R. K. Selecting nonlinear model structures for computer control. Journal of Process Control, v.13, n.1, pp. 1-26, 2003.

PEARSON, R. K. Nonlinear empirical modeling techniques. Computers \& Chemical Engineering, v.10-12 n.30, p. 1514-1528, 2006.

PICHE, S. et al. Neural Network Based model Predictive Control. In: ADAVANCES IN NEURAL INFORMATION PROCESSING SYSTEMS. Proceedings p. 1029-1035, 2000.

PORFÍRIO, C. R.; ALMEIDA NETO, E.; ODLOAK, D. Multi-model predictive control of an industrial C3/C4 splitter. Control Engineering Practice v.11, n. 7 p. 765-779, 2003. 
POTTS, A. S.; ROMANO, R. A.; GARCIA, C. Improving performance and stability of MPC relevant identification methods. Control Engineering Practice, v.22, n.1, p. 20-33, 2014.

QIN, S. J.; BADGWELL. T. A survey of model predictive control technology. Control Engineering Practice, v.7, n.11, p. 733-764, 2003.

QUACHIO, R.; GARCIA, C. Application of the PLS-PH Method for Identifying Polynomial NARX Models. Journal of Control, Automation and Electrical Systems, v.25, n.2, p. 184-194, 2014.

RAZÓN, L. F.; SCHMITZ, L. A. Multiplicities and instabilities in chemically reacting systems - a review. Chemical Engineering Science, v.42, n.5, p. 1005-1047, 1987.

RIBEIRO, A. H.; AGUIRRE, L. A. Relações estáticas de modelos NARX MISO e sua representação de Hammerstein. In: CONGRESSO BRASILEIRO DE AUTOMÁTICA, 20. Anais, Belo Horizonte, p. 617-624, 2014.

RODRIGUES, G. G. et al. Identificação de um forno elétrico não-linear utilizando modelos NARMAX polinomiais. In: CONGRESSO BRAILEIRO DE AUTOMÁTICA, 11, Anais, São Paulo, p. 953-958, 1996.

ROMANO, R. A. Identificação de processos não lineares e quantificação de atrito e válvulas de controle. - Tese (Doutorado) - Escola Politécnica, Universidade de São Paulo, São Paulo, 2010.

SAYED, A. H.; KAILATH, T. 2001. A survey of spectral factorization methods. Numerical Linear Algebra with Applications, 8(6-7), pp. 467-496.

SEBORG, D. E. et al. Process Dynamics and Control. $3^{a}$ ed. Hoboken: Wiley, 2010.

SHAFIEE, G. et al. Nonlinear predictive control of a polymerization reactor based on piecewise linear Wiener model, Chemical Engineering Journal, v.143, n.1-3, p. 282-292, 2008. 
SHI, Y. T. et al. A Nonlinear Model Predictive Control based on Least Squares Support Vector Machines NARX Model. In: INTERNATONAL CONFERENCE ON MACHINE LEARNING AND CYBERNETICS, 6, Hong Kong, Proceedings, Hong Kong. p. 721-725, 2007

SHOOK, D.; MOHTADI, C; SHAH, S. L. Identification for long-range predictive control. IEE Proceedings D, v.138, n.1, p. 75-84, 1991.

SINGSTAD, P. Modelling and multivariate control of high pressure autoclave reactors for polimerization of ethane - Thesis (PhD). Trondheim: The Norwegian Institute of Technology, 1992.

SKOGESTAD, S.; MORARI, M. LV-Control of a high-purity distillation column. Chemical Engineering Science, v.43, n.1, p.33-48, 1988.

SRINIWAS, G. R. et al. Nonlinear identification and control of a high-purity distillation column: a case study. Journal of Process Control, v.5, n.3, p. 149-162, 1995.

STOICA, P. \& NEHORAI, A. On multistep prediction error methods for time series models. Journal of Forecasting, v.8, n.4, p. 357-368, 1989.

UCHOA, S. et al. Modeling and Idenstification of the Bio-ethanol production Process from scratch: Cybernetics vs. Unstrutured Modeling. In: EUROPEAN SYMPOSIUM ON COMPUTER AIDED PROCESS, 18, Proceedings, p. 707-711, 2008.

UPPAL, A.; RAY, W. H. On the dynamic behavior of continuous stirred tank reactors. Chemical Engineering Science, v.29, n.4, p. 967-985, 1974.

WANG, L. A tutorial on model predictive control: Using a linear velocity-form model. Developments in Chemical Engineering and Mineral Processing, v.12, n.5-6, p.573614, 2004.

XAUMIER, F. et al., 1999. Supervisory and Temperature Control of Batch Reactor by NMPC: An Experimental Study. Computers and Chemical Engineering, v.23, n. Supplement, p. S923-S926. 
XI, Y. G.; LI, D. W.; LIN, S. Model predictive control—status and challenges. Acta Automatica Sinica, v.39, n.3, p.222-236, 2013.

ZHAO, J.; ZHU, Y.; PATWARDHAN, R. Identification of k-step-ahead prediction error model and MPC control. Journal of Process Control, v.24, n.1, p. 48-56, 2014.

ZHU, Y. Identification of Hammerstein models for control using ASYM. International Journal of Control, v.73, n. 18, p. 1692-1702, 2000. 